\title{
Formal methods in dependable systems engineering: a survey of professionals from Europe and North America
}

\author{
Mario Gleirscher ${ }^{1}$ (D) . Diego Marmsoler ${ }^{2}$
}

Published online: 9 September 2020

(C) The Author(s) 2020

\begin{abstract}
Context Formal methods (FMs) have been around for a while, still being unclear how to leverage their benefits, overcome their challenges, and set new directions for their improvement towards a more successful transfer into practice.
\end{abstract}

Objective We study the use of formal methods in mission-critical software domains, examining industrial and academic views.

Method We perform a cross-sectional on-line survey.

Results Our results indicate an increased intent to apply FMs in industry, suggesting a positively perceived usefulness. But the results also indicate a negatively perceived ease of use. Scalability, skills, and education seem to be among the key challenges to support this intent.

Conclusions We present the largest study of this kind so far $(N=216)$, and our observations provide valuable insights, highlighting directions for future theoretical and empirical research of formal methods. Our findings are strongly coherent with earlier observations by Austin and Graeme (1993).

Keywords Formal methods · Empirical research · On-line survey · Usage · Usefulness · Practical challenges $\cdot$ Research transfer $\cdot$ Software engineering education \& training

\section{Acronyms}

CMMI Capability Maturity Model Integration

DI respondents with decreased usage intent

EOU ease of use

Communicated by: Hélène Waeselynck

Mario Gleirscher

Mario.Gleirscher@york.ac.uk

Diego Marmsoler

Diego.Marmsoler@tum.de

1 Department of Computer Science, University of York, York, UK

2 Institut für Informatik, Technical University of Munich, Garching, Germany 


$\begin{array}{ll}\text { FM } & \text { formal method } \\ \text { GQM } & \text { goal-question-metric } \\ \text { HQ } & \text { head quarter } \\ \text { ICT } & \text { information and communication technology } \\ \text { II } & \text { respondents with increased usage intent } \\ \text { IS } & \text { information system } \\ \text { LE } & \text { less experienced respondents } \\ \text { M } & \text { respondents with some motivations to use FMs } \\ \text { MbE } & \text { model-based engineering } \\ \text { ME } & \text { more experienced respondents } \\ \text { NP } & \text { non-practitioners } \\ \text { P } & \text { practitioners } \\ \text { PEOU } & \text { perceived ease of use } \\ \text { PU } & \text { perceived usefulness } \\ \text { RQ } & \text { research question } \\ \text { SE } & \text { software engineering } \\ \text { SMT } & \text { satisfiability modulo theory } \\ \text { TAM } & \text { technology acceptance model } \\ \text { TLD } & \text { top-level domain } \\ \text { NM } & \text { respondents without any motivations to use FMs } \\ \text { UFM } & \text { Use of FMs in mission critical SE } \\ \text { U } & \text { usefulness }\end{array}$

\section{Motivation and Challenges}

Over the past decades, many software errors have been deployed in the field and some of these errors had a clearly intolerable impact. ${ }^{1}$ Cost savings from reducing such impact have been the motivation of (FMs) as a first-class approach to error prevention, detection, and removal (Holloway 1997).

In university courses on software engineering, we learned that FMs are among the best we have to design and assure correct systems. The question "Why are FMs not used more widely?" (Knight et al. 1997) is hence more than justified. With a Twitter poll, ${ }^{2}$ which emerged from our coffee spot discussions, we solicited opinions on a timely paraphrase of a statement argued by Holloway (1997): "FMs should be a cornerstone of dependability and security of highly distributed and adaptive automation." What can a tiny opportunity sample of 22 respondents from our social network tell? Not much, well, (i) 55\% agrees, i.e., seem to attribute importance to this role of FMs, (ii) 14\% disagrees, i.e., oppose that view, (iii) $32 \%$ just don't know. Why should and how could FMs be a cornerstone?

Since the beginning of software engineering (SE) there has been a debate on the usefulness of FMs to improve SE. In the 1970s and 1980s, several SE and FM researchers had started to examine this usefulness and to identify error possibilities despite the rigour in FMs (Gerhart and Yelowitz 1976), with the aim of responding to critical observations of practitioners (Jackson 1987).

\footnotetext{
${ }^{1}$ See anecdotal evidence (grey literature, press articles) on software-related incidents, for example, by Kaner and Pels (1998) and Kaner and Pels (2018), Neumann (2018) and Charette (2018).

${ }^{2}$ See https://twitter.com/MarioGleirscher/status/889737625178976256.
} 
Hall (1990) and Bowen and Hinchey (1995a) illuminate 14 myths (e.g. "formal methods are unnecessary"), providing their insights on when FMs are best used and highlighting that FMs can be overkill in some cases but are highly recommended in others. The transfer of FMs into SE practice is by far not straightforward. Knight et al. (1997) examine reasons for the low adoption of FMs in practice. Barroca and McDermid (1992) ask: "To what extent should FMs form part of the [safety-critical SE] method?"

Glass (2002, pp. 148-149, 165-166) and Parnas (2010) observe that "many [SE] researchers advocate rather than investigate" by assuming the need for more methodologies. Glass summarises that FMs were supposed to help represent firm requirements concisely and support rigorous inspections ${ }^{3}$ and testing. He observes that changing requirements has become an established practice even in critical domains, and inspections, even if based on FMs, are insufficient for complete error removal. In line with Barroca and McDermid (1992, p. 591), he notes that FMs have occasionally been sold as to make error removal complete, but there is no silver bullet (Glass (2002), pp. 108-109). Bad communication between theorists and practitioners sustains the issue that FMs are taught but rarely applied (Glass (2002) and Holloway and Butler (1996), pp. 68-70). Parnas (2010) compares alternative paradigms in FM research (e.g. axiomatic vs. relational calculi) and points to challenges of FM adoption (e.g. valid simple abstractions).

In contrast, Miller et al. (2010) draw positive conclusions from recent applications of model checking and highlight lessons learned. In his keynote, O'Hearn (2018) conveys positive experiences in scaling FMs through adequate tool support for continuous reasoning in agile projects (see, e.g. Chudnov et al. (2018)). Many researchers (see, e.g. Aichernig and Tom (2003)) have been working on the improvement of FMs towards their successful transfer. Boulanger (2012) and Gnesi and Margaria (2013) summarise promising industry-ready FMs and present larger case studies.

Have software errors been overlooked because of hidden inconsistencies that can be detected when properly formalised? Are such errors compelling arguments for the wider use of FMs? Strong evidence for the ease of use of FMs and their efficacy and usefulness is scarce and largely anecdotal, rarely drawn from comparative studies (e.g. Pfleeger and Hatton (1997) and Sobel and Clarkson (2002)), often primarily conducted in research labs (e.g. Galloway et al. (1998) and Chudnov et al. (2018) and many others). In late response to Holloway and Butler's request for empirical data (Holloway and Butler 1996), Graydon (2015) still observes a lack of evidence for the effectiveness of FMs in assurance argumentation for safety-critical systems, suggesting empirical studies to examine hypotheses and collect evidence.

FMs have many potentials but SE research has reached a stage of maturity where strong empirical evidence is crucial for research progress and transfer. Jeffery et al. (2015) identify questions and metrics for FM productivity assessment, supporting FM research transfer.

Contributions We contribute to SE and FM research (1) by presenting results of the largest cross-sectional survey of FM use among SE researchers and practitioners to this date, (2) by answering research questions about the past and intended use of FMs and the perception of systematically mapped FM challenges, (3) by relating our findings to the perceived ease of use and usefulness of FMs using a simplified variant of the technology acceptance model

\footnotetext{
${ }^{3}$ For example, walking through development artefacts in a structured and moderated discussion group and with bug pattern checklists (Fagan 1976).
} 
for evaluating engineering methods and techniques, and (4) by providing a research design for repetitive (e.g. longitudinal) FM studies.

Overview The next section introduces important terms. Section 3 relates our work to existing research. In Section 4, we explain our research design. We describe our data and answer our research questions in Section 5. In Section 6, we summarise and interpret our findings in the light of existing evidence and with respect to threats to validity. Section 7 highlights our conclusions and potential follow-up work.

\section{Background and Terminology}

By formal methods, we refer to explicit mathematical models and sound logical reasoning about critical properties (Rushby 1994)—such as reliability, safety, security, more generally, dependability and performance — of electrical, electronic, and programmable electronic or software systems in mission- or property-critical application domains. Model checking, theorem proving, abstract interpretation, assertion checking, and formal contracts are examples of FMs. By use of FMs, we refer to their application in the development and analysis of critical systems and to substantially integrating FMs with the used programming methodologies (e.g. structured development, model-based engineering (MbE), assertion-based programming, test-driven development), notations (e.g. UML, SysML), and tools.

Tool and Method Evaluation In the following, we give an overview of several evaluation approaches and explain in Section 4.2 which approach we take.

The widely used technology acceptance model (TAM; (Davis 1989)) is a psychological test that allows the assessment of end-user IT based on the two constructs perceived ease of use (PEOU, i.e., positive and negative experiences while using an IT system) and perceived usefulness (PU, i.e., positive experiences of accomplishing a task using an IT system compared to not using this system for accomplishing the same task).

Complementary to TAM, Basili (1985) proposes the goal-question-metric (GQM) approach to method and tool evaluation. While GQM serves as a good basis for quantitative follow-up studies, we follow the user-focused TAM. Maturity models according to the Capability Maturity Model Integration (SEI, 2010) do not fit our purposes because they focus on engineering process improvement beyond particular development techniques. Poston and Sexton (1992) present tool survey guidelines based on technology-focused classification and selection criteria with a very limited view on tool usefulness and usability. Miyoshi and Azuma (1993) evaluate ease of use of development environments (i.e., specification and modelling tools) using metrics from the ISO/IEC 9126 quality model.

From comparing two models of predicting an individual's intention to use a tool, Mathieson (1991) supports TAM's validity and convenience but indicates its limits in providing enough information on users' opinions. For software methods and programming techniques, Murphy et al. (1999) show how surveys, case studies, and experiments can be used to compensate for this lack of information about usefulness and usability.

Because FMs are by definition based on a formal language and usually supported by tools, it is reasonable to adopt the TAM for the assessment of FMs. Unfortunately, the body of literature on the evaluation of FMs in TAM style is very small. However, Riemenschneider et al. (2002) apply TAM to methods (e.g. UML-based architecture design), concluding that "if a methodology is not regarded as useful by developers, its prospects for successful 
deployment may be severely undermined." According to their approach, FM usage intentions would be driven by (1) an organisational mandate to use FMs, (2) the compatibility of FMs with how engineers perform their work, and (3) the opinions of developers' coworkers and supervisors toward using FMs. Overall, the application of TAM to FMs allows causal reasoning from FM user acceptance towards intention of FM use.

Specialising the approach in Riemenschneider et al. (2002), ease of use (EOU) of a FM characterises the type and amount of effort a user is likely to spend to learn, adopt, and apply this FM. Usefulness (U) determines how fit a FM is for its purpose, that is, how well it supports the engineer to accomplish an appropriate task. If EOU and $U$ are measured by a survey whose data points are user perceptions then we talk of perceived ease of use (PEOU) and perceived usefulness (PU). Together, PEOU and PU form the user acceptance of a FM and, by support of Mathieson (1991) and Riemenschneider et al. (2002), can predict the intention to use this FM.

Whereas TAM is a model based on the two user-focused constructs PEOU and PU, Kitchenham et al. (1997) propose a meta-evaluation approach called DESMET for tools and methods based on multiple performance indicators (e.g. with TAM as one of the indicators).

\section{Related Work}

Table 1 shows a systematic map (Petersen et al. 2008) of 35 studies on FM research evaluation and transfer. For each study, we estimate ${ }^{4}$ the authors' attitude against or in favour of FMs, the motivation of the study, the approach followed, and the type of result obtained. Most of these works present personal experiences, opinions, case studies, or literature summaries. In contrast, the work presented in this paper focuses on the analysis of experience from a wide range of practitioners and experts. However, we found four similar studies.

Austin and Graeme (1993) sought to explain the low acceptance of FMs in industry around 1992. Using a questionnaire similar to ours with only open questions, they evaluated 111 responses from a sample of size 444, using a sampling method similar to ours (then using different channels). Responses from FM users are distinguished from general responses. Their questions examine benefits, limitations, barriers, suggestions to overcome those barriers, personal reasons for or against the use of FMs, and ways of assessing FMs.

In a second study in 2001, Snook and Harrison (2001) conduct interviews with representatives of five companies to discover the main issues involved in FM use, in particular, issues of understandability and the difficulty of creating and utilising formal specifications.

A similar, though more comprehensive interview study was performed by Woodcock et al. (2009) in 2009. They assess the state of the art of the application of FMs, using questionnaires to collect data on 62 industrial projects.

Liebel et al. (2016, pp. 102-103) assess effects on and shortcomings of the adoption of $\mathrm{MbE}$ in embedded SE including a discussion of FM adoption. The authors observe a lack of tool support, bad reputation, and rigid development processes as obstacles to FM adoption. Their data suggests a need of FM adoption. 30\% of the responses from industry declare the need for FMs as a reason to adopt MbE. Moreover, responses indicate that MbE adoption

\footnotetext{
${ }^{4}$ This estimate is based on opinions and attitudes expressed by the original authors and, where unavailable, on our own interpretation when reading the studies.
} 
Table 1 Overview of related work on FM use and adoption, grouped by primary focus and motivation

\begin{tabular}{|c|c|c|c|c|c|c|}
\hline Study & A & Motivation & Support & $\mathrm{E}$ & $\mathrm{C}$ & $\mathrm{R}$ \\
\hline \multicolumn{7}{|l|}{ Surveys } \\
\hline Austin and Graeme (1993) & $=$ & LoEv & Interviews & & $\bullet$ & $\bullet$ \\
\hline Snook and Harrison (2001) & $=$ & LoEv & Interviews & $\bullet$ & & \\
\hline Oliveira (2004) & $=$ & Edu./Train. & Course websites & $\bullet$ & & \\
\hline Woodcock et al. (2009) ${ }^{a}$ & $=$ & LoEv & Interviews & & $\bullet$ & \\
\hline Davis et al. (2013) & + & TechTx & Interviews & & $\bullet$ & $\bullet$ \\
\hline Liebel et al. (2016) & + & LoEv & Online questionnaire & $\bullet$ & & \\
\hline Ferrari et al. (2019) & + & TechTx & Literature study & $\bullet$ & & \\
\hline \multicolumn{7}{|l|}{ Literature Studies and Summaries } \\
\hline Wing (1990) & + & SotA & $\mathrm{O} / \mathrm{E}$ & $\bullet$ & $\bullet$ & \\
\hline Bloomfield et al. (1991) & $=$ & SotA & & $\bullet$ & & \\
\hline Fraser et al. (1994) & $=$ & TechTx & & & & $\bullet$ \\
\hline Heitmeyer (1998) & $=$ & TechTx & & & & $\bullet$ \\
\hline Gleirscher et al. (2019) & + & TechTx & SWOT analysis & $\bullet$ & $\bullet$ & \\
\hline \multicolumn{7}{|c|}{ Expert Opinions and Experience Reports } \\
\hline Jackson (1987) & $=$ & TechTx & & & $\bullet$ & \\
\hline Bjorner (1987) & $=$ & TechTx & & & $\bullet$ & \\
\hline Barroca and McDermid (1992) & $=$ & SotA & Multiple cases & & $\bullet$ & \\
\hline Bowen and Hinchey (1995a) & + & Hyp. Testing & & & & $\bullet$ \\
\hline Bowen and Hinchey (1995b) & + & TechTx & & & & $\bullet$ \\
\hline Hinchey and Bowen (1996) & - & TechTx & & & $\bullet$ & \\
\hline Heisel (1996) & + & TechTx & & & & $\bullet$ \\
\hline Holloway and Butler (1996) & + & LoEv & & & $\bullet$ & \\
\hline Lai (1996) & + & TechTx & & & $\bullet$ & \\
\hline Bowen and Hinchey (2005) & + & Hyp. Testing & Literature study & & & $\bullet$ \\
\hline Parnas (2010) & $=$ & TechTx & & & $\bullet$ & $\bullet$ \\
\hline \multicolumn{7}{|l|}{ Case Studies and Experiments } \\
\hline Gerhart and Yelowitz (1976) & $=$ & LoEv & Multiple cases, O/E & $\bullet$ & $\bullet$ & $\bullet$ \\
\hline Hall (1990) & + & Hyp. Testing & $\mathrm{O} / \mathrm{E}$ & & & $\bullet$ \\
\hline Craigen et al. $(1995)^{b}$ & + & SotA & Multiple cases, $\mathrm{O} / \mathrm{E}$ & $\bullet$ & & \\
\hline Knight et al. (1997) & $=$ & TechTx & Field experiment & $\bullet$ & & \\
\hline Pfleeger and Hatton (1997) & $=$ & Hyp. Testing & Effect analysis & $\bullet$ & & \\
\hline Sobel and Clarkson (2002) & $=$ & Hyp. Testing & Lab experiment & $\bullet$ & & \\
\hline Miller et al. (2010) & $=$ & TechTx & Multiple cases, $\mathrm{O} / \mathrm{E}$ & $\bullet$ & & \\
\hline Klein et al. (2018) & + & TechTx & & $\bullet$ & & \\
\hline Chudnov et al. (2018) & $=$ & TechTx & & $\bullet$ & & \\
\hline
\end{tabular}

${ }^{a}$ See also Bicarregui et al. (2009), ${ }^{b}$ see also Craigen et al. (1993) and Craigen (1995); (A)ttitude, (E)valuation/analysis, (C)hallenges, (R)ecommendations, $+/=/-\ldots$ positive/neutral/negative, LoEv ... lack of empirical evidence, Hyp. Testing ... hypotheses testing, Edu./Train. ... education/training, O/E ... opinion/experience report, SotA ... state of the art, SWOT ... strengths, weaknesses, opportunities, and threats, TechTx ... technology transfer 
has a positive effect on FM adoption. One limitation of their study is the small number of responses from FM users.

While these studies focus on the elicitation of the state of the art and the state of practice, the main focus of our study is to compare the current FM adoption or use with the intention to adopt and use FMs in the future. To the best of our knowledge, our study offers the largest set of data points investigating the use of FMs in SE, so far. In Section 6.3, we provide a further discussion of how our findings relate to the findings of these studies, particularly to the works of Austin and Graeme (1993) and Woodcock et al. (2009).

\section{Research Method}

In this section, we describe our research design, our survey instrument, and our procedure for data collection and analysis. For this research, we follow the guidelines of Kitchenham and Pfleeger (2008) for self-administered surveys and use our experience from a previous more general survey (Gleirscher and Nyokabi 2018).

\subsection{Research Goal and Questions}

The questions in Section 1 have led to this survey on the use, usage intent, and challenges of FMs. Our interest is devoted to the following research questions (RQs):

RQ1 In which typical domains, for which purposes, in which roles, and to what extent have FMs been used?

RQ2 Which relationships can we observe between past experience in using FMs and the intent to use FMs?

RQ3 How difficult do study participants perceive widely known FM challenges to be?

RQ4 What can we say about the perceived ease of use and the perceived usefulness of FMs?

\subsection{Construct and Link to Research Questions}

Table 2 lists the (C)oncepts that constitute the construct Use of FMs in mission-critical $S E$ (UFM), the corresponding scales, the points of measurement, and references to (Q)uestions from the questionnaire.

Measuring Past and Intended Use For RQ1 ( UFM), we examine potential application domains for FMs (C1), roles when using FMs (C2), motivations and purposes of using FMs (C6, C4), and the extent of $U F M$ at the general (C5) and specific (C3) experience level of our study participants when using FMs.

For RQ2, we compare the past $\left(U F M_{p}\right)$ and intended use $\left(U F M_{i}\right)$ of FMs regarding the domain $(\mathrm{C} 1)$, role $(\mathrm{C} 2)$, FM class $(\mathrm{C} 3)$, and purpose (C4). We measure $U F M_{i}$ by relative frequency (Table 4) with respect to a participants' current situation, FM class, and purpose of use. Using a relative instead of an absolute frequency scale slightly reduces the burden on respondents to make detailed and, hence, uncertain predictions of $U F M_{i}$.

For RQ3, we measure the perception of difficulty of several obstacles (C7) known from the literature and from our experience. 
Table 2 Concepts and scales for the construct "Use of FMs in mission-critical SE" (UFM)

\begin{tabular}{|c|c|c|c|}
\hline Concept & Id. & Description [Scale] & Point [Question] \\
\hline \multicolumn{4}{|c|}{ Measured twice... } \\
\hline Domain & C1 & Application domains of FMs [MC among domains] & Past [Q1], Intent [Q8] \\
\hline Role & $\mathrm{C2}$ & Role in using FMs [MC among roles] & Past [Q4], Intent [Q9] \\
\hline Use & $\mathbf{C 3}$ & $\begin{array}{l}\text { Use of FMs [experience level/relative frequency per FM } \\
\text { class] }\end{array}$ & $\begin{array}{l}\text { Past [Q5/Q6], Intent } \\
\text { [10/11] }\end{array}$ \\
\hline Purpose & C4 & Purpose of using FMs [absolute/relative frequency per purpose] & Past [Q7], Intent [Q12] \\
\hline \multicolumn{4}{|c|}{ Measured once... } \\
\hline Experience & C5 & Level of FM experience [duration ranges in years] & Single [Q2] \\
\hline Motivation & C6 & Motivation to use FMs [degree per motivational factor] & Single [Q3] \\
\hline Obstacles & C7 & Difficulty of obstacles to using FMs [degree per challenge] & Single [Q13] \\
\hline
\end{tabular}

MC. . multiple-choice

Method Evaluation and TAM-style Interpretation We follow DESMET (Kitchenham et al. 1997) and Murphy et al. (1999) insofar as we combine a qualitative survey (i.e., FM evaluation by SE practitioners and researchers) and a qualitative effects analysis based on the past and intent measurements for C4 (i.e., subjective assessment of effects of FMs by asking SE practitioners and researchers).

We assume $U F M$ is, nowadays, to a large extent implying the use of the tools automating the corresponding FMs. This assumption is justified inasmuch as for all FMs referred to in this survey, tools are available. In fact, in the past two decades (the period most survey respondents could have possibly used FMs), the development of a FM has mostly gone hand in hand with the development of its supporting tools.

For RQ4, we associate our findings from RQ2 and RQ3 with PEOU and U. Whereas TAM predicts $U F M_{i}$ of a specific tool by measuring PEOU and PU, we directly interrogate past (like in Mohagheghi et al. (2012), Fig. 2) and intended use of classes of FMs. We measure $U F M_{i}(\mathrm{C} 1, \mathrm{C} 2, \mathrm{C} 3, \mathrm{C} 4)$ in more detail than TAM. Our approach relates to TAM for methods (Riemenschneider et al. (2002), Table 2) inasmuch as we collect data for PEOU through asking about potential obstacles to the further use of FMs (C7) based on experience with past FM use $\left(U F M_{p}\right)$. For this, respondents are asked to rate the difficulty of several known challenges to be tackled in typical FM applications. Furthermore, $U F M_{i}$ is known to be correlated with PU. We then interpret the answers to RQ3 to examine the PEOU and, furthermore, interpret the answers to RQ2 to reason about PU. In Section 4.4, we discuss our questionnaire including the questions for measuring the sub-constructs.

\subsection{Study Participants and Population}

Our target group for this survey includes persons with (1) an educational background in engineering and the sciences related to critical computer-based or software-intensive systems, preferably having gained their first degree, or (2) a practical engineering background in a reasonably critical system or product domain involving software practice. We use (study or survey) participant and respondent as synonyms. We talk of FM users to refer to the part of the population that has already used FMs in one or another way. See Appendix A.1 and Table 8 for a more fine-grained analysis of the population. 


\subsection{Survey Instrument: On-line Questionnaire}

Table 3 summarises the questionnaire we use to measure UFM (Table 2). The scales used for encoding the answers are described in Table 4.

Although we do not collect personal data, respondents could leave us their email address if they want to receive our results. We expect participants to spend about 8 to 15 minutes to complete the questionnaire. However, we thought it to be unnecessary in our case to instrument the questionnaire or our tooling to allow us to determine the time spent for submitting complete data points.

Face and Content Validity We derived answer options from the literature, our own experience with FMs, SE research training, discussions with other SE researchers and colleagues from industry, pilot responses, and coding of open answers. Particularly, the classification of FM methods (C3; Q5, Q6, Q10, Q11) and the list of obstacles or challenges (C7; Q13) were derived from our own training, literature knowledge prior to this study, and experience as well as from occasional personal discussions with SE experts from academia and industry. Most questions are half-open, allowing respondents to go beyond given answer options. We treat degree and relative frequency as 3-level Likert-type scales.

Table 3 Summary of questions from the questionnaire

\begin{tabular}{|c|c|c|c|c|}
\hline Id. & Question or question template & Scale (see Table 4) & Sec. & Fig. \\
\hline Q1 & $\begin{array}{l}\text { In which application domains }(\mathrm{C} 1) \text { in industry } \\
\text { or academia have you mainly used FMs? }\end{array}$ & MC among domains & 5.2 & 2 \\
\hline Q2 & $\begin{array}{l}\text { How many years of } F M \text { experience (including } \\
\text { the study of FMs, C5) have you gained? }\end{array}$ & Duration range in years & 5.2 & 3 \\
\hline Q3 & $\begin{array}{l}\text { Which have been your motivations (C6) } \\
\text { to use FMs? }\end{array}$ & Degree per motivational factor & 5.2 & 4 \\
\hline Q4 & In which roles $(\mathrm{C} 2)$ have you used FMs? & MC among roles & 5.3 & 5 \\
\hline Q5 & $\begin{array}{l}\text { Describe your level of experience (C3) for } \\
\langle\text { class of formal description techniques }\rangle \text {. }\end{array}$ & Level of experience per class & 5.3 & 6 \\
\hline Q6 & $\begin{array}{l}\text { Describe your level of experience }(\mathrm{C} 3) \text { for } \\
\langle\text { class of formal reasoning techniques }\rangle \text {. }\end{array}$ & Level of experience per class & 5.3 & 7 \\
\hline Q7 & I have mainly used FMs for $(\mathrm{C} 4) \ldots$ & Absolute frequency per purpose & 5.3 & 8 \\
\hline Q8 & $\begin{array}{l}\text { In which domains }(\mathrm{C} 1) \text { in industry or academia do } \\
\text { you intend to use FMs? }\end{array}$ & MC among domains & 5.4 & 9 \\
\hline Q9 & $\begin{array}{l}\text { In which roles (C2) would (or do) you intend to } \\
\text { use FMs? }\end{array}$ & MC among roles & 5.4 & 10 \\
\hline Q10 & $\begin{array}{l}\text { I (would) intend to use }(\mathrm{C} 3) \\
\langle\text { class of formal description techniques }\rangle\langle\text { this }\rangle \text { often. }\end{array}$ & Relative frequency per class & 5.4 & 11 \\
\hline Q11 & $\begin{array}{l}\text { I (would) intend to use }(\mathrm{C} 3) \\
\langle\text { class of formal reasoning techniques }\rangle\langle\text { this }\rangle \text { often. }\end{array}$ & Relative frequency per class & 5.4 & 12 \\
\hline Q12 & I (would) intend to use FMs for (C4) $\langle$ purpose $\rangle$. & Relative frequency per purpose & 5.4 & 13 \\
\hline Q13 & $\begin{array}{l}\text { For any use of FMs in my future activities, } \\
\text { I consider }\langle\text { obstacle }\rangle(\mathrm{C} 7) \text { as }\langle\text { that }\rangle \text { difficult. }\end{array}$ & Degree of difficulty per obstacle & 5.5 & 16 \\
\hline
\end{tabular}

MC. . multiple-choice 
Table 4 Scales used in the questionnaire

\begin{tabular}{|c|c|c|}
\hline Name & Values & Type \\
\hline $\begin{array}{l}\text { degree of } \\
\text { motivation }\end{array}$ & $\begin{array}{l}\text { "no motivation", "moderate motivation", "strong motivation } \\
\text { (or requirement)", }\end{array}$ & L3 \\
\hline $\begin{array}{l}\text { degree of } \\
\text { difficulty }\end{array}$ & $\begin{array}{l}\text { "not as an issue.", "as a moderate challenge.", "as a tough challenge.", } \\
\text { "I don't know." }\end{array}$ & L3 \\
\hline $\begin{array}{l}\text { experience level } \\
\text { (duration-based) }\end{array}$ & $\begin{array}{l}\text { "I do not have any knowledge of or experience in FMs.", "less than } \\
3 \text { years", "3 to } 7 \text { years", "8 to } 15 \text { years", " } 16 \text { to } 25 \text { years", "more than } 25 \\
\text { years" }\end{array}$ & $\mathrm{O}$ \\
\hline $\begin{array}{l}\text { experience level } \\
\text { (task-based) }\end{array}$ & $\begin{array}{l}\text { "no experience or no knowledge", "studied in (university) course", } \\
\text { "applied in lab, experiments, case studies", "applied once in engineering, } \\
\text { practice" "applied several times in engineering practice" }\end{array}$ & $\mathrm{O}$ \\
\hline $\begin{array}{l}\text { frequency } \\
\text { (absolute) }\end{array}$ & $\begin{array}{l}\text { "not at all.", "once.", "in } 2 \text { to } 5 \text { separate tasks.", "in more than } 5 \\
\text { separate tasks." }\end{array}$ & $\mathrm{O}$ \\
\hline $\begin{array}{l}\text { frequency } \\
\text { (relative) }\end{array}$ & $\begin{array}{l}\text { "no more or not at all.", "less often than in the past.", "as often as in the } \\
\text { past.", "more often than in the past.", "I don't know." }\end{array}$ & L3 \\
\hline choice & single/multiple: $(c h)$ ecked, $(u n)$ checked & $\mathrm{N}$ \\
\hline
\end{tabular}

bold... express lack of knowledge or indecision; (N)ominal, (O)rdinal, Ln ... Likert-type scale with $n$ values

For each question, we provide "do not know" (dnk)-options to include participants without previous knowledge of FMs in any academic or practical context. If participants are not able to provide an answer they can choose, e.g. "do not know", "not yet used", "no experience", or "not at all", and proceed. This way, we reduce bias by forced response. We indicate $d n k$-answers whenever we exclude them. Our questionnaire tool (Section 4.6) supports us with getting complete data points, reducing the effort to deal with missing answers.

\subsection{Data Collection: Sampling Procedure}

We could not find an open, non-commercial panel of engineers. Large-scale panel services are either commercial (e.g. Decision Analyst (2018)) or they do not allow the sampling of software engineers (e.g. Leiner (2014)). Hence, we opt for a mixture of opportunity, volunteer, and cluster-based sampling. To draw a diverse sample of potential FM users, we

1. advertise our survey on various on-line discussion channels,

2. invite software practitioners and researchers from our social networks, and

3. ask these people to disseminate our survey.

We examine $\mathrm{C} 5, \mathrm{C} 1, \mathrm{C} 2$, and $\mathrm{C} 3$ from Table 2 to check how well our sample covers the given concept categories. The better the coverage of these categories the wider is the range of analyses possible from our data set. Less covered categories might indicate inappropriate concepts as well as the case that our sample just does not touch this fraction of the target population. Under the assumption that the sample is drawn from the target population in a uniformly random fashion, we would be able to draw conclusions about the constitution of the target population. However, as noted, this assumption was in our case not controllable. 


\subsection{Data Evaluation and Analysis}

For RQ1, we summarise the data and apply descriptive statistics for categorical and ordinal variables in Section 5.3. We answer RQ2 by comparison of the data for the past and future views regarding the domain $(\mathrm{C} 1)$, role (C2), FM class (C3), and purpose (C4) in Section 5.4. Then, in Section 5.5, we answer RQ3 by

- describing the challenge difficulty ratings after associating one of (1) domain, (2) motivational factor, (3) role, (4) purpose, and (5) FM class with challenge (C7) and

- distinguishing (1) more experienced (ME, > 3 years) from less experienced respondents (LE, $\leq 3$ years), (2) practitioners ( $\mathrm{P}$, practised at least once) from nonpractitioners (NP, not used or only in course or lab), (3) motivated (M, moderately or strongly motivated by at least one specified factor) from unmotivated respondents (U, no motivating factor specified), (4) respondents' past and future views, and (5) respondents with increased usage intent (II) from ones with decreased usage intent (DI).

We apply association analysis between these categorical and ordinal variables, using pairs of matrices (e.g. Fig. 17). We answer RQ4 by arguing from results for RQ1, 2, and 3.

Half-open and Open Questions We code open answers in additional text fields as follows: If we can subsume an open answer into one of the given options, we add a corresponding rating (if necessary). If we cannot do this then we introduce a new category "Other" and estimate the rating. Finally, we cluster the added answers and split the "Other" category (if necessary). For Q13, we performed the latter step combined with independent coding (Neuendorf 2016) to confirm that the understanding of the challenge categories is consistent among the authors of the present study. For MC questions, we eliminate the choice of "I do/have not..." options from the data if ordinary answer options where also checked.

Tooling We use Google Forms (Google 2018) for implementing our questionnaire (Appendix A.11) and for data collection (Section 4.5) and storage. For statistical analysis and data visualisation (Section 4.6), we use GNU R (The R Project 2018) (with the packages likert, gplots, and ggplot 2 and some helpers from the "Cookbook for R" and the "Stack Exchange Stats" community ${ }^{5}$ ). Content analysis and coding takes place in a spreadsheet application. A draft of Appendix A has been archived in Gleirscher and Marmsoler (2018).

\section{Execution, Results, and Analysis}

In this section, we summarise the responses to the questions in Table 3 and answer the RQs 1, 2, and 3 as explained in Section 4.1. To answer RQ1, we describe the sample in Section 5.2 and discuss some facets of FM use in Section 5.3. For RQ2, we summarise data about past use and usage intent in Section 5.4. For RQ3, we analyse further data in Section 5.5.

\footnotetext{
${ }^{5}$ See http://www.cookbook-r.com and https://stats.stackexchange.com.
} 
Table 5 Channels used for sampling

\begin{tabular}{ll}
\hline Channel type & Examples \& references \\
\hline General panels & SurveyCircle, www.surveycircle.com \\
LinkedIn groups & E.g. on ARP 4754, DO-178, FME, ISO 26262 \\
Mailing lists & E.g. system safety (U Bielefeld, formerly U York) \\
Newsletters & BCS FACS; GI RE, SWT, TAV \\
Personal pages & E.g. Facebook, Twitter, LinkedIn, Xing \\
ResearchGate & Q\&A forums on www.researchgate.net \\
Xing groups & E.g. Safety Engineering, RE
\end{tabular}

\subsection{Survey Execution}

For data collection, we (1) advertised our survey on the channels in Table 5 and (2) personally invited $>30$ persons. The sampling period lasted from August 2017 til March 2019. In this period, we repeated step 1 up to three times to increase the number of participants. Figure 1 summarises the distribution of responses. The channels in Table 5 particularly cover the European and North American areas.

\subsection{Description of the Sample (Answering RQ 1)}

A size estimation of the channels in Table 5 yields around $65 \mathrm{~K}$ channel memberships (for some channels we make a best guess but, e.g. for LinkedIn the counts are given). Assuming participants are, on average, member of at least three of the channels, we could have reached up to $20 \mathrm{~K}$ real persons. Given a recent estimate of worldwide 23 million SE practitioners (Evans Data 2018) and assuming that at least 1\% are mission-critical SE practitioners, our population might comprise at least $230 \mathrm{~K}$ persons, possibly around $38 \mathrm{~K}$ in the US and $61 \mathrm{~K}$ in Europe. ${ }^{6}$ We received $N=216$ responses resulting in an estimated response rate between 1 and $2 \%$ and a population coverage of at most $0.1 \%$ globally and $0.2 \%$ in the US and in Europe. About $40 \%$ of our respondents provided their email addresses, the majority from the US, UK, Germany, France, and a sixth from other EU and non-EU countries.

In the following, we summarise the responses to the questions about the application domain $(\mathrm{Q} 1)$, the level of experience $(\mathrm{Q} 2)$, and the motivations (Q3) of a FM user.

Guide to the Figures For Likert-type ordered scales, we use centred diverging stacked bar charts (see, e.g. Fig. 4) as recommended by Robbins and Heiberger (2011). The horizontal bars in each line show the answer fractions according to the legend at the bottom and are annotated with the percentages of the left-most, middle, and right-most answer options. These bars are aligned by the midpoint of the middle group (for 3- and 5-level scales) or by the boundary between the two central groups (for 4-level scales). Bar labels often abbreviate the corresponding answer options in the questionnaire. The questionnaire copy in Appendix A.11 contains short definitions, explanations, and examples to clarify the answer

\footnotetext{
${ }^{6}$ An estimation in Gleirscher et al. (2019) suggests that about 5\% of the overall ICT/IS developer population a re embedded systems practitioners in critical and non-critical domains. Moreover, Evans Data (2018) and Wikipedia contributors (2018) describe data from 2016 and 2017, suggesting that 3.87 million (19\%) SE practitioners live in the US and about 13.3 million (39\%) in Europe, the Middle East, and Africa. According to an analysis of data from Stack Overflow by ATOMICO (2019), there is a "software engineering talent pool" of about 6.1 million in Europe.
} 


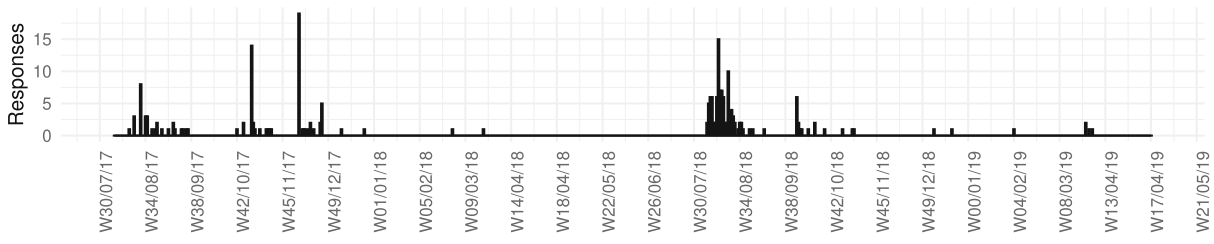

Fig. 1 Distribution of responses over time

options. For sake of brevity, we do not repeat this information here. "M" denotes the median, "CI" the 95\% confidence interval for the median calculated according to Campbell and Gardner (1988), "X" the number of excluded data points per answer option, and "NA" the number of invalid data points.

Q1: Application Domain For each domain, Fig. 2 shows the number of participants having experience in that domain. ${ }^{7}$ Note that 180 of the respondents do have experience with applying FM in different industrial contexts, while only 36 have not applied FMs to any application domain. Medical healthcare is an example where participants could have checked more than one answer category because medical devices would belong to "device industry" and emergency management IT would belong to "critical infrastructures". See Appendix A.11 for more information about the answer categories.

Q2: FM Experience Figure 3 depicts participants' years of experience in using FMs, showing that the sample covers all experience levels. However, the fraction of respondents with no experience (i.e., category "0") is comparatively low. According to Section 4.6, one third of the participants can be considered LEs with up to three years of experience, and two thirds can be considered MEs with at least three years of experience ( 29 of those with even more than 25 years). A further analysis of the study participants' experience profile is available from Table 8 in Appendix A.1 on page 36.

Q3: Motivation Figure 4 suggests that regulatory authorities play a subordinate role in triggering the use of FMs. In contrast, intrinsic motivation (in terms of private interest) seems to be the major factor for using FMs. For 9 respondents, none of the given factors was motivating at all. The 88 open responses for this question could either be subsumed in at least one of the given categories (65 in "Own (private) interest", 11 in other categories) or be declared as a comment (3) or not a further motivation (9). Hence, coding did not require an additional answer category to Q3.

\subsection{Facets of Formal Methods Use (Answering RQ 1)}

In the following, we summarise the responses to the questions about the role of a user (Q4), use in specification (Q5), use in analysis (Q6), and the underlying purpose (Q7) of such use.

Q4: Role Figure 5 shows in which roles the respondents applied FMs. An analysis of the MC answers shows that $72 \%$ of the participants used FMs in an academic environment, as a researcher, lecturer, or student. 50\% of the participants applied FMs in practice, as an engineer or consultant (see also Gleirscher and Marmsoler (2018)).

\footnotetext{
${ }^{7} \mathrm{MC}$ entails that the sum of answers can exceed $N$.
} 


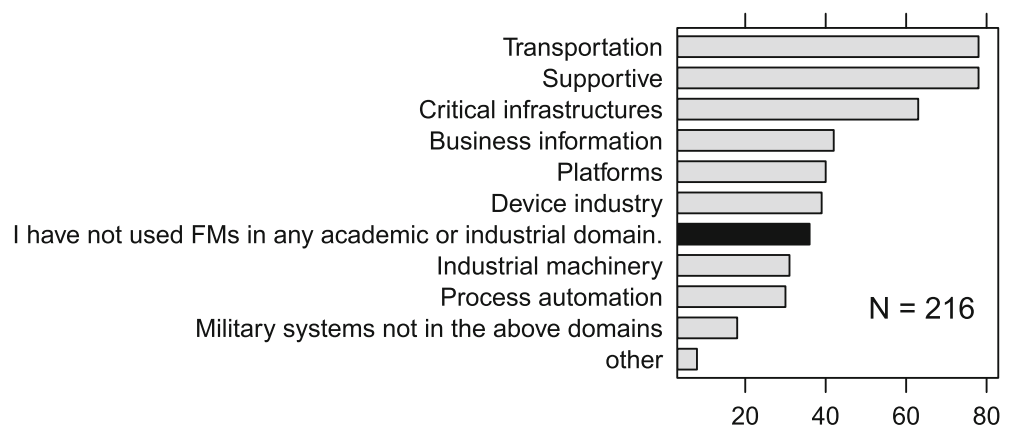

Fig. 2 (Q1) In which application domains in industry or academia have you mainly used FMs? (MC)

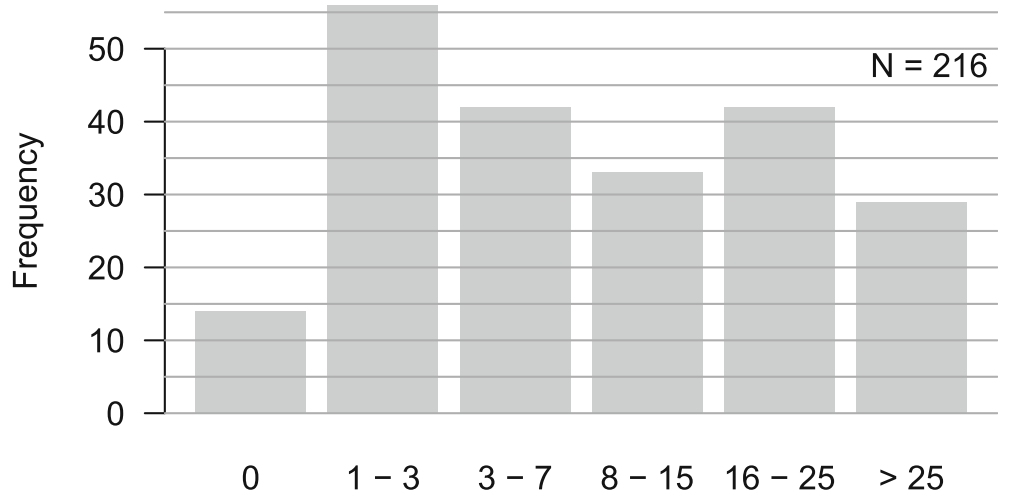

Fig. 3 (Q3) How many years of FM experience (including the study of FMs) have you gained?

Study or research program $(X=0, M=$ moderate, $\mathrm{Cl}[$ moderate, strong motivation], $\mathrm{NA}=0$ )

Own interest $(X=0, M=$ moderate, $C \mid$ [moderate,strong motivation], $\mathrm{NA}=0$ )

Employer / research collaborators $(X=0$ $\mathrm{M}=$ moderate, $\mathrm{Cl}[$ moderate, moderate], $\mathrm{NA}=0$ )

Customers / scientific community $(X=0$ $\mathrm{M}=$ moderate, $\mathrm{Cl}[$ moderate, moderate], $\mathrm{NA}=0$ ) Superior / principal investigator $(X=0, M=n o$, $\mathrm{Cl}[$ no, moderate], NA=0)

Regulatory authorities $(X=0, M=n o$, $\mathrm{CI}[\mathrm{no}$, moderate], $\mathrm{NA}=0$ )

On behalf of an $\mathrm{FM}(\mathrm{X}=0, \mathrm{M}=\mathrm{no}, \mathrm{CI}[$ no, moderate], $\mathrm{NA}=0$ )

$$
100
$$

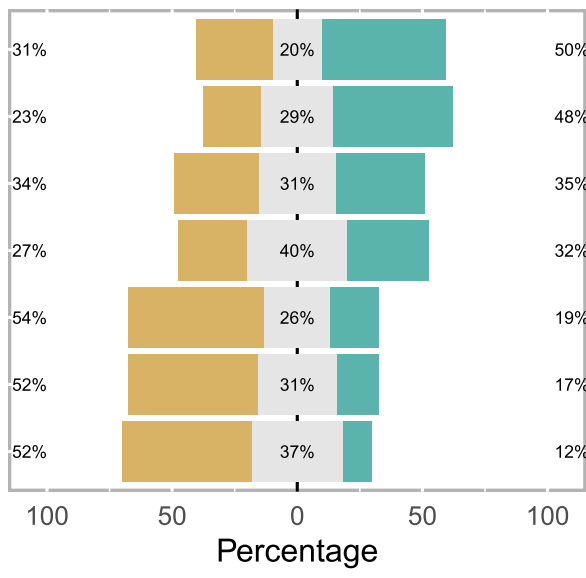

Degree of motivation: no moderate strong motivation

Fig. 4 (Q3) Which have been your motivations to use FMs? 


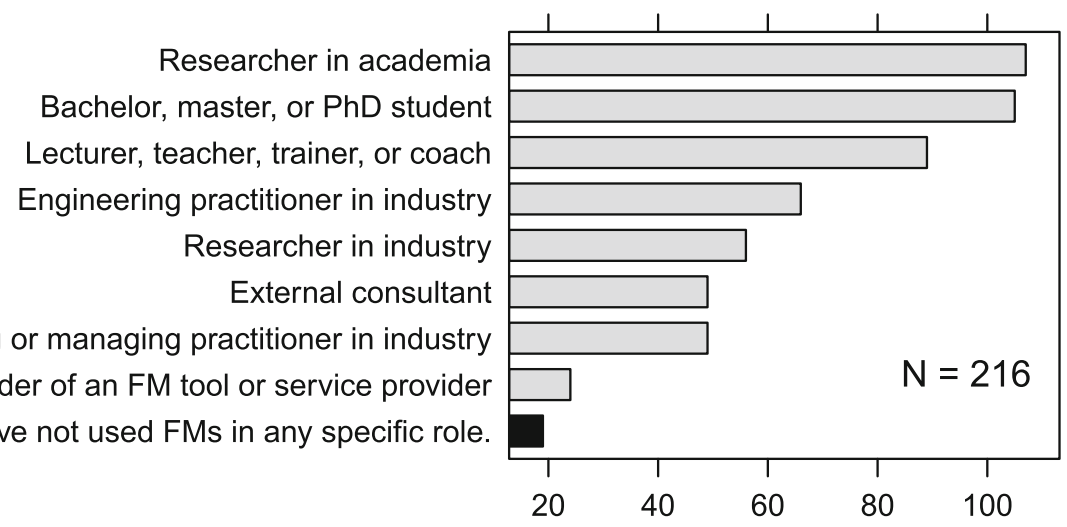

Fig. 5 (Q4) In which roles have you used FMs? (MC)

Q5: Use in Specification The degree of usage of FMs for specification is depicted in Fig. 6. There is an almost balanced proportion between theoretical and practical experience with the use of various specification techniques. Only the use of FMs for the description of dynamical systems seems to be remarkably low.

Q6: Use in Analysis The use of FMs for analysis is depicted in Fig. 7. Similar to specification techniques, we observe an almost balanced proportion between theoretical and practical experience with the usage of various analysis techniques. Outstanding is the use of assertion checking techniques, such as contracts. As expected from the observations for Q5, the use of FMs in computational engineering, such as algebraic reasoning about differential equations, is again exceptionally low.

Q7: Purpose Figure 8 depicts the participants' purposes to apply FMs. It seems that the respondents employ FMs mainly for assurance, specification, and inspection. Synthesis, on the other hand, to them seems to be only a subordinate purpose in the use of FMs.

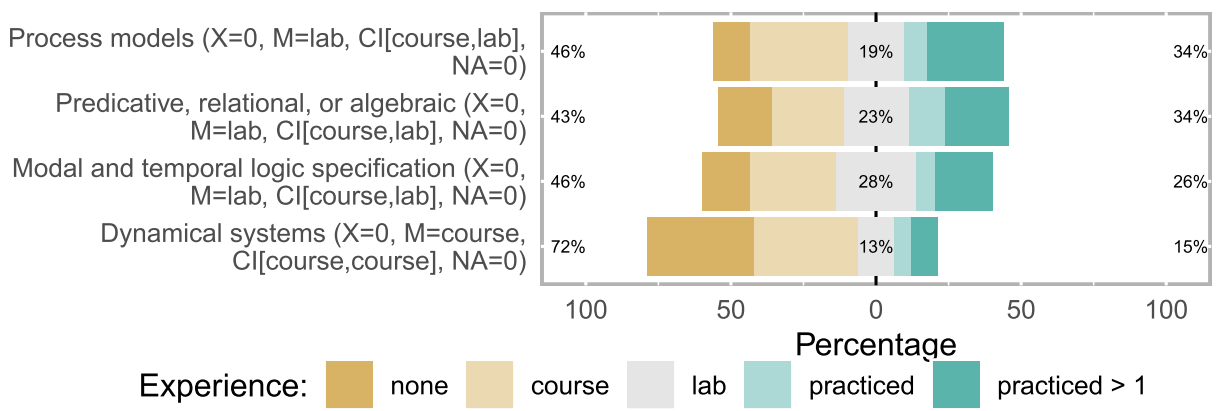

Fig. 6 (Q5) Describe your level of experience with each of the following classes of formal description techniques 


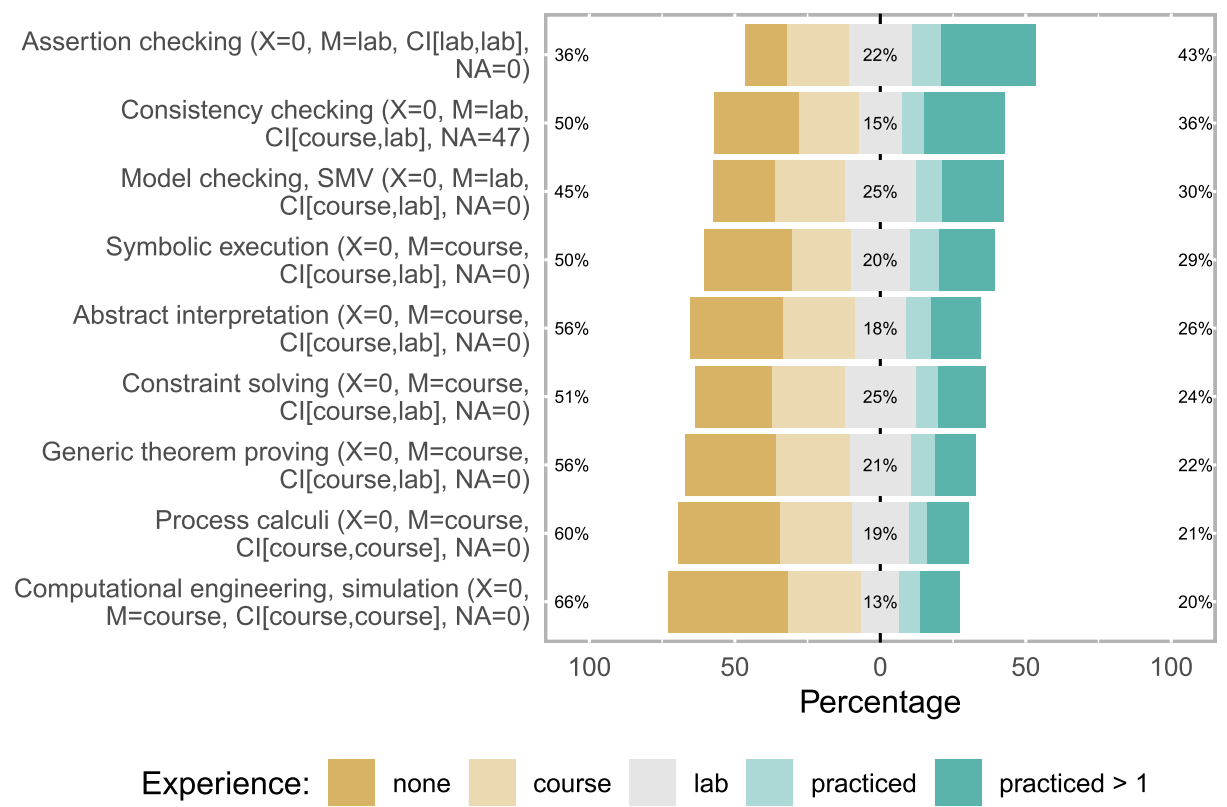

Fig. 7 (Q6) Describe your level of experience with each of the following classes of formal reasoning techniques

\subsection{Past Use Versus Usage Intent (Answering RQ 2)}

We investigate the usage intent of FMs across various domains and roles as well as the participants' intent to use various FMs and their intended purpose to use FMs.

Application Domain Figure 9 compares the respondents' past domains of FM application with their intended domains (see Q8). This figure reveals two insights into the participants' intentions to use FMs: (i) Fewer participants do not want to apply FMs in the future (19) than participants that have not used FMs (36, see yellow bars). Ten participants fall into both categories, they have not used FMs and do not intend to use FMs. (ii) The intended

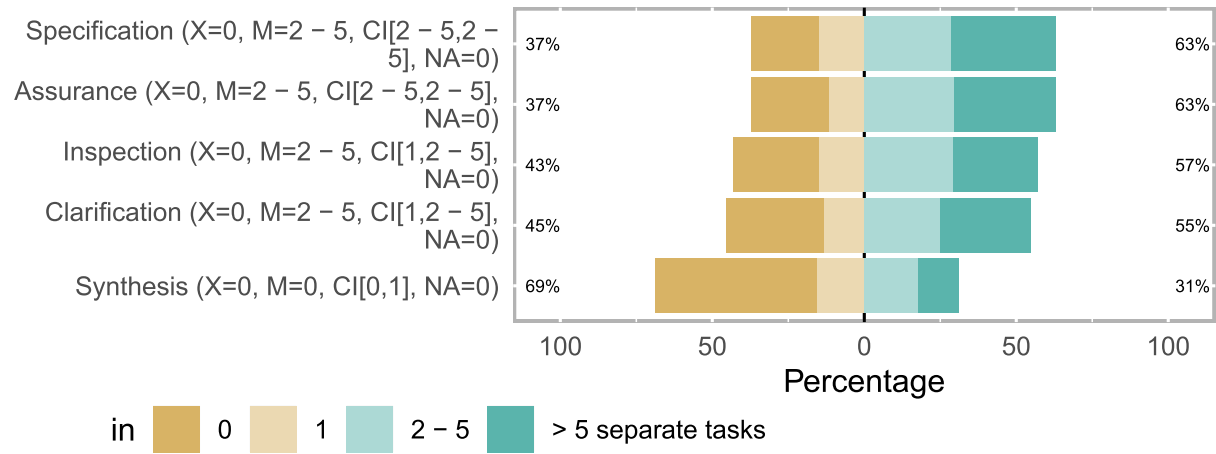

Fig. 8 (Q7) I have mainly used FMs for ... 
I would not or do not intend to use FMs in any... I have not used FMs in any academic or industri...

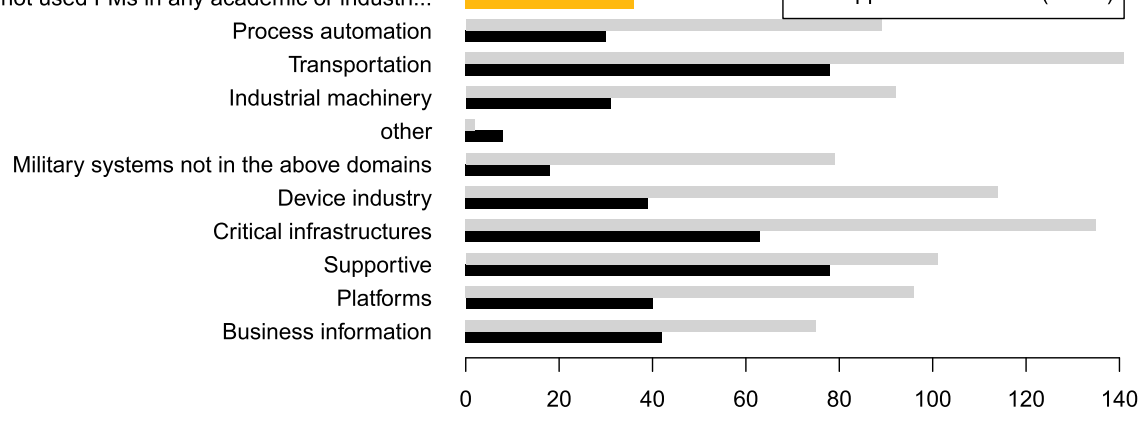

Fig. 9 Number of respondents using FMs by domain (past vs. intent)

application of FMs outperforms the current application of FMs across all domains. Hence, there is a tendency to increase the use of FMs across all application domains.

Role Figure 10 compares the participants' roles in which they applied FMs in the past with their intended role to apply FMs in the future (see Q9. Similar to the results for the application domain, we observe that some participants, who have not applied FMs in any role so far, intend to apply such methods in the future. However, the comparison reveals that academic disciplines (i.e., researcher and lecturer) seem to be stable. There is only a small difference between the number of participants who applied FMs in academic domains in the past and the number of participants who want to apply such methods to these domains in the future.

In contrast, there is a significant increase in the number of participants aiming to apply FMs, across all industrial roles.

Furthermore, the diagram shows a strong contrast between past and indented use in the category "Bachelor, master, or PhD student." We can see several reasons for this difference. From the respondents who "used FMs as a student," many (i) might not be able to "use FMs as a student" anymore because of having graduated, (ii) did not find FMs or the way FMs were taught as helpful, or (iii) moved into a business domain with no foreseeable demand for the application of FMs.

I do not or would not intend to use FMs in any ...

I have not used FMs in any specific role

Engineering practitioner in industry

Stakeholder of an FM tool or service provider Lecturer, teacher, trainer, or coach

Researcher in industry

Researcher in academia

External consultant

Consulting or managing practitioner in industry

Bachelor, master, or $\mathrm{PhD}$ student

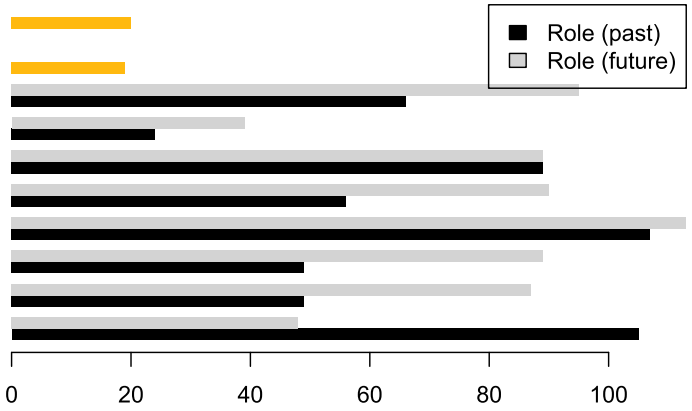

Fig. 10 Number of respondents applying FMs by role (past vs. intent) 


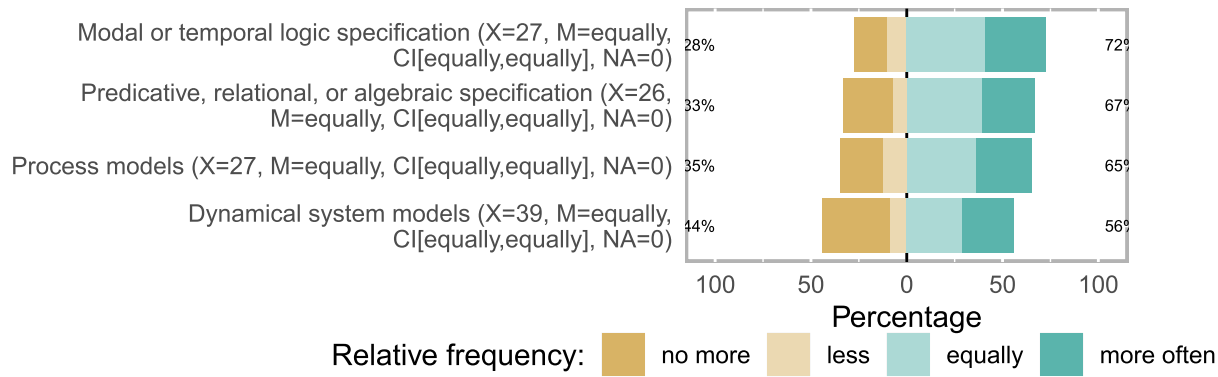

Fig. 11 (Q10) I (would) intend to use ...

Q10: Intended Use for Specification Figure 11 depicts the respondents' intended future use of various FMs for system specification (i.e., formal description techniques). The figure shows an almost equal amount of participants aiming to decrease (i.e., "no more" and "less") and increase (i.e., "more often") their use of FMs for specification. Only dynamical system models again seem to be an exception: more participants want to decrease their use of this technology, compared to participants who want to increase it.

Q11: Intended Use for Analysis The respondents' intended use of FMs for the analysis of specifications (i.e., formal reasoning techniques) is depicted in Fig. 12. Except for process calculi, we observe a general tendency of the participants to increase their future FM use.

Q12: Intended Purpose Figure 13 indicates why respondents intend to apply FMs. Again, there is a tendency of the participants to increase FM use across all listed purposes.

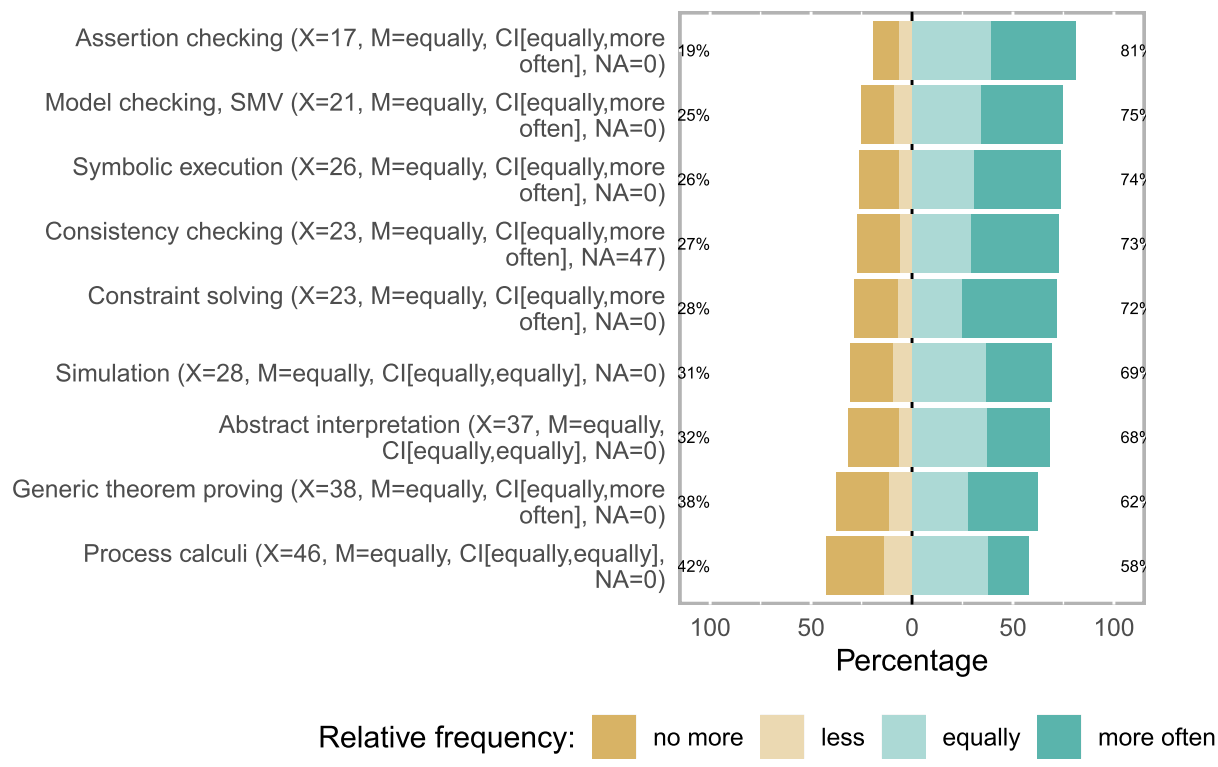

Fig. 12 (Q11) I (would) intend to use ... 


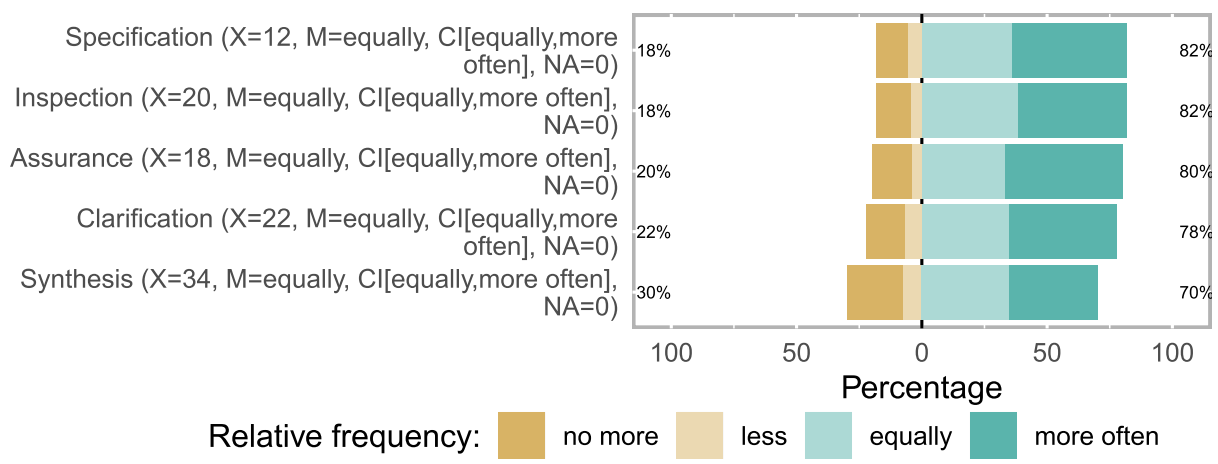

Fig. 13 (Q12) I (would) intend to use FMs for ...

Q7 and Q12: Comparison of Code- and Model-based FMs In the following, we regard practitioners with experience level "applied several times in engineering practice" or "applied once in engineering practice" and frequency "applied in 2 to 5 separate tasks" or "applied in more than 5 separate tasks" (see Table 4). We compare users of code-based FMs (CBs; including "abstract interpretation", "assertion checking", "symbolic execution", "consistency checking"; with $\mathrm{N}=128$ ) with users of model-based FMs (MBs; including "process calculi", "model checking", "theorem proving", and "simulation"; with N=114). While some of the FM classes can be seen as both, code- and model-based, we made a choice based on our experience but left out "constraint solving" because it is a fundamental technique intensively applied in both.

The comparison of past and future use for code-based (top half of Fig. 21 in Appendix A.4) and model-based FMs (bottom half of Fig. 21), for example, in inspection (e.g. error detection, bug finding) shows the following:

- CBs show slightly more frequently an increased intent (the "more often" group) than MBs; for both sub-groups, respondents with 2 to 5 and with more than 5 past uses.

- MBs show slightly more frequently a decreased intent (the "no more" group) than CBs.

Looking at assurance (e.g. proof, error removal) shows the following:

- MBs show slightly more frequently an increased intent than CBs when looking at respondents who have used FMs more than 5 times. However, MBs indicate slightly less frequently an increased intent than CBs when looking at respondents with 2 to 5 uses.

- CBs indicate more $d n k s$ after 2 to 5 uses and slightly more frequently a decreased intent after 5 uses in comparison with MBs.

Q1, Q5, and Q6: Practised FM Classes by Application Domain We asked respondents about their use of each FM class independent of the application domain and about their general use of FMs in each such domain. Hence, we can only approximate past usage per FM class and application domain assuming that the overall usage per respondent is uniformly distributed among the specified FM classes and domains. For that, we interpret (and count) each respondent who specifies a domain in combination with "applied once in engineering practice" or "applied several times in engineering practice" for an FM class as a practitioner who has used $\left(U F M_{p}\right)$ or, respectively, wants to use $\left(U F M_{i}\right)$ FMs of that class in that domain. More generally, we count a respondent who specifies $n$ domains, say $d_{1}$ to $d_{n}$, in 


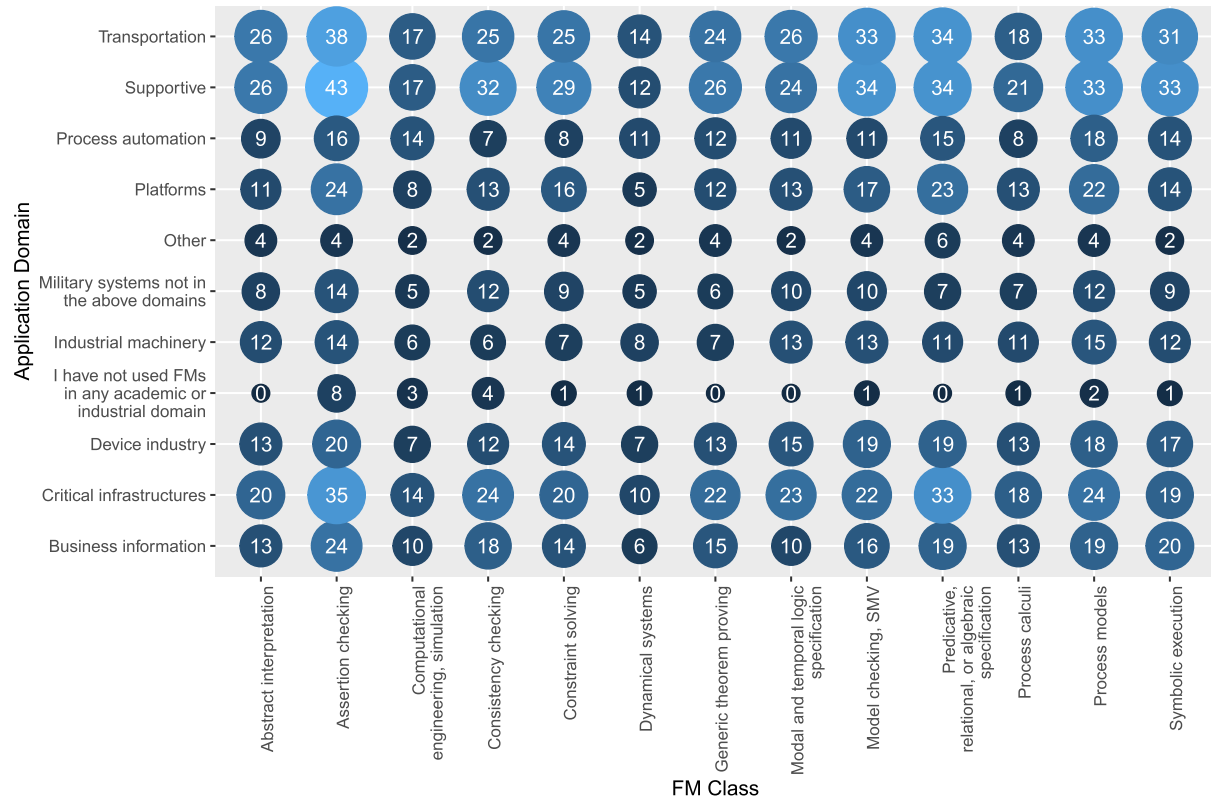

Fig. 14 Approximation (likelihood) of practised use $\left(U F M_{p}\right)$ by FM class and application domain

combination with "applied once in engineering practice" or "applied several times in engineering practice" for $m$ FM classes, say $c_{1}$ to $c_{m}$, as a practitioner who has used $\left(U F M_{p}\right)$ or, respectively, wants to use ( $U F M_{i}$ ) FMs of the classes $c_{1}$ to $c_{m}$ in the domains $d_{1}$ to $d_{n}$. Figs. 14 and 15 show these approximations for $U F M_{p}$ and $U F M_{i}$.

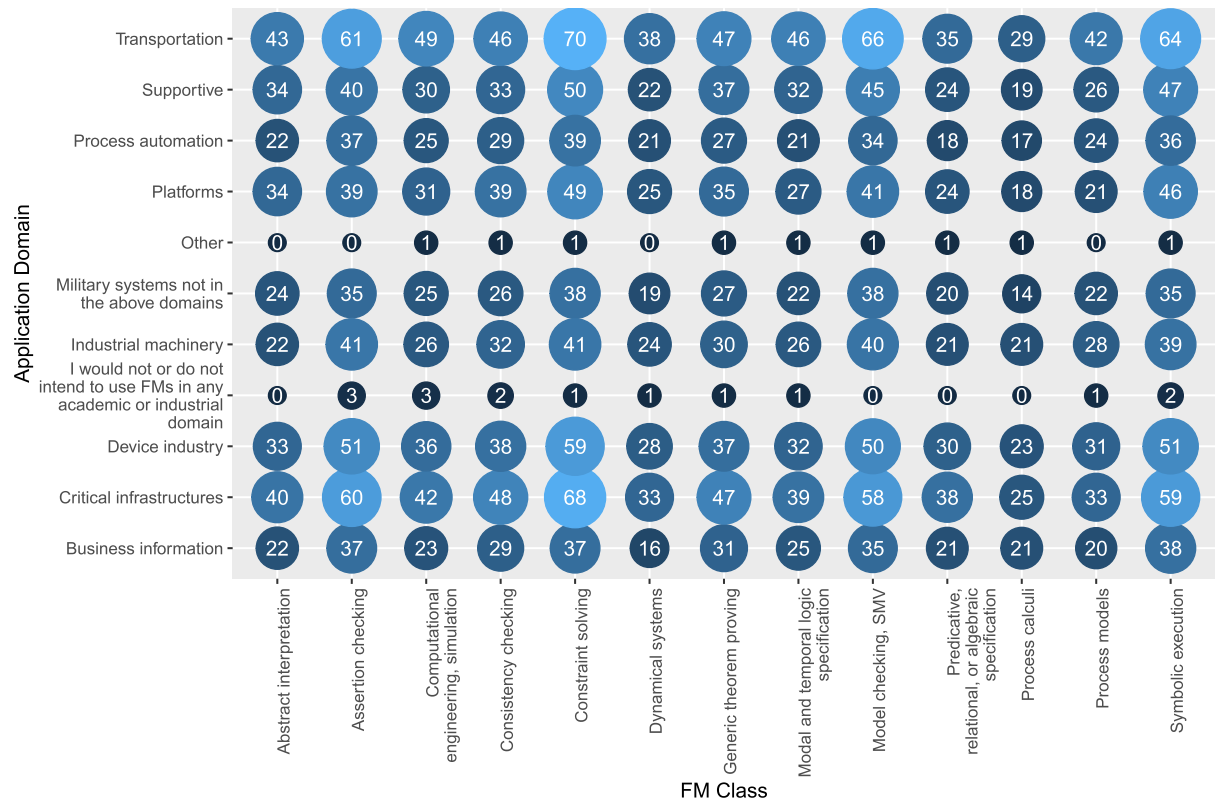

Fig. 15 Approximation (likelihood) of increased usage intent $\left(U F M_{i}\right)$ by FM class and application domain 


\subsection{Perception of Challenges (Answering RQ 3)}

Table 6 lists the FM challenges subject to discussion, their background, and literature referring to them. We apply the procedure described in Section 4.6.

General Ranking (Q13) Figure 16 shows the respondents' ratings of all challenges. Most of them believe that scalability will be the toughest challenge and maintainability is considered the least difficult of all rated obstacles. For reuse of proof results, proper abstractions, and tool support, the participants distribute more uniformly across moderate and high difficulty.

In the following, we compare specific groups of respondents by how they perceive the difficulty of the various challenges. We group respondents according to the criteria in Section 4.6 and according to the role, motivating factor, FM class, and purpose they specified. Appendix A.6 provides some background material for the following association analyses.

Less Experienced (LE) Versus more Experienced (ME) Respondents (Q2) The comparison of the difficulty ratings of LEs with the ratings of MEs shows that (i) LEs less often perceive the given challenges as tough, t (ii) MEs significantly more often rate scalability as tough, (iii) both groups show the closest agreement on transfer of verification results and skills and education.

Non-practitioners (NP) Versus Practitioners (P) by Past Purpose (Q7) The perception of skills and education and scalability as the most difficult challenges is largely independent of the purpose, again Ps attributing more significance to scalability. Scalability, the forerunner in Fig. 16, exhibits the most tough-ratings from NPs in synthesis and from Ps in assurance and clarification (see the top half of Fig. 22 in Appendix A.6).

Decreased Intent (Di) Versus Increased Intent (II) by Purpose (Q12) The comparison of the difficulty ratings of respondents with no or decreased intent to use FMs for a specific purpose and of respondents with equal or increased intent shows: (i) Scalability and skills and education, both forerunners in Fig. 16, show the most tough-ratings from IIs for assurance $(67 \%)$ and inspection (66\%) and from DIs for synthesis (53\%). (ii) The trend in Fig. 16 is more clearly observable from IIs than from DIs, where transfer of verification results and automation and tool support seem to be tougher than skills and education.

Non-Practitioners (NP) Versus Practitioners (P) by FM Class (Q5, Q6) The top half of Fig. 17 shows for NPs, the trend in Fig. 16 is largely independent of the FM class, except for consistency checking and logic leading with tough proportions of $49 \%$.

The bottom half of Fig. 17 shows for Ps, difficulty ratings across FM classes vary more: The foremost challenges in Fig. 16 received the most tough-ratings from users of process models, dynamical systems, process calculi, model checking, and theorem proving. Difficulty ratings of users are often centred on moderate or tough, proper abstraction and skills and education show a comparatively wide variety across FM classes.

The histograms in the lower right corners in Fig. 17 indicate that (i) NPs' difficulty ratings vary less than Ps' ratings, (ii) NPs' ratings are more independent from the FM classes, and (iii) NPs' difficulty ratings are lower on average than Ps' ratings. Appendix A.6 contains several such association matrices with more detailed data in the matrix cells. 


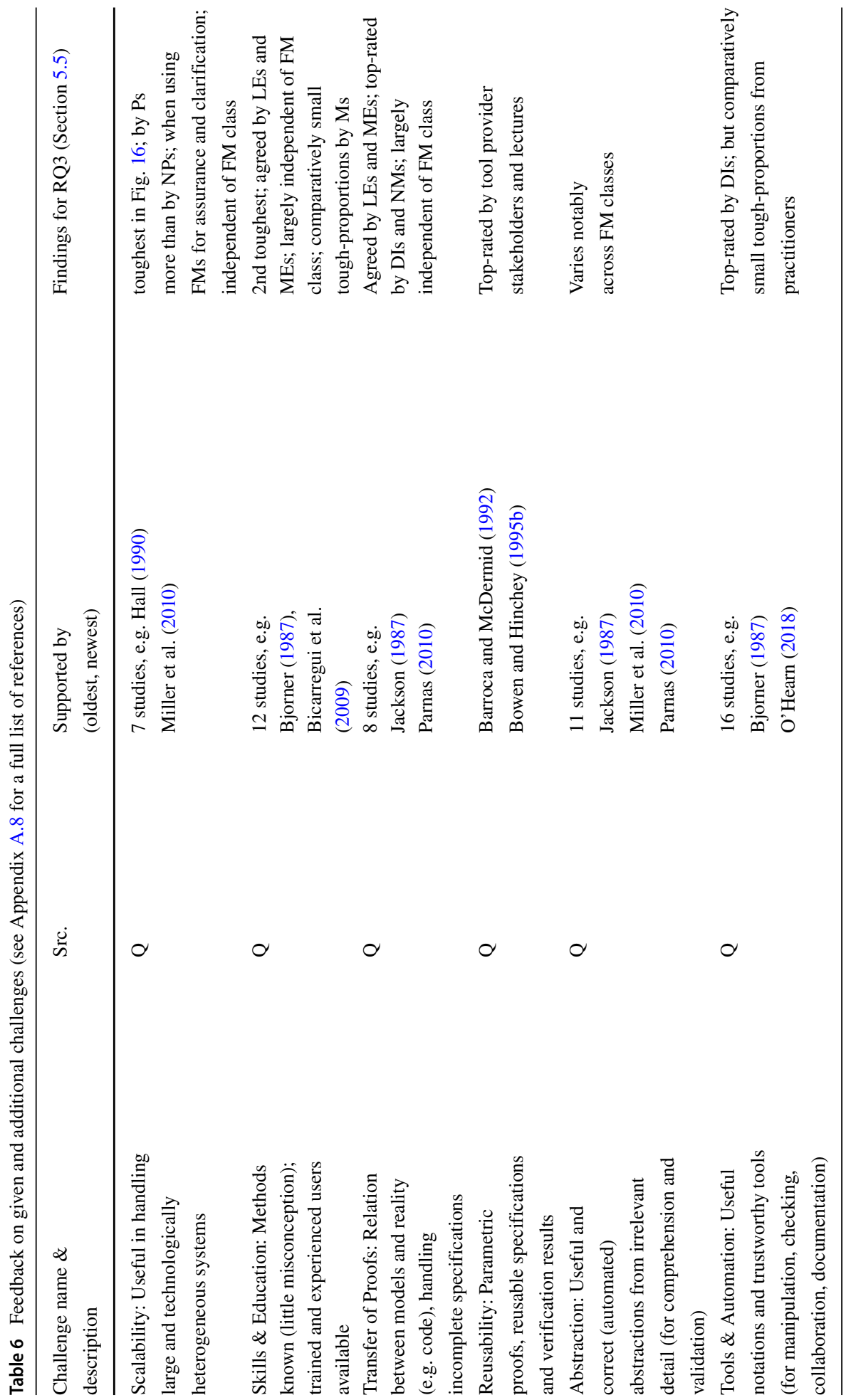

\section{囪 Springer}




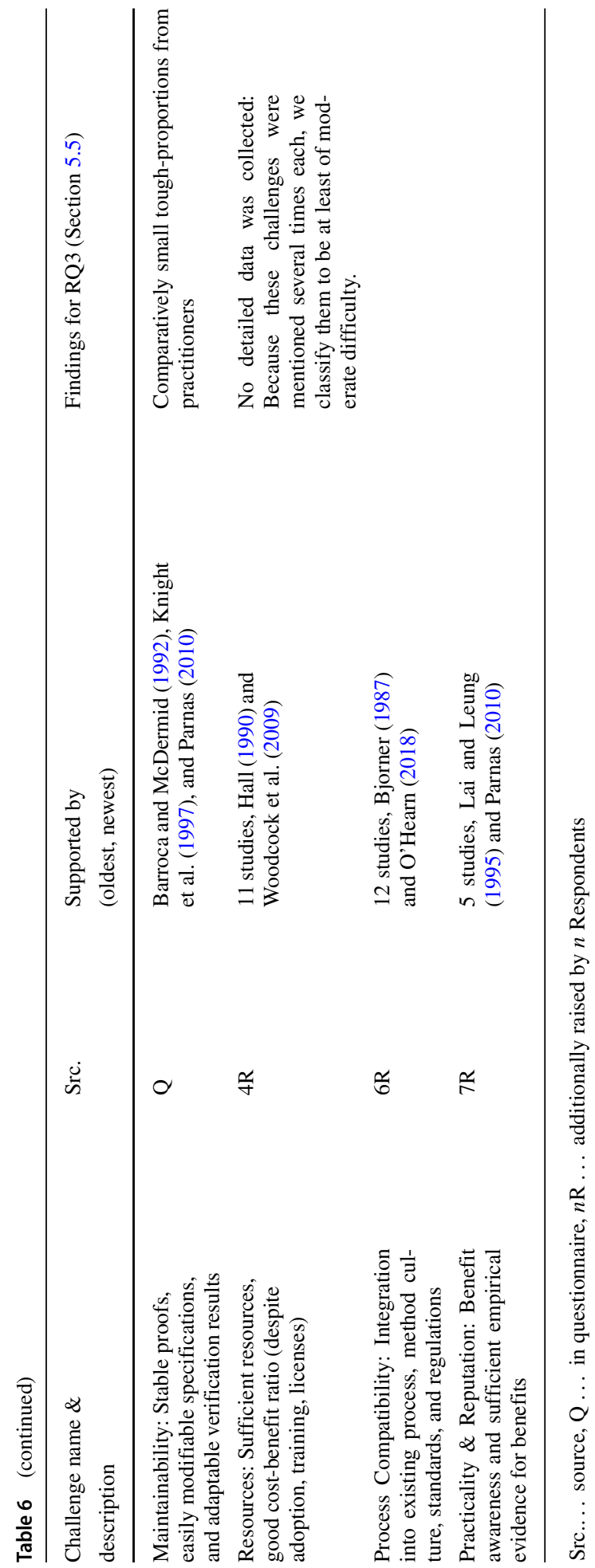




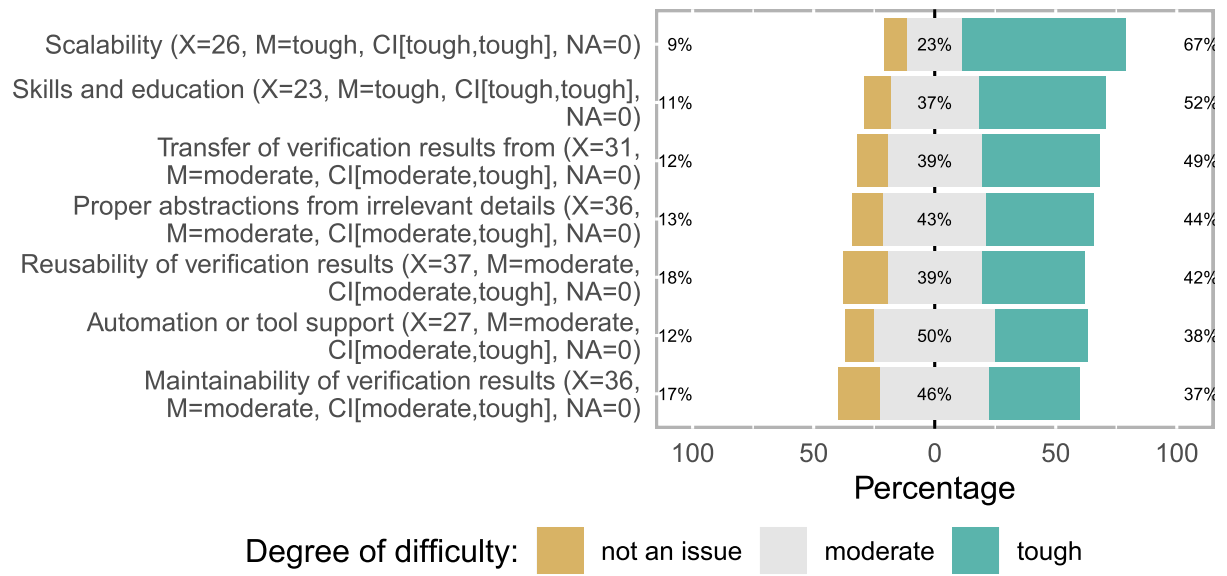

Fig. 16 (Q13) For any use of FMs in my future activities, I consider $\langle$ obstacle $\rangle$ as [not an|a moderate|a tough] issue

Decreased Intent (DI) Versus Increased Intent (II) by FM Class (Q10, Q11) The trend in Fig. 16 is supported by many tough ratings (48\%) for transfer of verification results from DIs in consistency checking. However, DIs in process calculi provide comparatively many tough-ratings (39\%) for the generally low-ranked automation and tool support. Assertion checking exhibits comparatively low tough-proportions across all challenges whereas process calculi exhibit comparatively high tough-ratings. Mirroring the trend in Fig. 16, IIs show less variance than DIs across all FM classes.

Unmotivated (U) Versus Motivated (M) Respondents by Motivating Factor (Q3) Respondents with moderate to strong motivation to use FMs more likely identify the given challenges as moderate to tough, regardless of the motivating factor. The trend in Fig. 16 seems explainable by many tough ratings from respondents motivated by regulatory authorities (69\%), not motivated by tool providers (56\%), and not motivated by superiors/principal investigators (56\%, see Fig. 24 in Appendix A.6). Us' tough-ratings are notably lower than Ms' tough-ratings.

Past and Future Views by Role (Q4, Q9) Although participants show role-based discrepancies between their past and intended use of FMs (Fig. 10), the perception of difficulty of the rated challenges seems to be largely similar, following the trend in Fig. 16. The high ranking of scalability (and reusability of verification results) is supported by many toughratings from tool provider stakeholders for the past view and many from lecturers for the future view. Respondents not having used FMs or not planning to use FMs exhibit the lowest tough-ratings but also the highest fractions of $d n k$-answers.

Past and Future Views by Domain (Q1, Q8) The trend in Fig. 16 is underpinned by highest tough-proportions for respondents from the transportation, military systems, industrial machinery, and supportive domains. 
Comparison of Challenge Difficulty across FMs (users not practicing FMs, past)

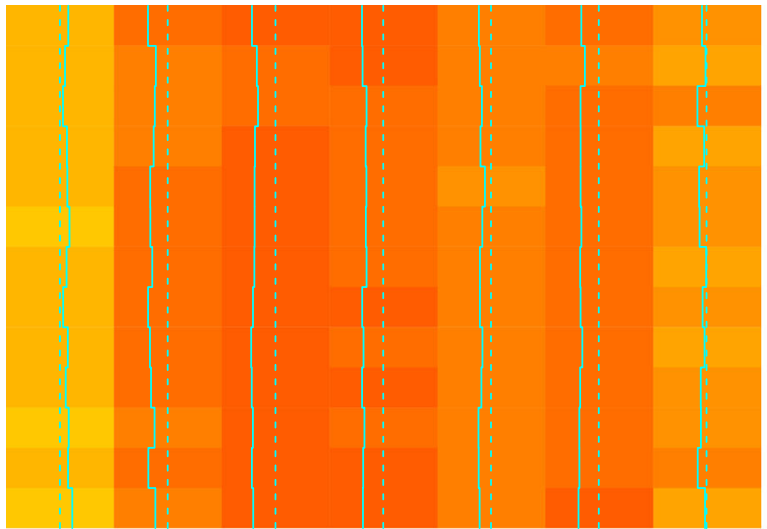

Predicative, relational, or algebraic specification

Modal and temporal logic specification

Process models

Dynamical systems

Abstract interpretation

Assertion checking

Process calculi

Model checking, SMV

Constraint solving

Generic theorem proving

Computational engineering, simulation

Symbolic execution

Consistency checking

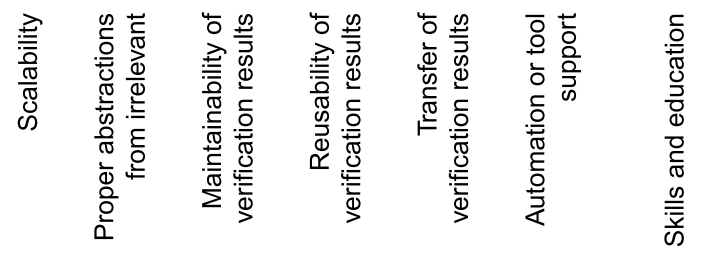

Key/Histogram of Toughs

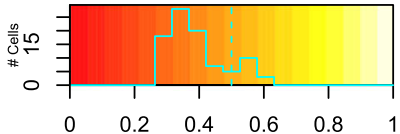

Tough-proportion of all ratings per cell

\section{Comparison of Challenge Difficulty across FMs (users practicing FMs, past)}

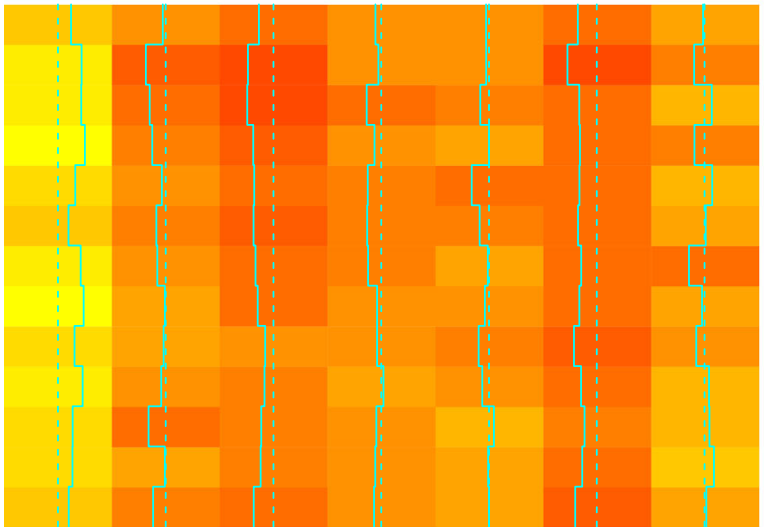

Predicative, relational, or algebraic specification

Modal and temporal logic specification

Process models

Dynamical systems

Abstract interpretation

Assertion checking

Process calculi

Model checking, SMV

Constraint solving

Generic theorem proving

Computational engineering, simulation

Symbolic execution

Consistency checking

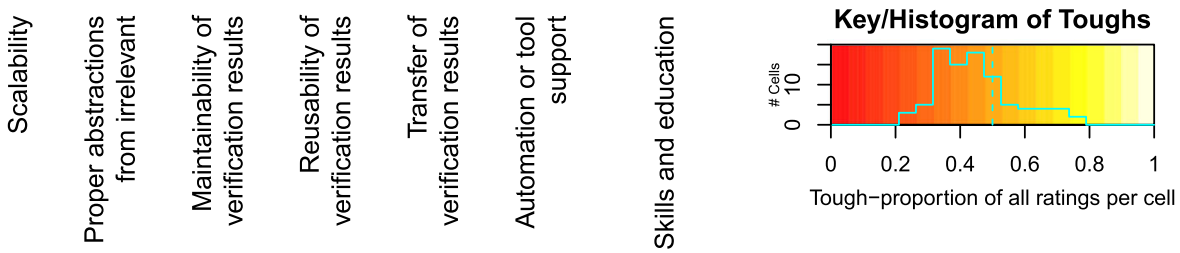

Fig. 17 Difficulty of challenges (cols): NPs (top) compared to Ps (bottom) by class of used FM (rows). Legend: In each cell of an association matrix, both the solid vertical line and the colour (gradient from red to white) represent the tough proportions (from 0 to $100 \%$ ), with the dotted vertical line marking the $50 \%$ margin. The histogram (to the lower right corner of each matrix) counts the combinations (cells) in each $5 \%$-band of tough ratings. E.g. $\sim 70 \%$ of "process calculi" users perceive "scalability" as a tough challenge 


\section{Discussion}

In this section, we discuss and interpret our findings, relate them to existing evidence, outline general feedback on the questionnaire, and critically assess the validity of our study.

\subsection{Findings and Their Interpretation}

The following (F)indings are based on the data summarised and analysed in the Sections 5.2 to 5.4. All findings are then collected in Table 7 on page 26 .

\section{Findings for RQ 1}

F1 Regulatory authorities with their norms, codes, or policies represent only a minor motivating factor to use FMs. Intrinsic motivation (maybe market-triggered) seems to be stronger. This finding is consistent with what we know from the literature survey in Gleirscher et al. (2019): FMs are not formally required by corresponding standards today, not even for the highest safety integrity levels. If regulatory authorities change their recommendations to requirements, then this might spike as a motivating factor.

Table 7 Summary of findings per research question

RQ1: In which typical domains, for which purposes, in which roles, and to what extent have FMs been used?

F1 Intrinsic motivation to use FMs is stronger than norms or codes of regulatory authorities.

F2 The fraction of respondents with no experience at all is comparatively low.

F3 Respondents use FMs the least in computational engineering and for dynamical systems.

RQ2: Which relationships can we observe between past experience in using FMs and intent to use FMs?

F4 Increased intent to use FMs observable across all application domains.

F5 Amount of experience is positively associated with the strength of usage intent.

F6 The responses do not show any significant differences between code- and model-based FMs.

F7 Respondents show high likelihoods of an increased intent to use FMs such as

"model checking" or "assertion checking" in areas such as "transportation" or "critical infrastructures".

RQ3: How difficult do study participants perceive widely known FM challenges?

F8 Scalability and skills \& education lead the challenge difficulty ranking.

F9 Maintainability of proof results is found to be the least worrying challenge.

F10 Reusability of proof results is rated as tough by several practitioner groups.

F11 FM users with decreased usage intent rate tool deficiencies as their top obstacle.

F12 Respondents identified resources, process compatibility, and reputation as further obstacles.

F13 All considered challenges are generally perceived as moderate or tough.

F14 Among the FM classes, process models are most positively associated with tough scalability.

RQ4: What can we say about the perceived ease of use and the perceived usefulness of FMs?

F15 Respondents perceive the usefulness of FMs as mainly positive and intend to increase their use.

F16 Respondents perceive the ease of use of FMs as mainly negative.

Relationship to Existing Evidence (from the literature):

F17 Proof maintainability and reusability are least covered by the literature.

F18 We repeat Austin and Graeme (1993), excluding benefit analysis but with

a broader sample and more detailed questions. 
F2 The low fraction of respondents with no experience in Fig. 3 may have been caused (1) by our choice of expert channels in Table 5 where the likelihood of encountering FM users is probably higher than in more generic SE channels (e.g. Stack Overflow) and (2) by the fact that SE students will usually have an FM course or some lectures about FMs such that they would choose "1-3 years" in Q2 and "studied in course" in Q3.

F3 We observe the least use of FMs in computational engineering and for reasoning about dynamical systems, for example, reasoning about the correctness of algorithms, and their implementation in embedded software, controlling such systems. One explanation for this is that our sample mainly comprises software and systems engineers who will work less intensively with such FMs than, for example, mechanical or control engineers. Another explanation is that such FMs are still less widely known, less well developed, or less well supported by tools than FMs focusing on the reasoning about pure software.

\section{Findings for RQ 2}

F4 It seems that in all given domains (Fig. 9, except for other) respondents intend to increase their future use of FMs. Moreover, we observe that this tendency is independent of the particular FM class (except process calculi) or purpose. The data also suggest that the use of FMs by teachers and researchers is saturated. This saturation indicates a stable intent to teach FMs, to perform research in FMs, or to otherwise use FMs in teaching or research. However, there is an increased intent to apply FMs in industrial contexts in the future. One explanation could be that engineers have already wanted to use FMs but have not had the opportunity or were not told or permitted to do so. Another explanation for an increased intent of FM non-users could be due to some bias when answering questions about whether someone would do (e.g. try out) something.

F5 Our data suggest that experience in using a certain FM class is positively associated with the intent to use this FM class in the future. To investigate this suspicion, we analysed the intended use of a FM class based on the experience of participants in using this class (also by association analysis as described in Section 4.6). We observe that the more experience one has with using a specific FM class, the more likely they will apply it in the future (see the two charts in the Appendices A.3 and A.5). No experience with a specific FM class correlates with a low intent to use that class. Participants not having used FMs and, hence, unfamiliar with them might not have had the need in the first place. Only little experience with a certain FM class significantly increases the intent to apply it again in the future. Similar observations can be made for the use of FMs in general for a specific purpose.

F6 The differences in past and intended use between code- and model-based FMs (Section 5.4), for example, when looking at inspection and assurance, are marginal. Moreover, we cannot find a significant difference or a trend between these two categories of FMs when considering different purposes, experience levels, and usage frequencies.

F7 The approximation in the Figs. 14 and 15 allows the, albeit vague, interpretation of the numbers as the likelihood that respondents have used (Fig. 14) or want to use (Fig. 15) a particular FM in a particular domain. Assuming this model, Fig. 15 indicates the highest likelihoods of an increased $U F M_{i}$ for methods such as "assertion checking", "constraint solving", "model checking", and "symbolic execution" in domains such as "transportation", "critical infrastructures", and the "device industry".

\section{Findings for RQ 3}


F8 Scalability and skills and education lead the challenge ranking, independent of the domain, FM class, motivating factor, and purpose. Practitioners see scalability as more problematic than non-practitioners, whereas non-practitioners perceive skills and education as more problematic than practitioners. Fig. 18 may explain the latter by showing a high fraction of students among the 46 non-practitioners.

F9 Maintainability of proof results or other verification artefacts was found to be the least difficult challenge. However, in the lower half of Fig. 17, the challenge column "maintainability" shows relatively low frequencies for "modal and temporal logic" and "model checking" (possibly because of the high level of automation) whereas "theorem proving" (possibly because of a low level of automation) and "constraint solving" (possibly because of being too versatile or generic for the present purpose) show the highest frequencies of tough ratings. See Fig. 26 in the Appendix A.6 for more details.

F10 Reusability of proof results was rated as tough by several practitioner groups.

F11 FM users with decreased usage intent rate tool deficiencies as their top obstacle to FM adoption.

F12 Furthermore, our respondents raised three additional challenges (i.e., resources, process compatibility, and practicability \& reputation) which we cross-validated with the literature (see highlighted rows in Table 6). The fact that these obstacles were mentioned several times in addition to the given obstacles justifies them to be highly relevant and at least moderate. However, our data does not allow to rank them more precisely.

F13 Challenges are perceived as moderate or tough, largely similarly between the pairs of groups we distinguish in Section 4.6.

F14 With $72 \%$ of tough ratings for scalability, process calculi (e.g. ACP, CCS, CSP) perform in the midfield despite their high reputation as compositional methods. Scalability of process models (e.g. Petri nets, Mealy machines, labelled transition systems, Markov models) is also ranked in the middle field of tough challenges. The ranking of these models, however, is unsurprising in the light of the difficult scalability of model checking, a frequently used verification technique for process models and the leader in this ranking (cf. Fig. 17). One explanation for the high number of tough-ratings from NPs in synthesis could be that NPs might either not associate FMs with synthesis in general, or because automated synthesis of sophisticated artefacts is known to be an unsolved problem in many cases, independent of the use of FMs.

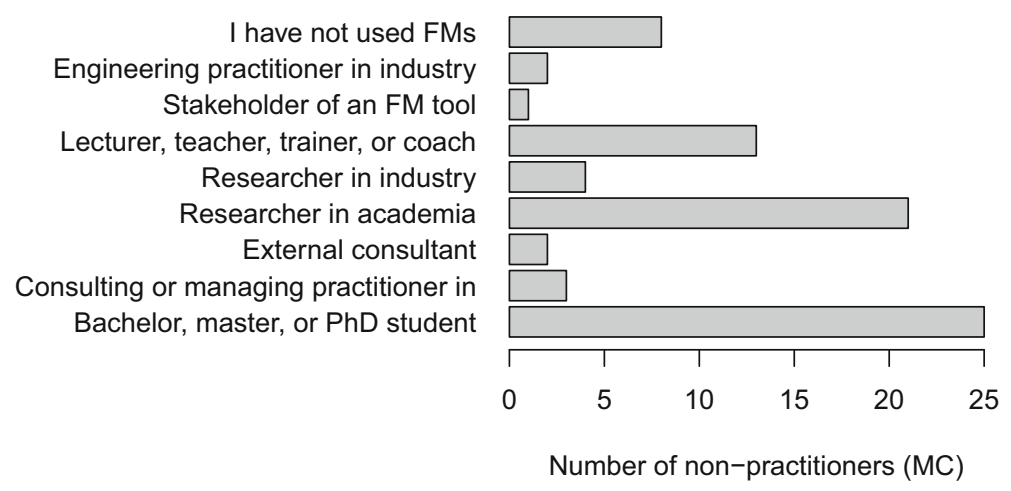

Fig. 18 The past role profile of the 46 non-practitioners (out of 216 respondents) helps to explain finding F8 


\subsection{Relationship to TAM for Methods (Answering RQ 4)}

In analogy to the reasoning in Davis (1989), an increased positive experience with practically applying FMs forms a high degree of PU (Section 2). Davis (1989, pp. 329, 331) observed that current and intended usage are significantly correlated with PU, less with PEOU. In fact, F4 suggests an increased intent to use FMs in the future. Moreover, F4 suggests a positive association of the degree of experience with $U F M_{i}$, that is, more experience increases the intent. F15 Because the use of FMs is not mandatory for most respondents, a likely explanation for an increased intent $\left(U F M_{i}\right)$ is that our respondents perceive the usefulness of FMs to be more positive than negative.

Inspired by Riemenschneider et al. (2002), in the last paragraph of Section 4.2, we justify the use of challenge scales to collect data for PEOU and PU. We justify the validity of the FM-specific challenge scale using the studies in Table 1. The column "supported by" in Table 6 indicates studies discussing the corresponding challenges. From these discussions, we infer that tackling these challenges contributes to an increased EOU and U. First, the studies suggest that FMs are easier to use if users have sufficient skills and education, if the methods scale to large systems, if mature tools and automation are available, and if proofs are easily maintainable and reusable. Second, the studies suggest that FMs are more useful if they are compatible with the process, if their cost-benefit ratio is low, if their abstractions are correct and expressive, and if proofs can be correctly transferred to reality. Hence, these challenges represent FM-specific substrata (Davis 1989, p. 325) of EOU and U for FMs. Moreover, a high degree of PEOU corresponds to an increased positive user experience with FMs which translates to a low proportion of tough ratings for the obstacles measured in Q13. However, from F13, we observe that respondents rate most challenges as moderate to tough, largely independent of other variables (F8).

F16 Overall, it thus seems that our respondents perceive the ease of use of FMs to be more negative than positive. According to Table 6, many of the surveyed studies discuss skills \& education (12 studies) and tools \& automation (16) as important challenges. Moreover, Fig. 16 suggests that conceptual difficulties (possibly, from a lack of education and training, from difficulties in FM teaching, from a lack of FM students) seem to be at least as responsible for the negative ease of use as the lower ranked tool deficiencies. Indeed, in a recent discussion of "push-button verifiers", O'Hearn (2018) highlights that both conceptual expertise and tool deficiencies are still significant bottlenecks. However, an investigation of respondents' experiences with FM tools in comparison to their experiences with FM concepts goes beyond the possibilities of the data collected for this study.

\subsection{Relationship to Existing Evidence}

Our systematic map shows that our list of challenges is completely backed by substantial literature (see Table 6) raising and discussing these challenges. F17 However, the fact that maintainability and reusability were least covered by our literature is, on the one hand, in line with F9 but, on the other hand, not with F9 and typical cultures of reuse in practice.

Beyond the general findings about FM benefits in Austin and Graeme (1993), we steered our half-open questionnaire towards a refined classification of responses, comparing past with intended use, and interrogating recently perceived obstacles among a methodologically and geographically more diverse sample. Their sample mainly covers Z and VDM users in the UK. Our questionnaire has less focus on representation and methodology and excludes both questions on benefits and on suggestions to overcome obstacles. Regarding the latter, 
Austin and Graeme (1993) mention the improvement of education and standardisation, the preparation of case studies, and the definition of FM effectiveness metrics.

F18 The report of Austin and Graeme (1993) from the National Physical Laboratory archive was unfortunately no more available to us. We finally managed to get access to a paper copy provided by a friendly colleague. This, however, only happened after conducting this survey. Anyway, we found that our conclusions are nearly identical to Austin and Graeme's. The data from Fig. 16 and Table 6 confirms that many of the obstacles (i.e., limitations and barriers) they identified back in 1991/2 remain (e.g. understanding the notation and the underlying mathematics, resistance to process changes), some have been lightly addressed (e.g. lack of cost/benefit evidence) and some have been more strongly addressed (e.g. lack of expressiveness, lack of appropriate tools). Not mentioned in Austin and Graeme (1993) is scalability, rated by our respondents to be the toughest obstacle.

F5 is in line with other observations in Woodcock et al. (2009) and Bicarregui et al. (2009) that the repeated use of a FM results in lower overheads (i.e., an experienced effort or cost reduction and improved error removal), up to an order of magnitude less than its first use (Miller et al. 2010). Finally, our study generalises the main findings about barriers in Davis et al. (2013) to several geographies and application domains, however, using an on-line questionnaire instead of interviews and not asking for barrier mitigations.

\subsection{Threats to Validity}

We assess our research design with regard to four common criteria (Shull et al. 2008; Wohlin et al. 2012). Per threat (々), we estimate its criticality (minor or major), describe it, and discuss its partial (o) or full $(\checkmark)$ mitigation.

\subsubsection{Construct Validity}

Why would the construct (Section 4.2) appropriately represent the phenomenon?

maj 々: Inappropriate questions and conceptual misalignment / To support face validity, we applied our own experience from FM use to develop a core set of questions. For the design of our questionnaire, we use feedback from colleagues, from respondents we personally know, and from the general feedback on the survey to improve and support content validity. A positive comparison with the questionnaire in Austin and Graeme (1993) finally confirms the appropriateness of our questions. However, we might have needed additional questions to check for conceptual alignment, for example, to more precisely determine whether the respondents' understanding of FMs and of the use or application of FMs closely matches ours. However, from 18 respondents giving feedback on our questionnaire, only one commented on the definition and one on the classification of FMs. That suggests that many respondents did not have or were not aware of misunderstandings worth mentioning. $\circ$

min 々: Questionnaire limited for measurement of PEOU (e.g. per FM class) and PU I We avoid deriving conclusions specific to a FM or a corresponding tool from our data. $\checkmark$

min 々: Bias by omitted scale values (e.g. FM class, domain, purpose) / Respondents are encouraged to provide open answers to all questions, helping us to check scale completeness. Between $8 \%$ and $40 \%$ of the respondents made use of the text field "Other." Our systematic map confirms that we have not listed unknown challenges in QR13. We identified three additional challenges via open answers and the literature. We believe to have achieved good criterion validity through questions and scales for distinguishing important sub-groups (see Section 4.6) of our population. 
min 々: Educational background asked indirectly/We approximate what we need to know by using data from Q1, Q3, Q4, and Q5.

\subsubsection{Internal Validity}

Why would the procedure in Section 4 lead to reasonable and justified results?

min 々: Incomplete data points / After the 47th response, feedback from colleagues and respondents resulted in an extension of Q3 with the option "on behalf of FM tool provider" (Fig. 4) and of Q6 and Q11 with the option "consistency checking" (Fig. 7). The enhancement of 169 complete data points to 216 maintained all trends.

$\min$ 々: Duplicate \& invalid answers / To identify intentional misconduct, we checked for timestamp anomalies and for duplicate or meaningless phrases in open answers. Voluntarily provided email addresses (90/220) indicate only 4 double participants. We remove these 4 data points from our data set.

Google Forms includes data points only if all mandatory questions are answered and the submit button is pressed. We also performed a consistency check of MC questions and corrected 5 data points where "I do/have not. .." was combined with other checked options. $\checkmark$

min 々: Inter-vs. intra-UFM inference / Our study design is not suitable for "inter-UFM predictions", for example, to predict that (dis)satisfied model checking practitioners have an increased (a decreased) intent to use theorem proving. However, the argumentation in the Sections 4.2 and 6.2 aims at "intra-UFM predictions", that is, inferring an increased or decreased intent to use model checking from the quantity and quality of past experience in using model checking. Such predictions may inherit possible limitations of TAM studies. $\circ$

\subsubsection{External Validity}

Why would the procedure in Section 4 lead to similar results with more general populations?

maj 々: Low response rate / We believe our estimates in Section 5.2 to be sensible. We tried to (i) improve targeting by repetitively advertising on multiple appropriate channels, (ii) spot unreliable contact information, (iii) provide incentive (study results via email), (iv) keep the questionnaire short and comprehensible, (v) avoid forced answers, and (vi) allow lack of topic knowledge. Some uncertainties remain, for example, lack of sympathy, personal motivation, and interest, or strong loyalty, and high expectations in the outcome, or intentional bias. However, from an estimated population of around $100 \mathrm{~K}$ (i.e., the rounded sum of $38 \mathrm{~K}$ and $61 \mathrm{~K}$ ), the minimum sample size for $95 \%$ confidence intervals with continuous scale error margins of less than $7 \%$ is 196 , consistent with the ballpark figure in Gleirscher et al. (2019, p. 117:29). Our sample ( $=216)$ exceeds this number. The $95 \%$ confidence intervals for the Likert items show that the margin of error for the median sometimes deviates by one category (e.g. Fig. 4).

In this first study, we aim at understanding common perceptions, such as "FMs are not practically useful" or "FMs are difficult to apply". Because these statements address FMs as a whole, we believe such local errors do not affect our general conclusions. However, the response rate ( 1 to $2 \%$ ) and population coverage $(0.1 \%$, cf. Section 5.1$)$ were too low to avoid such errors and refute specific null-hypotheses, such as "FM $m$ is effective for role $r$ and purpose $p$ in domain d" (by the FM community) or "FM $m$ is difficult to apply for role $r$ and purpose $p$ in domain d" (by SE practitioners), with satisfactory statistical power. $\checkmark$

maj 々: Bias towards specific groups Shull et al. (2008, p. 181) / We distributed our questionnaire over general SE channels. We mix opportunity (only 5 to $10 \%$ chain referral), volunteer, and cluster-based sampling. Selection bias, a problem in snowball 
sampling (Biernacki and Waldorf 1981), is limited by good visibility and accessibility of the target population in these channels (Section 5.2) as well as little use and control of referral chains among respondents. Our sample includes $50 \%$ practitioners according to Section $4.6, \approx 21 \% \mathrm{NP}$ (incl. laypersons), and $\approx 31 \%$ pure academics. A bias towards FM experts (Fig. 3) does not harm our PEOU discussion led by practitioners but shapes our PU discussion. Regarding application domains, our conclusions cannot be generalised to, e.g. critical IT systems in the finance and e-voting sectors.

$\min \downarrow$ : Non-response / We decided not to enforce responses or provide incentives. Still, our data suggests that our advertisement stimulated responses from FM-critical minds. $\circ$

min 々: Lack of FM knowledge / 11 to $18 \%$ of our respondents did not know specific challenges (Fig. 16). For RQ1 (Figs. 2 and 16), $d n k$-data points have no influence because the findings of RQ1 directly describe and interpret the status quo of $U F M_{p}$. For test purposes, we included $d n k$-data points in the analyses of RQ2 and RQ3 (Figs. 11 and 16), with no relevant influence.

min 々: Geographical background missing / Respondents were not required to own a Google account to avoid tracking and to increase anonymity and the response rate. The limited geographical knowledge about our sample constrains the generalisability of our conclusions, e.g. to geographies such as China, India, or Brazil.

\subsubsection{Reliability}

Why would a repetition of the procedure in Section 4 with different samples from the same population lead to the same results?

maj 々: Internal consistency / All 7 items for the concept "obstacle to c (C7) show good internal consistency for our sample with a Cronbach $\alpha=0.84$, the PEOU-part of C7 consisting of 5 items shows an $\alpha=0.79$ (Shull et al. 2008). The other concepts are not measured with multiple items.

maj 々: Change of proportions / The limited sample and the low response rate make it hard to mitigate this risk. However, we compared the first (til 4.8.2018, $N_{1}=114$ ) and second (from 5.8.2018, $N_{2}=102$ ) half of our sample to simulate a repetition of our survey with the same questionnaire. A two-sided Mann-Whitney U test for difference does not show a significant difference between these two groups (e.g. for Q13 and Q4). Only for the Q3 item "On behalf of FM tool provider," a $p=0.07$ indicates a potential difference. The addition of that item only after the 47 th respondent might explain this difference.

\section{Conclusions}

We conducted an on-line survey of mission-critical software engineering practitioners and researchers to examine how formal methods have been used, how these professionals intend to use them, and how they perceive challenges in using them. This study aims to contribute to the body of knowledge of the software engineering and formal methods communities.

Overall Findings From the evidence we gathered for the use of formal methods, we make the following observations:

- Intrinsic motivation is stronger than the regulatory one.

- Despite the challenges, our respondents show an increased intent to use FMs in industrial contexts. 
- Past experience is correlated with usage intent.

- All challenges were rated either moderately or highly difficult, with scalability, skills, and education leading. Experienced respondents rate challenges as highly difficult more often than less experienced respondents.

- From the literature and the responses, we identified three additional challenges: sufficient resources, process compatibility, good practicality/reputation.

- The negative responses to the questions about obstacles to FM effectiveness suggest that the ease of use of FMs is perceived more negative than positive.

- Gaining experience and confidence in the application of a FM seems to play a role in developing a positive perception of usefulness of that FM.

Barroca and McDermid (1992) present evidence to show that FMs can be used in industry effectively and more widely. Their observation from 1992 is that FM use had been limited, benefits were clear but limitations were subtle. In response to Barroca and McDermid's finding "FMs are both oversold and under-used", our insights from the analysis of RQ 2 and 3 lead us to conclude that today FMs are probably more underused than oversold. However, our data also suggests that these methods still need substantial improvement and support in several areas in order for their benefits to be better utilised.

General Feedback on the Survey The questionnaire seems to be well-received by the participants. One of them found it an "interesting set of questions." This impression is confirmed by another participant:

"Well chosen questions which do not leave me guessing. Relevant to future FM research and practice."

Another respondent noted:

"Thank you very much for this survey. It is very constructive and important. It handles most of the issues encountered by any practitioner and user of FMs."

Only one participant found the questionnaire difficult for FM beginners.

Implications Towards a Research Agenda In the spirit of Jeffery et al. (2015) and complementing the suggestions from the SWOT analysis in Gleirscher et al. (2019), we want to make another step in setting out an agenda for future FM research.

To address scalability, we need more research on how compositional methods (e.g. automated assume-guarantee reasoning, Cofer et al. (2012); automated assertion checking, Leino and Rustan (2017)) can be better leveraged in practical settings. To address skills and education, we need an enhanced and up-to-date FM body of knowledge (FMBoK; Oliveira et al. (2018)). From his survey of "FMs courses in European higher education", Oliveira (2004) observes that (i) "model-oriented specification", "formalising distribution, concurrency and mobility", and "logical foundations of formal methods" showed to be the topic areas most frequently taught by FM lecturers, and (ii) Z, B, SML, CSP, and Haskell showed to be the most popular formal notations and languages taught in these courses. A comparison of the current state with Oliveira's observations can help to evaluate and revise current FM curricula (e.g. for undergraduate SE as suggested in Davis et al. (2013)) and to derive recommendations for improved FM courses fostering good modelling, composition, and refinement skills in SE practice. To address controllable abstractions, we need semantics workbenches for underpinning domain-specific languages with formal semantics. We believe that further steps in theory integration and unification (Gleirscher et al. 2019) can help establish proof hierarchies and, hence, reusability and proof transfer. 
To address process compatibility, we need more research in continuous reasoning (e.g. O'Hearn (2018) and Chudnov et al. (2018)), a revival of activities, possibly even regulations, in tool integration and model data interchange, and guidance on how to update engineering development processes. To address reputation, we need to provide more incentives for practitioners to use FMs and take recent progress in FM research into account when changing current software processes, policies, regulations, and standards. This includes convincing practitioners to invest in the support of large-scale studies for monitoring FM use in industry. Cost-savings analyses of FM applications (e.g. Jeffery et al. (2015)) supported by strong empirical designs (i.e., controlled field experiments) can help to collect the necessary evidence for decision making, successful knowledge transfer, and for implementing this vision.

This survey underpins and enhances the analysis of strengths and weaknesses of FMs in Gleirscher et al. (2019) and can be a guide (1) for consulting and managing practitioners when considering the introduction of FMs into a engineering organisation, (2) for research managers when shaping a grant programme for FM experimentation and transfer, and (3) for associate editors when organising a journal special section on applied FM research.

Future Work Our survey is another important step in the research of effectively applying FM-based technologies in practice. To put it with the words of one of our participants: "[A] closed questionnaire is just a start."

Hence, we aim at a follow-up study (i) to find out which particular FM (and tool) is used in which domain for which particular purpose and role (e.g. was SMT solving used for model checking in certification or for task scheduling at run-time?), (ii) to measure where particular techniques work well (e.g. which types of formal contracts work well in control software requirements management in a DO-178C context?), (iii) to measure key indicators for successful use of FMs, (iv) to identify management techniques needed to accommodate the changes in working practices, and, finally, (v) to provide guidance to future projects wishing to adopt FMs.

In a next survey, we like to ask about typical FM benefits, about suggestions for barrier mitigation (Davis et al. 2013), pose more specific questions on scalability and useful abstraction, the geographical ${ }^{8}$ and educational background, and for conceptual alignment. Further analysis of obstacles, benefits, and usage intent could also benefit from a more fine-grained distinction between FMs directly applied to program code and FMs focusing on more abstract models. We would also like to change from 3-level to 5-level Likert-type scales to receive fine-granular responses. Our research design accounts for repeatability, hence, allowing us to go for a longitudinal study.

The research design, and even our current data set, allows the derivation of the usage intent $\left(U F M_{i}\right)$ for each FM class, application domain, and obstacle. These $U F M_{i}$ values could be used to analyse whether a particular FM might be (1) underused (i.e., domains with an increased usage intent indicate a potential for more applicability) or (2) oversold (i.e., domains with a lower usage intent and were obstacles are perceived as being particularly tough and, hence, FMs as being less effective).

Acknowledgements It is our pleasure to thank all survey participants for their time spent and their valuable responses, and all channel moderators for forwarding our postings. We are much obliged to Jim Woodcock, who has led previous studies in our direction, and supported us to critically reflect our work and relate it to existing evidence. He connected us with John Fitzgerald, who made his paper copy of Austin and Graeme

\footnotetext{
${ }^{8}$ According to https://en.wikipedia.org/wiki/United_Nations_geoscheme.
} 
(1993) available to us such that we were able to complete our investigation. We are grateful to John Fitzgerald and also to John McDermid for helpful feedback and for encouraging us to do further research in this direction. We would like to spend sincere gratitude to Krzysztof Brzezinski, Louis Brabant, and Emmanuel Eze for pointing us to several related works.

Funding Partly funded by the Deutsche Forschungsgemeinschaft (DFG, German Research Foundation) under the Grant no. 381212925.

\section{Compliance with Ethical Standards}

Conflict of interests The authors declare that they have no conflict of interest.

Open Access This article is licensed under a Creative Commons Attribution 4.0 International License, which permits use, sharing, adaptation, distribution and reproduction in any medium or format, as long as you give appropriate credit to the original author(s) and the source, provide a link to the Creative Commons licence, and indicate if changes were made. The images or other third party material in this article are included in the article's Creative Commons licence, unless indicated otherwise in a credit line to the material. If material is not included in the article's Creative Commons licence and your intended use is not permitted by statutory regulation or exceeds the permitted use, you will need to obtain permission directly from the copyright holder. To view a copy of this licence, visit http://creativecommons.org/licenses/by/4.0/.

\section{Appendix: A Supplementary Material for "Formal Methods in Dependable Software Engineering: A Survey"}

In the following, we provide additional material to the survey, including

1. a more detailed analysis of responses to certain questions (Appendix A.1),

2. further visualizations of the collected data (Appendices. A.2 and A.6),

3. more details on our analysis of related work (Table 9 in Appendix A.7),

4. more details on the mapping from studies to challenges (Appendix A.8),

5. a copy of the advertisement flyer (Appendix A.9),

6. a screenshot of the Twitter poll (Appendix A.10), and

7. a copy of the whole questionnaire (Appendix A.11).

\section{A.1 Data for Analysis of RQ, 1 and Estimation of External Validity}

Based on the responses for question Q1, the Table 8 provides an overview of categories of respondents referred to in our analysis (particularly, in Section 5.2 and Fig. 10) along with the corresponding counts based on the sample from 31.3.2019 with $N=220$.

For question Q1, by practitioner, we mean "practitioner in dependable or mission-critical software engineering." To include respondents from all areas of the population or at any study stage, we generalize "practitioner" by the term "user". Below, for the questions Q5 and Q6, we then refer to "formal method user" and "FM-non-user".

\subsection{A.2 Geographical Analysis of the Sample}

Figure 19 shows geographical aspects of the sample for this study.

\section{A.3 Usage Intent (UFM $)_{i}$ by Purpose (for Analysis of RQ2)}

The comparison in Fig. 20 (and in the figures of the Appendices A.4 and A.5) contains two columns. 
Table 8 Overview of categories of respondents for Q1, Q3, Q4, Q5, and Q6

\begin{tabular}{|c|c|c|c|}
\hline Category of respondents to ... & Description & Count & Fraction \\
\hline \multicolumn{4}{|l|}{... Question Q4: } \\
\hline $\begin{array}{l}\text { Respondents with academic } \\
\text { educational background (AEB) }\end{array}$ & $\begin{array}{l}\text { Researchers in academia; } \\
\text { bachelor, master, or PhD students; lecturers, } \\
\text { teachers, trainers, coaches }\end{array}$ & 156 & $72 \%$ \\
\hline $\begin{array}{l}\text { Academics with pure transfer } \\
\text { experience }\end{array}$ & $\begin{array}{l}\text { AEB cut with researchers in industry, } \\
\text { consulting and managing practitioners, } \\
\text { and external consultants; without } \\
\text { engineering practitioners in industry and } \\
\text { without tool provider stakeholders }\end{array}$ & 35 & $16 \%$ \\
\hline $\begin{array}{l}\text { Academics with practical } \\
\text { experience }\end{array}$ & $\begin{array}{l}\text { AEB cut with engineering practitioners in } \\
\text { industry }\end{array}$ & 41 & $21 \%$ \\
\hline $\begin{array}{l}\text { Academics with experience in } \\
\text { transfer and practice }\end{array}$ & $\begin{array}{l}\text { AEB cut with researchers in industry, } \\
\text { consulting and managing practitioners, } \\
\text { and external consultants; cut with } \\
\text { engineering practitioners in industry } \\
\text { and without tool provider stakeholders }\end{array}$ & 31 & $14 \%$ \\
\hline $\begin{array}{l}\text { Practitioners incl. transfer } \\
\text { practitioners and industrial } \\
\text { consultants, all with academic } \\
\text { background }\end{array}$ & $\begin{array}{l}\text { AEB cut with researchers in industry, } \\
\text { consulting and managing practitioners, } \\
\text { external consultants, and engineering } \\
\text { practitioners in industry }\end{array}$ & 86 & $40 \%$ \\
\hline Pure academics & $\begin{array}{l}\text { AEB without respondents specifying } \\
\text { additional roles }\end{array}$ & 66 & $31 \%$ \\
\hline $\begin{array}{l}\text { Respondents not specifying an } \\
\text { educational background (NEB) }\end{array}$ & The complement of AEB & 60 & $27 \%$ \\
\hline $\begin{array}{l}\text { Respondents not specifying an } \\
\text { educational background and } \\
\text { being researchers in industry }\end{array}$ & $\begin{array}{l}\text { NEB intersected with researchers in } \\
\text { industry }\end{array}$ & 13 & $6 \%$ \\
\hline Consultants & $\begin{array}{l}\text { NEB intersected with consulting } \\
\text { or managing practitioners and external } \\
\text { consultants }\end{array}$ & 23 & $11 \%$ \\
\hline Pure practitioners & $\begin{array}{l}\text { NEB cut with engineering practitioners in } \\
\text { industry }\end{array}$ & 23 & $11 \%$ \\
\hline $\begin{array}{l}\text { Tool provider stakeholders not } \\
\text { specifying an educational } \\
\text { background }\end{array}$ & $\begin{array}{l}\text { NEB cut with stakeholder of an FM } \\
\text { tool or service provider }\end{array}$ & 5 & $2.3 \%$ \\
\hline Non-academic FM non-users & $\begin{array}{l}\text { NEB cut with "I have not used FMs } \\
\text { in any specific role." }\end{array}$ & 19 & $9 \%$ \\
\hline $\begin{array}{l}\text { Practitioners incl. industrial } \\
\text { consultants }\end{array}$ & $\begin{array}{l}\text { Consulting and managing practitioners, } \\
\text { external consultants, and engineering } \\
\text { practitioners in industry }\end{array}$ & 108 & $50 \%$ \\
\hline FM users (all) & $\begin{array}{l}\text { Respondents having used FMs in one or } \\
\text { another way and context in the past }\end{array}$ & 212 & $98 \%$ \\
\hline FM users (beyond students) & Excl. "only-in-course" respondents & 202 & $93.5 \%$ \\
\hline
\end{tabular}


Table 8 (continued)

\begin{tabular}{llll}
\hline Category of respondents to ... & Description & Count & Fraction
\end{tabular}

... Question Q1:

FM non-users

Respondents who chose "I have not use

36

$17 \%$

FMs in any academic or industrial

domain."

... Question Q3:

Respondents with no motivation

Respondents who selected "no" for all

motivating factors

... Questions Q5 and Q6:

Non-practitioners including FM

Respondents who chose "no experience

non-users

or no knowledge", "studied in (university)

course" or "applied in lab, experiments,

case studies" for all FM techniques. This

group includes laypersons.

Sample (N)

All valid responses

Estimated geographical reachability of population via survey channels

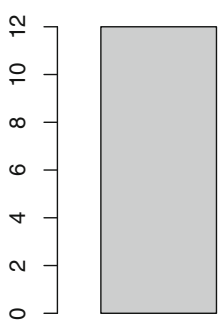

DE

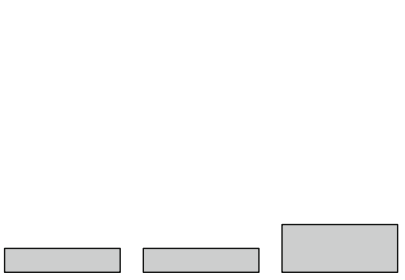

DE/IT DE/US

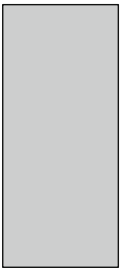

EU/US

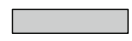

EU/US/AUS

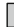

EU
FR

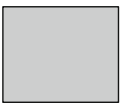

UK

Geographical distribution of respondents by email address (TLD, company HQ, if provided)

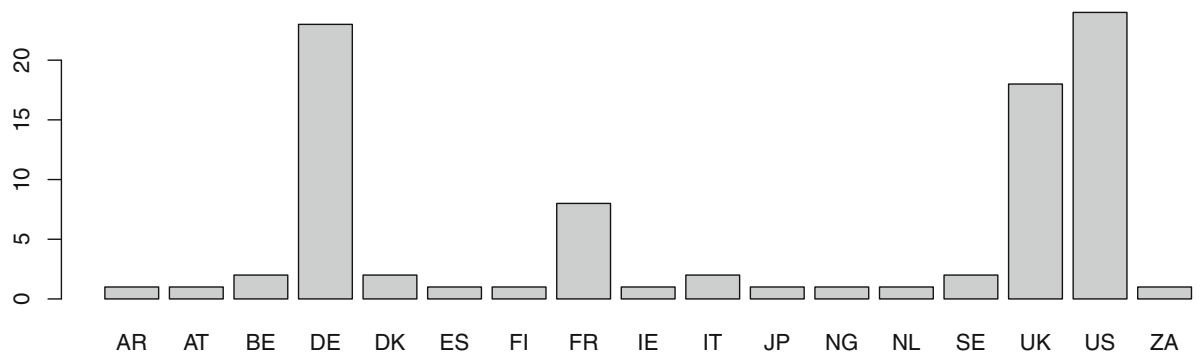

Fig. 19 Geographical analysis of the sample. Legend: top-level domain (TLD), head quarter (HQ) 


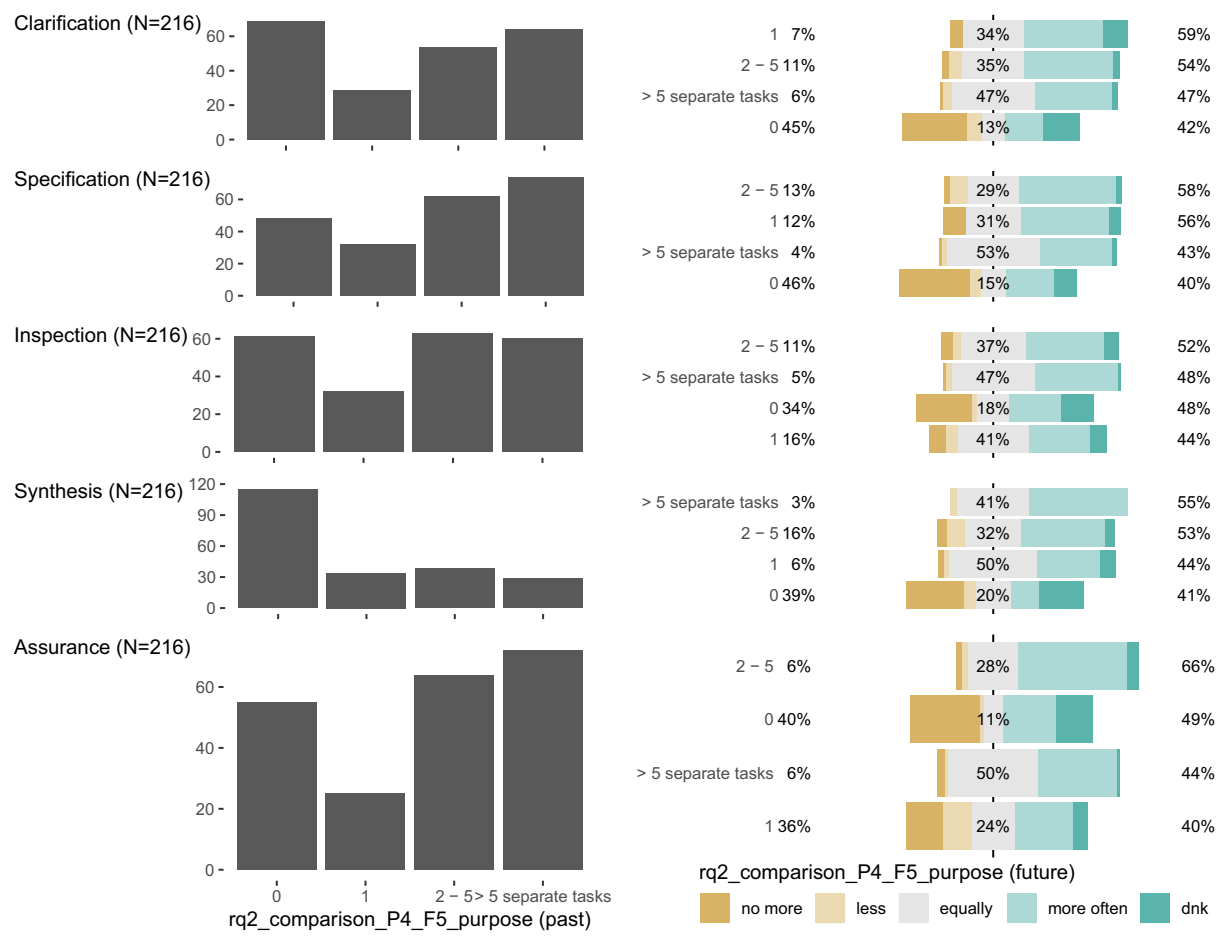

Fig. 20 Comparison of past and future usage intent by purpose

The left column describes for each purpose (e.g. specification) how often (e.g. in 2 to 5 separate tasks) respondents have used FMs in the past $\left(U F M_{p}\right)$.

The right column describes for each purpose the usage intent $\left(U F M_{i}\right)$ depending on how often respondents have used FMs in the past $\left(U F M_{p}\right)$. The horizontal bars representing the $U F M_{p}$ frequency categories are listed in descending order by the overall size of both $U F M_{i}$ groups "more often" and "dnk". We chose to keep $d n k$-answers visible despite the readability inconvenience caused by the $d n k$ s influencing the ordering. However, in the majority of cases the largest group of respondents intending to increase FM use in the future is visible first or near the top.

\section{A.4 Code-based vs. Model-based FMs for Assurance vs. Inspection}

The data for this comparison is summarised in Fig. 21. 
Clarification $(\mathrm{N}=128)$
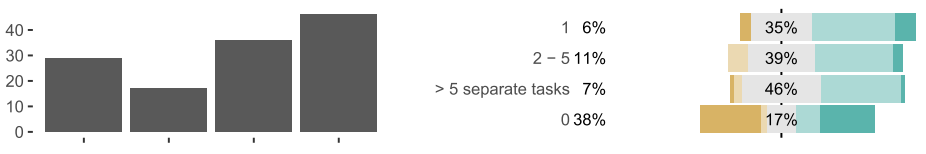

$59 \%$

$50 \%$

$48 \%$

$45 \%$

Specification $(\mathrm{N}=128)$
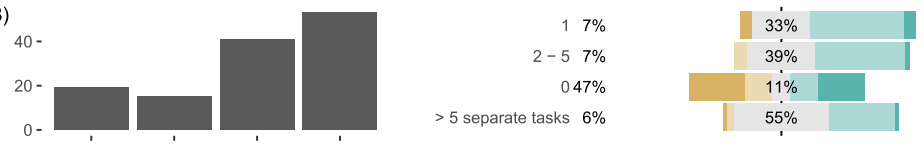

$60 \%$

$54 \%$

$42 \%$

$40 \%$

Inspection $(\mathrm{N}=128) 50$ -
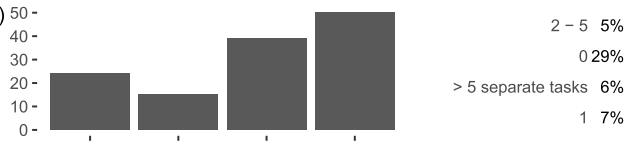

Synthesis $(\mathrm{N}=128) 60$
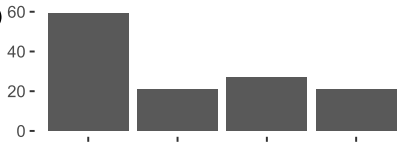

$>5$ separate tasks $0 \%$

$10 \%$

$2-519 \%$

$036 \%$

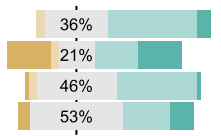

$59 \%$

$50 \%$

$48 \%$

$40 \%$

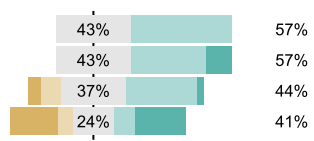

Assurance $(\mathrm{N}=128)$
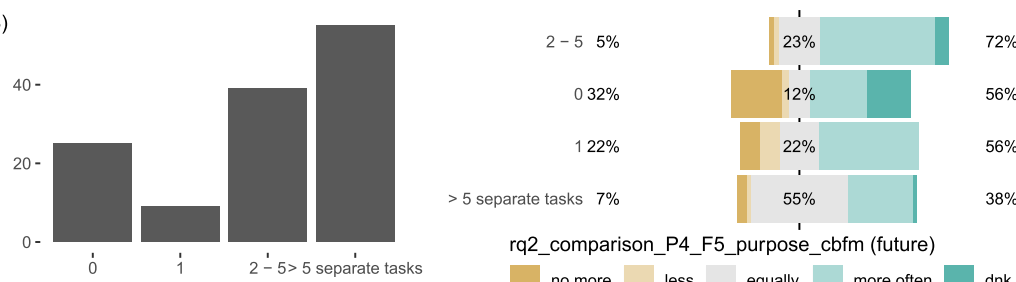

rq2_comparison_P4_F5_purpose_cbfm (past)

rq2_comparison_P4_F5_purpose_cbfm (future)

no more less equally more often dnk

Clarification $(\mathrm{N}=114)_{40}$
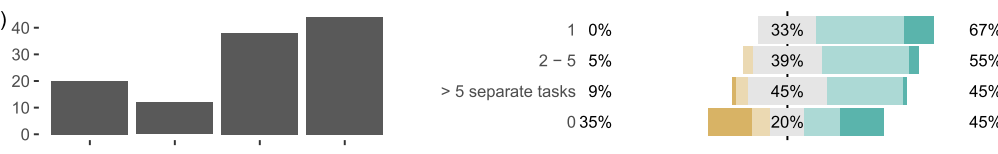

Specification $(\mathrm{N}=114) 50$
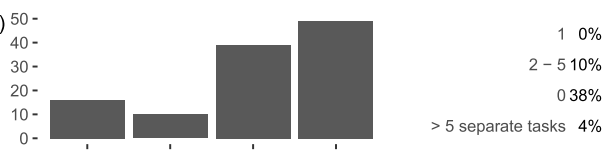

Inspection $(\mathrm{N}=114)$
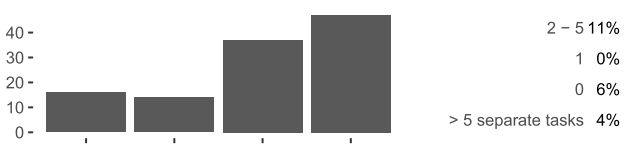

Synthesis $(\mathrm{N}=114)$
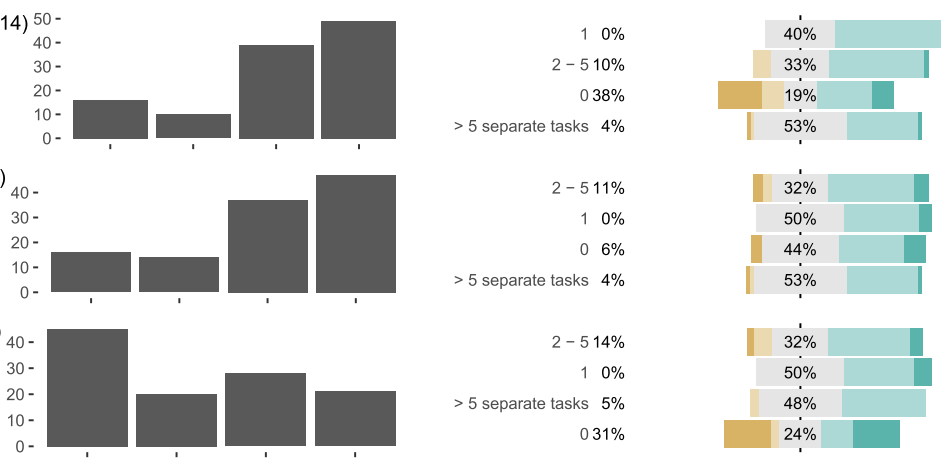

$60 \%$

$56 \%$

$44 \%$

$43 \%$
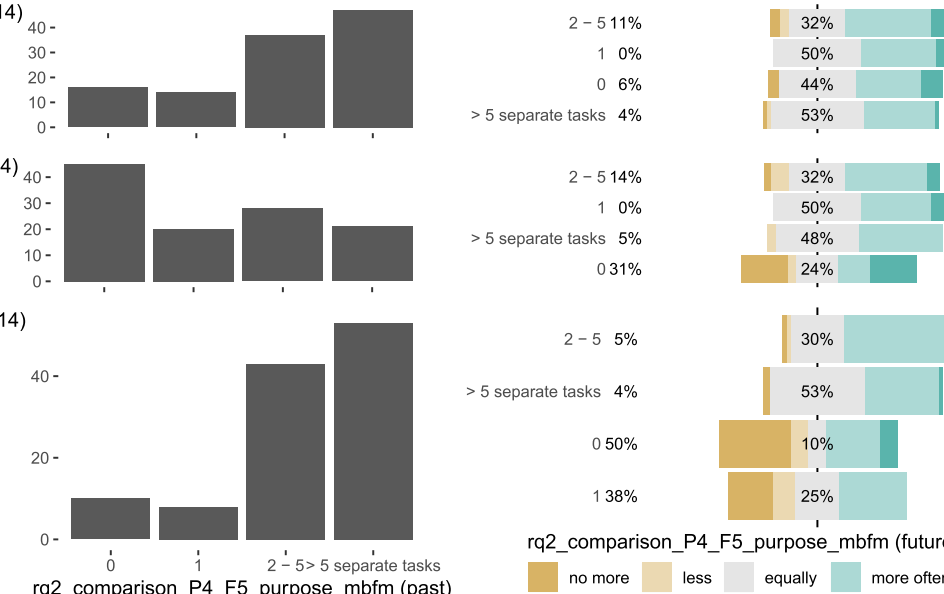

$57 \%$

$50 \%$

$50 \%$

$43 \%$

Assurance $(\mathrm{N}=114$

rq2_comparison_P4_F5_purpose_mbfm (future)

$54 \%$

$50 \%$

$48 \%$

$44 \%$

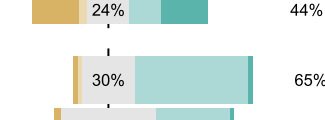

$43 \%$

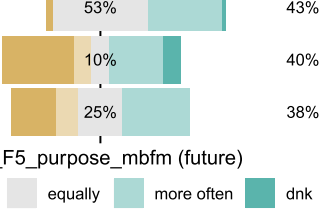

Fig. 21 Comparison of past and future usage for code-based (top half) and model-based FMs (bottom half) by purpose 


\section{A.5 Usage Intent (UFMi) by FM Class (for Analysis of RQ2)}
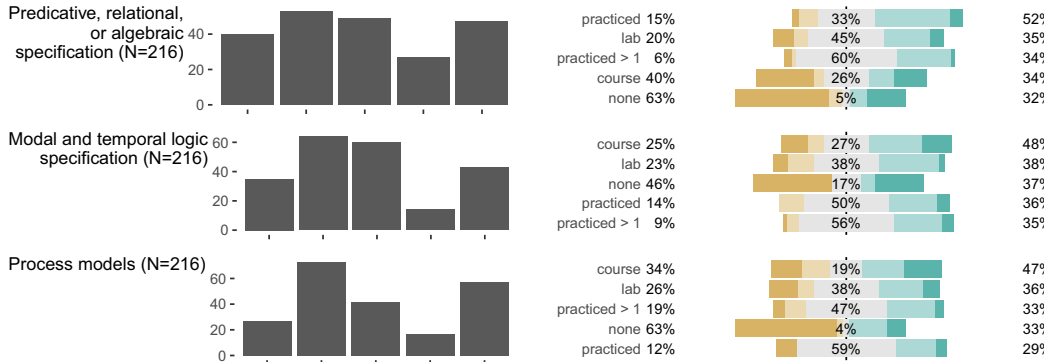

Dynamical systems 80

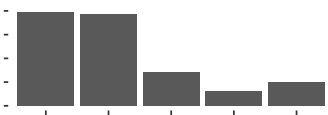

Abstract interpretation

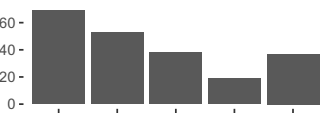

Assertion checking

$(\mathrm{N}=216) 60$

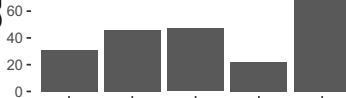

Process calculi $(\mathrm{N}=216$

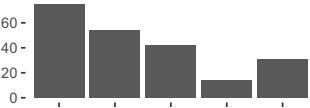

Model checking, SMV

$(\mathrm{N}=216) 40$

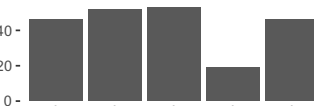

Constraint solving $(\mathrm{N}=216)_{40}$
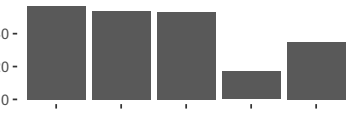

Generic theorem proving

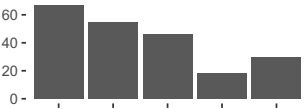

Computationa

engineering, simulation $(\mathrm{N}=216) 50$

$$
\begin{array}{r}
50- \\
25- \\
0-
\end{array}
$$

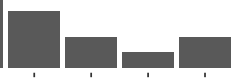

Symbolic execution
$(\mathrm{N}=216)$

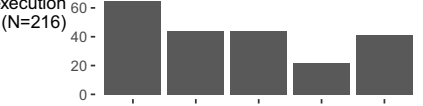

Consistency checking 50

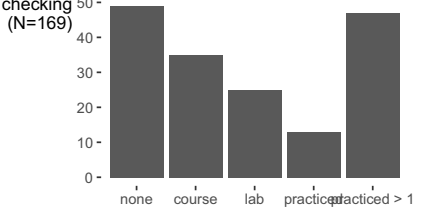

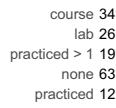
practiced $0 \%$
lab $29 \%$
practiced $>110 \%$
none $52 \%$
course $35 \%$
none $45 \%$
practiced $>15 \%$
course $28 \%$
lab $16 \%$
practiced $16 \%$
lab $11 \%$
practiced $23 \%$
course $24 \%$
none $45 \%$
practiced $>14 \%$

none $47 \%$ practiced $>110 \%$
lab $29 \%$

lab $29 \%$

course $31 \%$

practiced $36 \%$

practiced $>14 \%$ practiced $26 \%$ practiced $26 \%$
course $23 \%$ course $23 \%$
lab $15 \%$ none $48 \%$

practiced $12 \%$ lab $11 \%$ practiced > 1 9\% course $26 \%$ none $53 \%$

practiced $0 \%$ practiced $>1 \quad 3 \%$ lab $35 \%$

course $25 \%$

none $54 \%$

lab $17 \%$

practiced $>110 \%$

course $26 \%$

none $39 \%$

practiced $7 \%$

practiced $>110 \%$ practiced $14 \%$

course $16 \%$

$$
\text { lab } 14 \%
$$

none $46 \%$

course $17 \%$

practiced $23 \%$

practiced > $14 \%$

lab $4 \%$

none $57 \%$
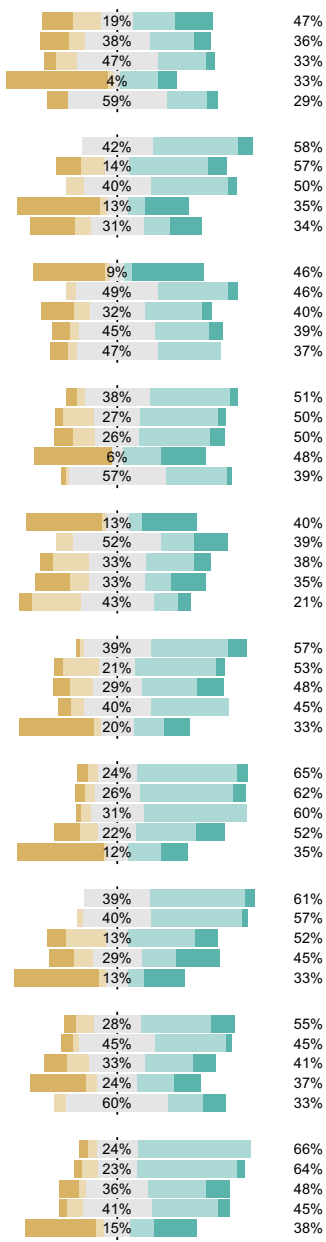

rq2_comparison_P2_P3_F3_F4_usiage (future)

no more less equally more often dnk rq2_comparison_P2_P3_F3_F4_usage (past) 


\section{A.6 Data for the Analysis of RQ3}

Figure 22 and the following figures in this section show pairs of matrices, so-called "heatmaps", useful for association analysis between categorical and ordinal variables. The cells

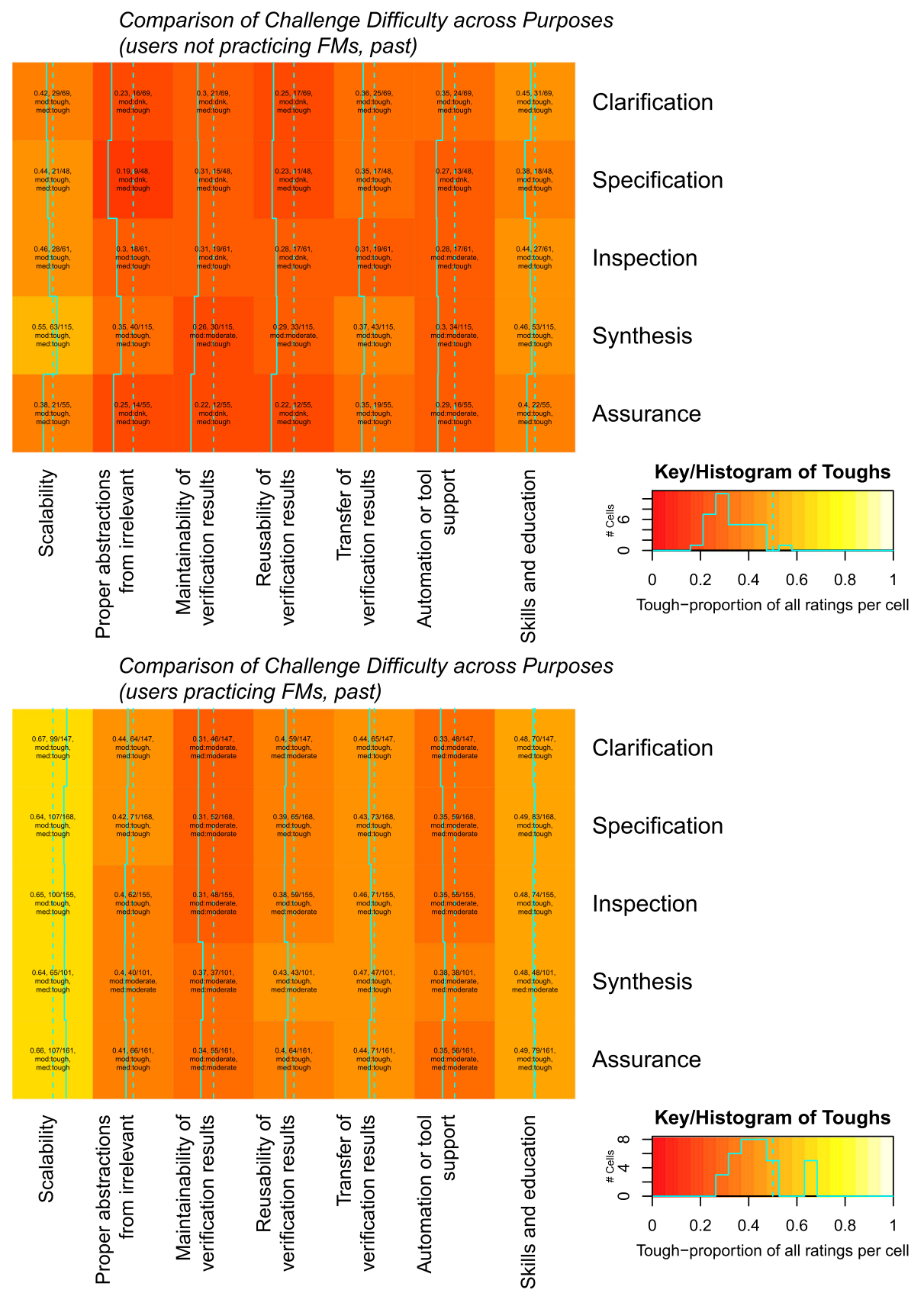

Fig. 22 Comparison of challenge difficulty across purposes $\left(U F M_{p}\right)$ 
Comparison of Challenge Difficulty across Purposes

(respondents with no or decreased intent, future)

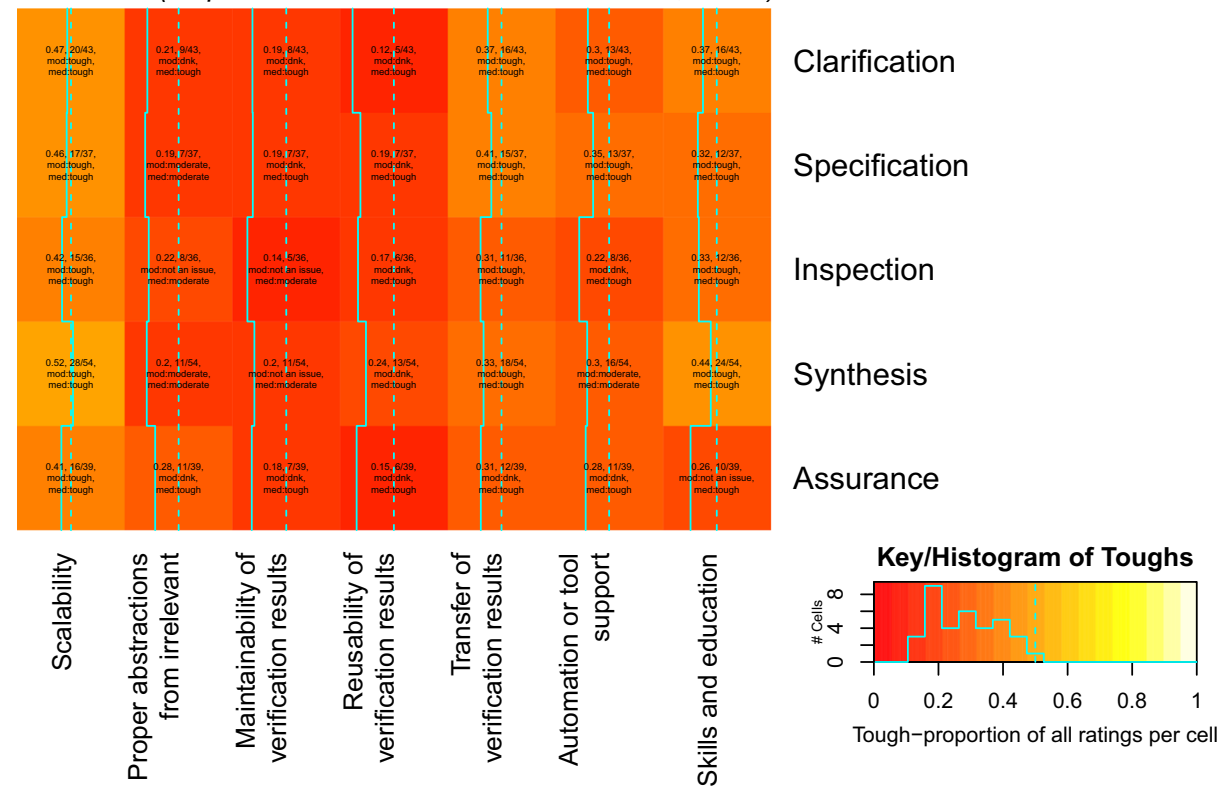

Comparison of Challenge Difficulty across Purposes (respondents with same or increased intent, future)

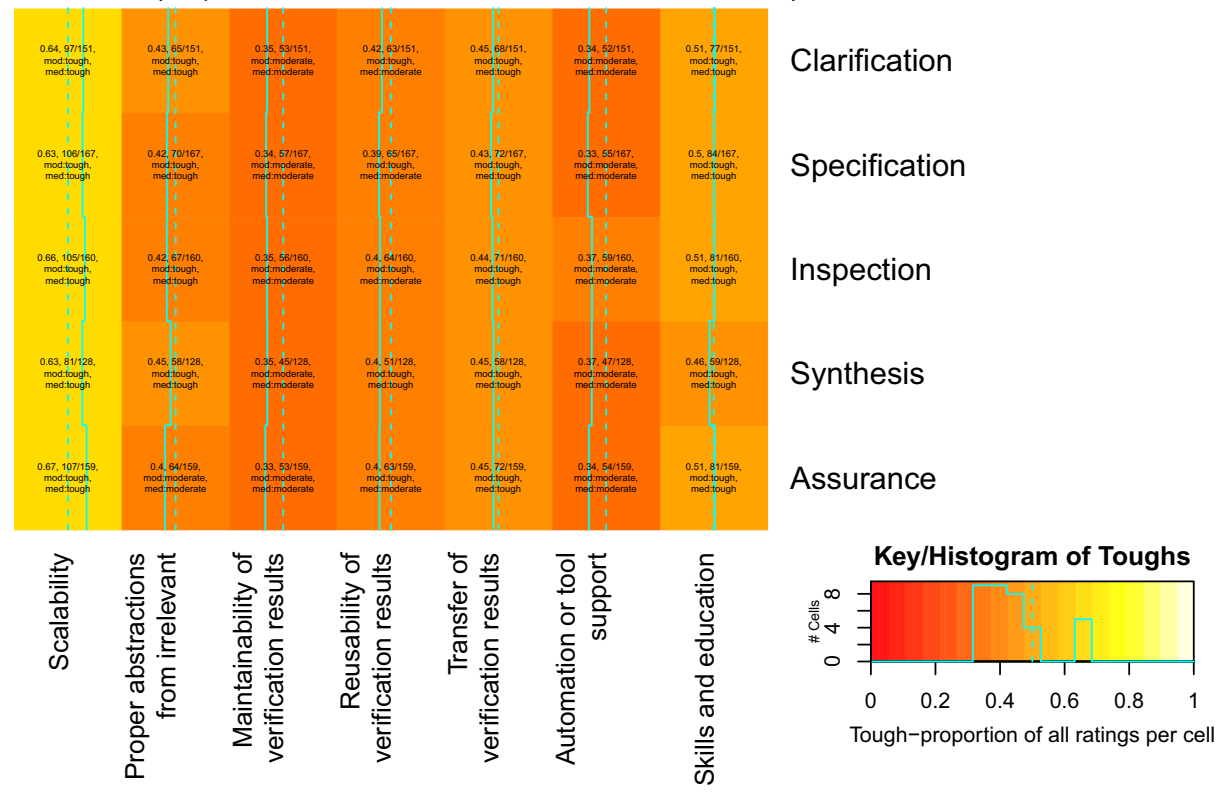

Fig. 23 Comparison of challenge difficulty across purposes $\left(U F M_{i}\right)$ 


\begin{tabular}{|c|c|c|c|c|c|c|c|}
\hline 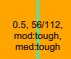 & 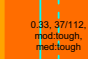 & 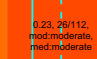 & 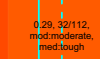 & 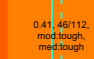 & 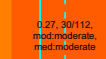 & 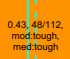 & Regulatory authorities \\
\hline 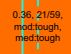 & 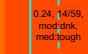 & 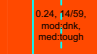 & 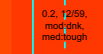 & 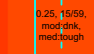 & 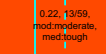 & 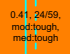 & Customers / scientific community \\
\hline 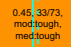 & 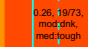 & 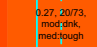 & 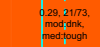 & 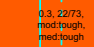 & 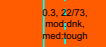 & 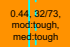 & Employer / research collaborators \\
\hline 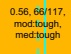 & 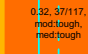 & 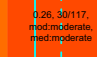 & 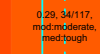 & 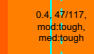 & 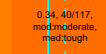 & 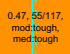 & Superior / principal investigator \\
\hline 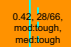 & 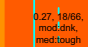 & 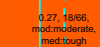 & 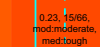 & 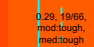 & 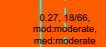 & 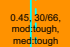 & Study or research program \\
\hline 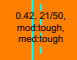 & 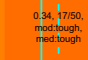 & 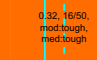 & 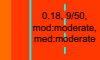 & 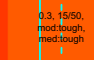 & 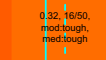 & 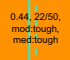 & Own interest \\
\hline 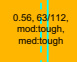 & 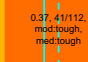 & 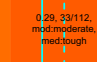 & 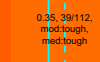 & 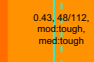 & 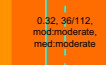 & 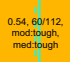 & On behalf of an FM tool \\
\hline \multirow{3}{*}{ 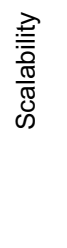 } & \multirow{3}{*}{ 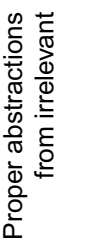 } & \multirow{3}{*}{ 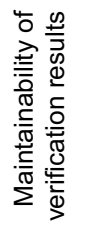 } & \multirow{3}{*}{ 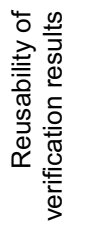 } & \multirow{3}{*}{ 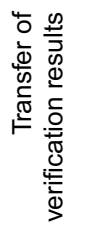 } & \multirow{3}{*}{ 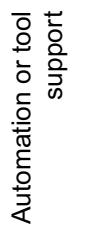 } & \multirow{3}{*}{ 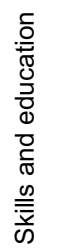 } & Key/Histogram of Toughs \\
\hline & & & & & & & 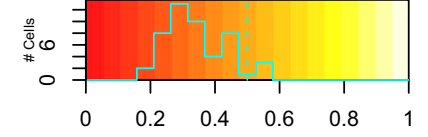 \\
\hline & & & & & & & Tough-proportion of all ratings per cell \\
\hline
\end{tabular}

Comparison of Challenge Difficulty across Motivations (users with at least moderate motivation)

\begin{tabular}{|c|c|c|c|c|c|c|c|}
\hline 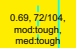 & 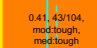 & 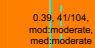 & 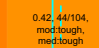 & 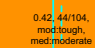 & 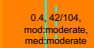 & 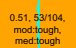 & Regulatory authorities \\
\hline $\begin{array}{c}0.68,1071157, \\
\text { modotugh, } \\
\text { medtough }\end{array}$ & 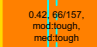 & 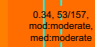 & 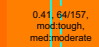 & 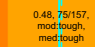 & 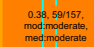 & 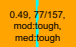 & Customers / scientific community \\
\hline 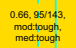 & 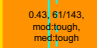 & 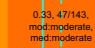 & 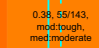 & 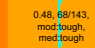 & 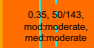 & 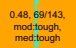 & Employer / research collaborators \\
\hline 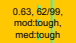 & 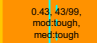 & 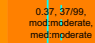 & 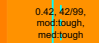 & 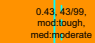 & 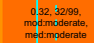 & 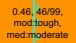 & Superior / principal investigator \\
\hline $\begin{array}{l}0.67 \text {. 100150, } \\
\text { motolugh, } \\
\text { medtough h }\end{array}$ & 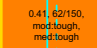 & 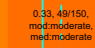 & 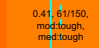 & $\begin{array}{l}\text { 0.47, 711150, } \\
\text { moldough, } \\
\text { medtrough h }\end{array}$ & 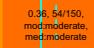 & 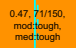 & Study or research program \\
\hline $\begin{array}{l}0.84 \text {, 1071766, } \\
\text { modotough, } \\
\text { medtough }\end{array}$ & 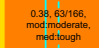 & 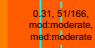 & 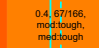 & 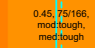 & 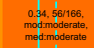 & 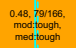 & Own interest \\
\hline 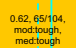 & 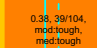 & 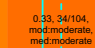 & 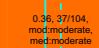 & 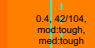 & 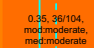 & 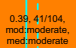 & On behalf of an FM tool \\
\hline \multirow{3}{*}{ 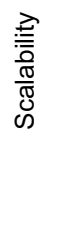 } & \multirow{3}{*}{ 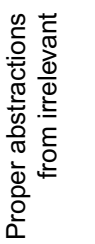 } & \multirow{3}{*}{ 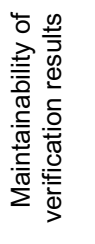 } & \multirow{3}{*}{ 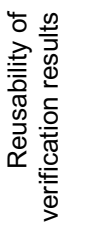 } & \multirow{3}{*}{ 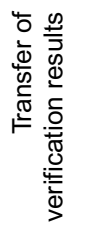 } & \multirow{3}{*}{ 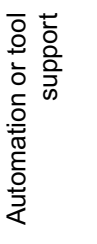 } & \multirow{3}{*}{ 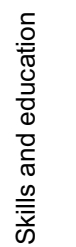 } & Key/Histogram of Toughs \\
\hline & & & & & & & $\begin{array}{llll}0.2 & 0.4 & 0.6 & 0.8\end{array}$ \\
\hline & & & & & & & Tough-proportion of all ratings per cel \\
\hline
\end{tabular}

Fig. 24 Comparison of challenge difficulty across motivations 


\section{Comparison of Challenge Difficulty across FMs (users not practicing FMs, past)}

\begin{tabular}{|c|c|c|c|c|c|c|}
\hline $\begin{array}{l}0.58, \text { 82:142, } \\
\text { modtough, } \\
\text { medtough }\end{array}$ & $\begin{array}{l}0.32,451 / 42, \\
\text { modimoderate, } \\
\text { med.tough }\end{array}$ & $\begin{array}{l}0.28,40 / 142, \\
\text { modimodorate, } \\
\text { medimododarate }\end{array}$ & $\begin{array}{l}0.3,43,142, \\
\text { modmoderate, } \\
\text { med tough }\end{array}$ & $\begin{array}{l}0.39,55 / 142, \\
\text { modituogh, } \\
\text { meditough }\end{array}$ & $\begin{array}{l}0.34,48142, \\
\text { moddmoderate, } \\
\text { med:tough }\end{array}$ & $\begin{array}{l}0.46,655 / 142, \\
\text { modituogh, } \\
\text { med tough }\end{array}$ \\
\hline $\begin{array}{l}\text { 0.55, 877159, } \\
\text { modtough, } \\
\text { meditough }\end{array}$ & 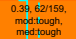 & $\begin{array}{l}\text { 0.33. } 52 \text { 2159, } \\
\text { mod.tough, } \\
\text { medtitough }\end{array}$ & $\begin{array}{l}0.31,491159, \\
\text { modmodedarate, } \\
\text { medt tough }\end{array}$ & $\begin{array}{l}\text { 0.4.6331159, } \\
\text { modtiough, } \\
\text { med tough }\end{array}$ & $\begin{array}{l}\text { 0.37. } 591599, \\
\text { molimoderate, } \\
\text { med:tough }\end{array}$ & $\begin{array}{l}0.49,78 / 159, \\
\text { moditough, } \\
\text { medt tough }\end{array}$ \\
\hline $\begin{array}{l}0.53,75142, \\
\text { modtough, } \\
\text { medtough }\end{array}$ & 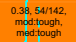 & 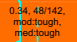 & 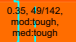 & $\begin{array}{l}0.42 .591 / 142, \\
\text { modtiough, } \\
\text { med tough }\end{array}$ & $\begin{array}{l}0.33,471142, \\
\text { modimoderate, } \\
\text { med-moderate }\end{array}$ & $\begin{array}{c}0.42,59 / 142, \\
\text { moditough, } \\
\text { med tough }\end{array}$ \\
\hline $\begin{array}{l}\text { 0.57. 1044194, } \\
\text { modtough, } \\
\text { medtough }\end{array}$ & 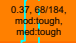 & 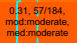 & $\begin{array}{l}0.34,622184, \\
\text { modtough, } \\
\text { medtrough }\end{array}$ & $\begin{array}{l}\text { 0.4. 74/184, } \\
\text { modituough. } \\
\text { med tough }\end{array}$ & $\begin{array}{l}0.33 .61194, \\
\text { modimoderate, } \\
\text { med-moderate }\end{array}$ & $\begin{array}{l}0.48,88 / 184, \\
\text { mod:tough, } \\
\text { medt tough }\end{array}$ \\
\hline $\begin{array}{l}\text { 0.57, 911160, } \\
\text { modtough, } \\
\text { medtough }\end{array}$ & $\begin{array}{l}\text { 0.34, 54/160, } \\
\text { modtough, } \\
\text { medtough }\end{array}$ & $\begin{array}{l}0.31,49160, \\
\text { modmodirate. } \\
\text { meditiough }\end{array}$ & $\begin{array}{l}0.34 .551160, \\
\text { modtough } \\
\text { medtrough }\end{array}$ & $\begin{array}{l}\text { 0.44, 711/160, } \\
\text { modtough, } \\
\text { medtough }\end{array}$ & $\begin{array}{l}\text { 0.33, 531460, } \\
\text { modmoderate, } \\
\text { med-moderate }\end{array}$ & $\begin{array}{l}0.43,69 / 160, \\
\text { modituough, } \\
\text { medtough }\end{array}$ \\
\hline $\begin{array}{l}0.59,73 / 124, \\
\text { modtough, } \\
\text { medtough }\end{array}$ & $\begin{array}{l}0.34, \text {.42/124, } \\
\text { modtough, } \\
\text { madtough tough }\end{array}$ & 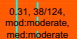 & 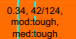 & $\begin{array}{l}0.42 .521124 \text {, } \\
\text { mod.tugugh } \\
\text { medt tough }\end{array}$ & $\begin{array}{l}\text { 0.34, 42/124, } \\
\text { mod.moderate, } \\
\text { meddmaderate }\end{array}$ & $\begin{array}{l}0.44,54 / 124, \\
\text { moditugh, } \\
\text { medtough }\end{array}$ \\
\hline $\begin{array}{l}0.56,966 / 171, \\
\text { modtlough, } \\
\text { medtough }\end{array}$ & $\begin{array}{l}0.36,61171, \\
\text { modfough, } \\
\text { medtough }\end{array}$ & $\begin{array}{l}0.3,52171 \text {. } \\
\text { modidoddarte. } \\
\text { meditough }\end{array}$ & $\begin{array}{l}\text { 0.35, 59:171, } \\
\text { modologgh, } \\
\text { medtough }\end{array}$ & $\begin{array}{l}\text { 0.4.6.68171, } \\
\text { mod.tough. } \\
\text { med tough }\end{array}$ & $\begin{array}{l}0.33,566171, \\
\text { modtmoderta, } \\
\text { med-moderate }\end{array}$ & $\begin{array}{l}\text { 0.5., 85:171, } \\
\text { modtough, } \\
\text { medt tough }\end{array}$ \\
\hline 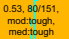 & $\begin{array}{l}0.32,48 / 151, \\
\text { modidmoderate, } \\
\text { med tough }\end{array}$ & $\begin{array}{l}\text { O29., 44/151, } \\
\text { modmodirate. } \\
\text { meditough }\end{array}$ & $\begin{array}{l}0.3,46 / 151, \\
\text { mimodmoderate, } \\
\text { med tough }\end{array}$ & $\begin{array}{l}\text { 0.4.601151, } \\
\text { modtiough. } \\
\text { medtough }\end{array}$ & $\begin{array}{l}\text { 0.33. } 501151, \\
\text { mod-moderate, } \\
\text { med-moderate }\end{array}$ & $\begin{array}{l}0.46,70 / 151, \\
\text { modtough, } \\
\text { medtlough }\end{array}$ \\
\hline 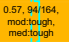 & $\begin{array}{l}\text { 0.34.55/164, } \\
\text { modimoderate, } \\
\text { med tough }\end{array}$ & 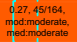 & $\begin{array}{l}0.32,521164, \\
\text { modmodedartet, } \\
\text { meditough }\end{array}$ & $\begin{array}{l}0.42 .699164 . \\
\text { modituough. } \\
\text { medt tough }\end{array}$ & $\begin{array}{l}0.35,571164, \\
\text { mod modertat, } \\
\text { med-moderate }\end{array}$ & $\begin{array}{l}0.48,79 / 164, \\
\text { modtough, } \\
\text { medt tough }\end{array}$ \\
\hline 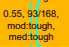 & 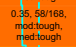 & $\begin{array}{l}\text { 0.28.,47168, } \\
\text { modimoderate, } \\
\text { med:moderate }\end{array}$ & $\begin{array}{l}\text { D.3.511168, } \\
\text { modmoderate, } \\
\text { med tough }\end{array}$ & $\begin{array}{l}\text { 0.41.69s.68 } \\
\text { moditlough, } \\
\text { medtough }\end{array}$ & $\begin{array}{l}0.33 .551 / 168, \\
\text { mod-moderate, } \\
\text { med-moderatie }\end{array}$ & $\begin{array}{l}0.45,75,668, \\
\text { modtough, } \\
\text { medtough }\end{array}$ \\
\hline $\begin{array}{l}\text { 0.58, 10od172, } \\
\text { modtough, } \\
\text { medtough }\end{array}$ & $\begin{array}{l}0.38, .65172 \text {. } \\
\text { modtough, } \\
\text { medtough }\end{array}$ & $\begin{array}{l}\text { 029, } 50172, \\
\text { modimoderate } \\
\text { med:moderate }\end{array}$ & $\begin{array}{l}0.33,56,172, \\
\text { modmoderate, } \\
\text { medtough }\end{array}$ & $\begin{array}{l}0.38,66 / 172, \\
\text { modtough. } \\
\text { med tough }\end{array}$ & $\begin{array}{l}0.32,55 / 172, \\
\text { moddmoderate, } \\
\text { med-maderate }\end{array}$ & $\begin{array}{l}0.45,771172, \\
\text { modtough. } \\
\text { medtlough }\end{array}$ \\
\hline $\begin{array}{l}0.58,888153, \\
\text { modtough, } \\
\text { medtough }\end{array}$ & $\begin{array}{l}0.32 .491 / 53, \\
\text { modimodarat, } \\
\text { medt.tough }\end{array}$ & 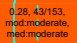 & $\begin{array}{c}0.31 .481153, \\
\text { midmodedarete. } \\
\text { medt tough }\end{array}$ & $\begin{array}{l}0.39 .59 / 153, \\
\text { modtough. } \\
\text { med tough }\end{array}$ & $\begin{array}{l}0.32,491 / 153, \\
\text { modt modertat, } \\
\text { med-moderate }\end{array}$ & $\begin{array}{l}0.42 .64 / 153, \\
\text { moditough. } \\
\text { medtough }\end{array}$ \\
\hline $\begin{array}{l}0.61,677109, \\
\text { modtough, } \\
\text { medtough }\end{array}$ & $\begin{array}{l}0.39, .421109 \text {, } \\
\text { modtough, } \\
\text { medtough }\end{array}$ & 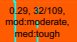 & 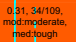 & $\begin{array}{l}0.39,433109 . \\
\text { modtiough. } \\
\text { med tough }\end{array}$ & $\begin{array}{l}\text { 0.31, 34109, } \\
\text { modomoderate, } \\
\text { medidmoderate }\end{array}$ & $\begin{array}{l}0.49,53 / 109 . \\
\text { moditough, } \\
\text { medtough }\end{array}$ \\
\hline
\end{tabular}

Predicative, relational, or algebraic specification

Modal and temporal logic specification

Process models

Dynamical systems

Abstract interpretation

Assertion checking

Process calculi

Model checking, SMV

Constraint solving

Generic theorem proving

Computational engineering, simulation

Symbolic execution

Consistency checking

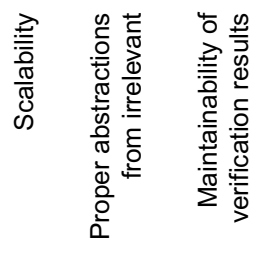

\begin{tabular}{|c|c|}
\hline 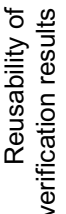 & 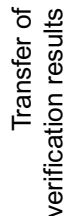 \\
\hline
\end{tabular}

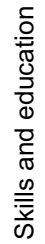

Key/Histogram of Toughs

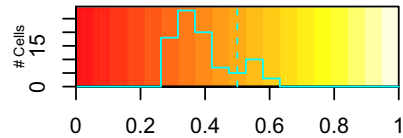

Tough-proportion of all ratings per cell

Comparison of Challenge Difficulty across FMs (users practicing FMs, past)

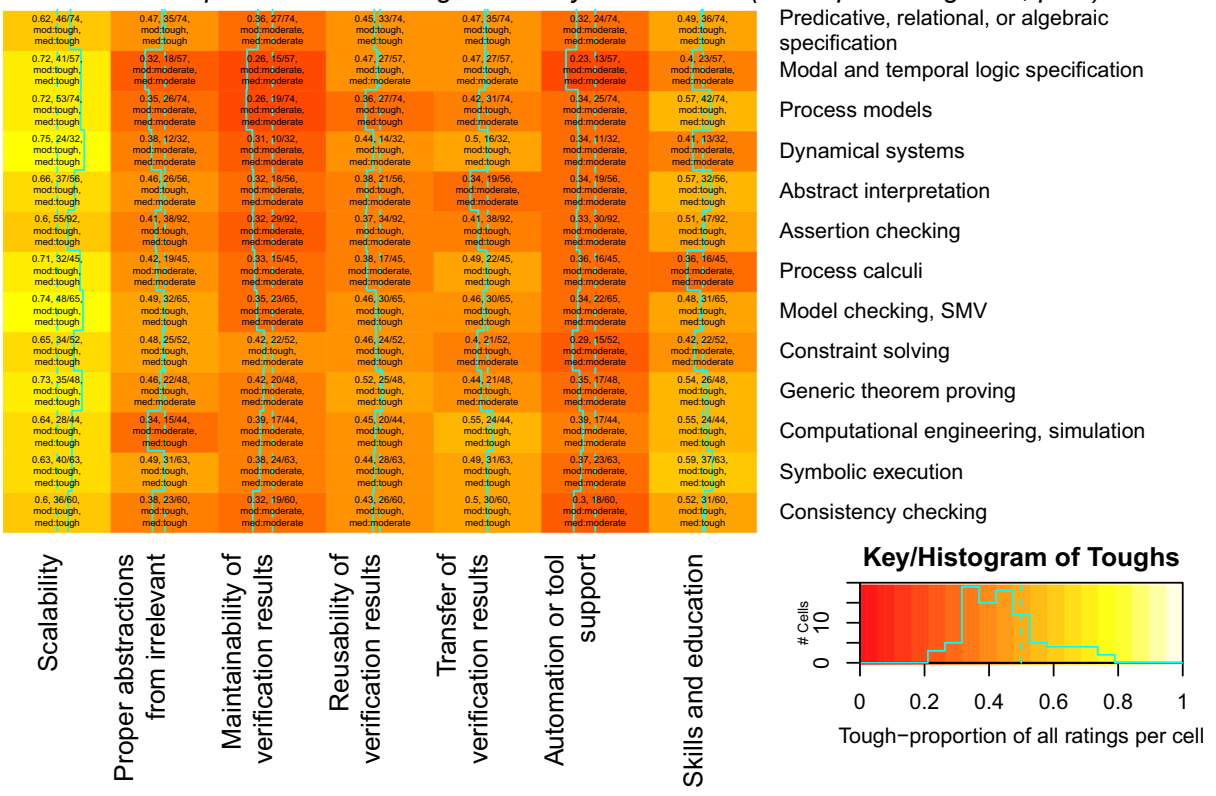

Fig. 25 Comparison of challenge difficulty across FM classes $\left(U F M_{p}\right)$ 


\section{Comparison of Challenge Difficulty across FMs (users with no or decreased intent, future)}

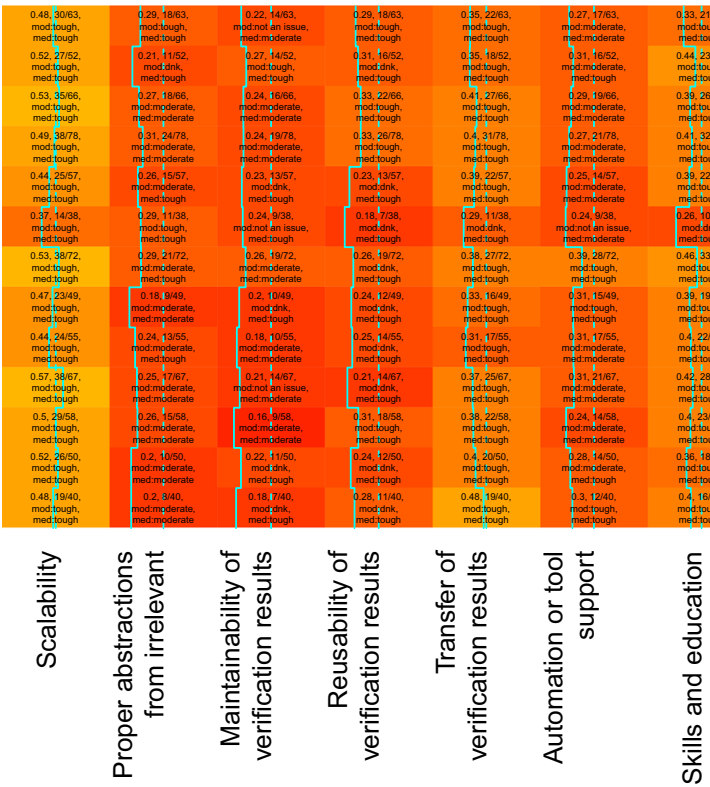

Comparison of Challenge Difficulty across FMs (users with same or increased intent, future)

\begin{tabular}{|c|c|c|c|c|c|}
\hline $\begin{array}{l}0.68,866127, \\
\text { modtituogh, } \\
\text { medtough }\end{array}$ & $\begin{array}{c}0.42,531.127, \\
\text { modimoderati. } \\
\text { med.tough }\end{array}$ & $\begin{array}{l}0.34 .431127, \\
\text { moddododerate, } \\
\text { med-moderate }\end{array}$ & $\begin{array}{l}\text { 0.38, 88/127, } \\
\text { modimoderate } \\
\text { medimoderate }\end{array}$ & $\begin{array}{l}\text { 0.46.588127, } \\
\text { mor tough, } \\
\text { medtough }\end{array}$ & $\begin{array}{l}0.34,431127, \\
\text { modimoderate, } \\
\text { medmimoderate }\end{array}$ \\
\hline $\begin{array}{l}0.63,86 / 137, \\
\text { moditovogh, } \\
\text { medtough }\end{array}$ & $\begin{array}{l}\text { 0.42.58/1137, } \\
\text { modotough, } \\
\text { medtough }\end{array}$ & 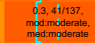 & $\begin{array}{l}\text { 0.38, 52/137, } \\
\text { mod.moderate } \\
\text { medimoderate }\end{array}$ & $\begin{array}{l}0.45,621137, \\
\text { modolough, } \\
\text { medtough }\end{array}$ & $\begin{array}{l}0.34,46 / 137, \\
\text { modimoderate. } \\
\text { medmodederate }\end{array}$ \\
\hline $\begin{array}{l}0.63,78 / 123, \\
\text { modituogh, } \\
\text { medtough, }\end{array}$ & $\begin{array}{c}0.41,501123, \\
\text { modtough, } \\
\text { medtiough }\end{array}$ & $\begin{array}{l}\text { 0.33, 411/123, } \\
\text { moddmoderate, } \\
\text { med-moderate }\end{array}$ & $\begin{array}{l}0.37,46 / 123, \\
\text { modimoderate } \\
\text { medimoderate }\end{array}$ & $\begin{array}{l}0.44,54 / 123, \\
\text { modolough, } \\
\text { medt tough }\end{array}$ & $\begin{array}{l}0.35,43 / 123, \\
\text { modimoderate } \\
\text { medmodicterate }\end{array}$ \\
\hline $\begin{array}{l}\text { 0.69, 68999, } \\
\text { mod.tugagh. } \\
\text { medtlough hi }\end{array}$ & $\begin{array}{l}\text { 0.37. 37/99, } \\
\text { mod-moderate. } \\
\text { medtitiough }\end{array}$ & $\begin{array}{l}\text { o.33, 33/99, } \\
\text { modimoderate, } \\
\text { med-moderate }\end{array}$ & 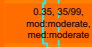 & $\begin{array}{l}0.4,40199, \\
\text { mod.moderate, } \\
\text { med-moderate }\end{array}$ & $\begin{array}{l}0.39,39.999 \\
\text { modimmoderate, } \\
\text { med moderate }\end{array}$ \\
\hline $\begin{array}{l}\text { 0.68. 831122, } \\
\text { mod.tough. } \\
\text { medtough }\end{array}$ & $\begin{array}{l}0.44,54 / 122, \\
\text { mod.tough, } \\
\text { medtough }\end{array}$ & $\begin{array}{l}0.32,391 / 122, \\
\text { modimboderate, } \\
\text { med-moderate }\end{array}$ & $\begin{array}{l}\text { 0.39, 48:122, } \\
\text { modiogogh } \\
\text { medimoderate }\end{array}$ & $\begin{array}{l}\text { 0.4. 499122, } \\
\text { modidmoderate, } \\
\text { med-moderate }\end{array}$ & 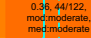 \\
\hline $\begin{array}{l}\text { 0.65. 105/161, } \\
\text { modtltuogh, } \\
\text { medtough }\end{array}$ & $\begin{array}{l}\text { o..39, 631461. } \\
\text { mod moderate. } \\
\text { med.tough }\end{array}$ & $\begin{array}{l}\text { 0.3.,49161, } \\
\text { modidoderate, } \\
\text { mad-moderate }\end{array}$ & $\begin{array}{l}0.39,621161, \\
\text { moditough, } \\
\text { medtough }\end{array}$ & $\begin{array}{l}0.46,741161, \\
\text { modolough, } \\
\text { medtough }\end{array}$ & $\begin{array}{l}0.35,57 / 161, \\
\text { modmodiderte } \\
\text { medmodederate }\end{array}$ \\
\hline $\begin{array}{l}\text { 0.68.67998, } \\
\text { modtough, } \\
\text { medtlough }\end{array}$ & 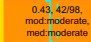 & 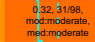 & $\begin{array}{c}0.41,40198, \\
\text { modidoggh, } \\
\text { med;moderate }\end{array}$ & $\begin{array}{l}\text { 0.46. 45198, } \\
\text { mod tough, } \\
\text { med:tough }\end{array}$ & $\begin{array}{l}\text { O.31: } 30198, \\
\text { modimoderate. } \\
\text { medimmoderate }\end{array}$ \\
\hline 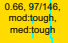 & $\begin{array}{c}0.45,65 / 446, \\
\text { mod.tough } \\
\text { medtough }\end{array}$ & $\begin{array}{l}0.35,51 / 146, \\
\text { modidmoderate, } \\
\text { medimoderate }\end{array}$ & $\begin{array}{l}\text { 0.41. 60:146, } \\
\text { modidough, } \\
\text { meditough }\end{array}$ & $\begin{array}{l}\text { 0.46.677146, } \\
\text { mod dough, } \\
\text { medtough }\end{array}$ & $\begin{array}{l}\text { 0.3., 53/146, } \\
\text { mocim:moderate, } \\
\text { medimaderate }\end{array}$ \\
\hline $\begin{array}{l}0.68 \text {. 94/138, } \\
\text { modtiough, } \\
\text { med tough }\end{array}$ & $\begin{array}{l}0.44,611138 \text {, } \\
\text { modtough, } \\
\text { medtough }\end{array}$ & $\begin{array}{l}\text { 0.33. 466/198, } \\
\text { modmoderate, } \\
\text { med-moderate }\end{array}$ & $\begin{array}{l}0.41,56 / 138, \\
\text { mod.tologh, } \\
\text { medtrough }\end{array}$ & $\begin{array}{l}0.44,611138, \\
\text { mod tough, } \\
\text { medtrough }\end{array}$ & $\begin{array}{l}\text { 0.34, 47/138, } \\
\text { modimoderate. } \\
\text { medimoderate }\end{array}$ \\
\hline $\begin{array}{l}0.59,66(1111, \\
\text { modtough, } \\
\text { medtough }\end{array}$ & $\begin{array}{l}\text { 0.44,491111, } \\
\text { mod.tough. } \\
\text { medituough }\end{array}$ & $\begin{array}{l}0.35 .39111, \\
\text { modomoderate. } \\
\text { meddmoderate }\end{array}$ & $\begin{array}{l}\text { 0.45, 50/111, } \\
\text { modocough, } \\
\text { meditough }\end{array}$ & $\begin{array}{l}\text { 0.45, 501111, } \\
\text { mod tough, } \\
\text { medtrough }\end{array}$ & $\begin{array}{l}\text { 0.32, 36/111, } \\
\text { modimoderate. } \\
\text { medimoderate }\end{array}$ \\
\hline $\begin{array}{l}\text { 0.64, 83/130, } \\
\text { mod.tough, } \\
\text { medtough }\end{array}$ & 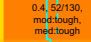 & 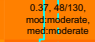 & $\begin{array}{l}\text { 0.36, 47/1930, } \\
\text { mocimoderate } \\
\text { medimaderate }\end{array}$ & $\begin{array}{l}0.43 .56 \text {. } 130 \text {, } \\
\text { modtough, } \\
\text { med:tough }\end{array}$ & $\begin{array}{l}\text { 0.37. } 88 / 130, \\
\text { modimaderate } \\
\text { medimimoderate }\end{array}$ \\
\hline $\begin{array}{l}0.63,881140, \\
\text { modtough, } \\
\text { medtough }\end{array}$ & $\begin{array}{l}0.44 .61140, \\
\text { mod.tough, } \\
\text { medtlough }\end{array}$ & $\begin{array}{l}0.33,466140, \\
\text { modidmoderate. } \\
\text { med-moderate }\end{array}$ & $\begin{array}{l}\text { 0.39, 54/440, } \\
\text { modidough, } \\
\text { medimoderate }\end{array}$ & $\begin{array}{l}0.44,611140, \\
\text { mod tologh, } \\
\text { medtrough }\end{array}$ & 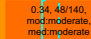 \\
\hline $\begin{array}{l}\text { 0.66.701106, } \\
\text { mod.tough, } \\
\text { medtough }\end{array}$ & $\begin{array}{l}0.42 .45 / 106 . \\
\text { mod.tough } \\
\text { meditough }\end{array}$ & $\begin{array}{l}0.33 .351 / 106, \\
\text { moddmoderate, } \\
\text { med-moderate }\end{array}$ & 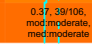 & $\begin{array}{l}\text { 0.42.45/106, } \\
\text { mod tough, } \\
\text { medimiderate }\end{array}$ & $\begin{array}{l}0.29,311106, \\
\text { modimaderate, } \\
\text { medmoderate }\end{array}$ \\
\hline 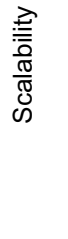 & 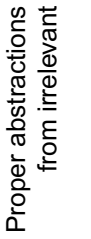 & 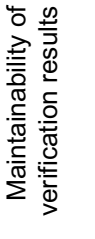 & 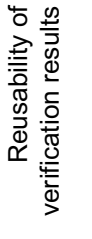 & 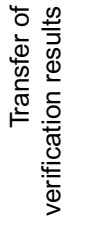 & 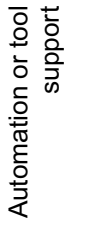 \\
\hline
\end{tabular}

Predicative, relational, or algebraic specification

Modal or temporal logic specification

Process models

Dynamical system models

Abstract interpretation

Assertion checking

Process calculi

Model checking, SMV

Constraint solving

Generic theorem proving

Simulation

Symbolic execution

Consistency checking

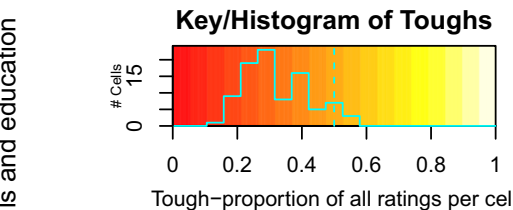

Tough-proportion of all ratings per cell

Predicative, relational, or algebraic specification

Modal or temporal logic specification

Process models

Dynamical system models

Abstract interpretation

Assertion checking

Process calculi

Model checking, SMV

Constraint solving

Generic theorem proving

Simulation

Symbolic execution

Consistency checking

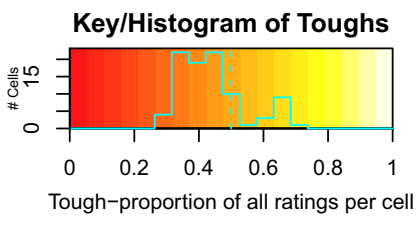

Fig. 26 Comparison of challenge difficulty across FM classes $\left(U F M_{i}\right)$ 


\section{Comparison of Challenge Difficulty across Roles (Past)}

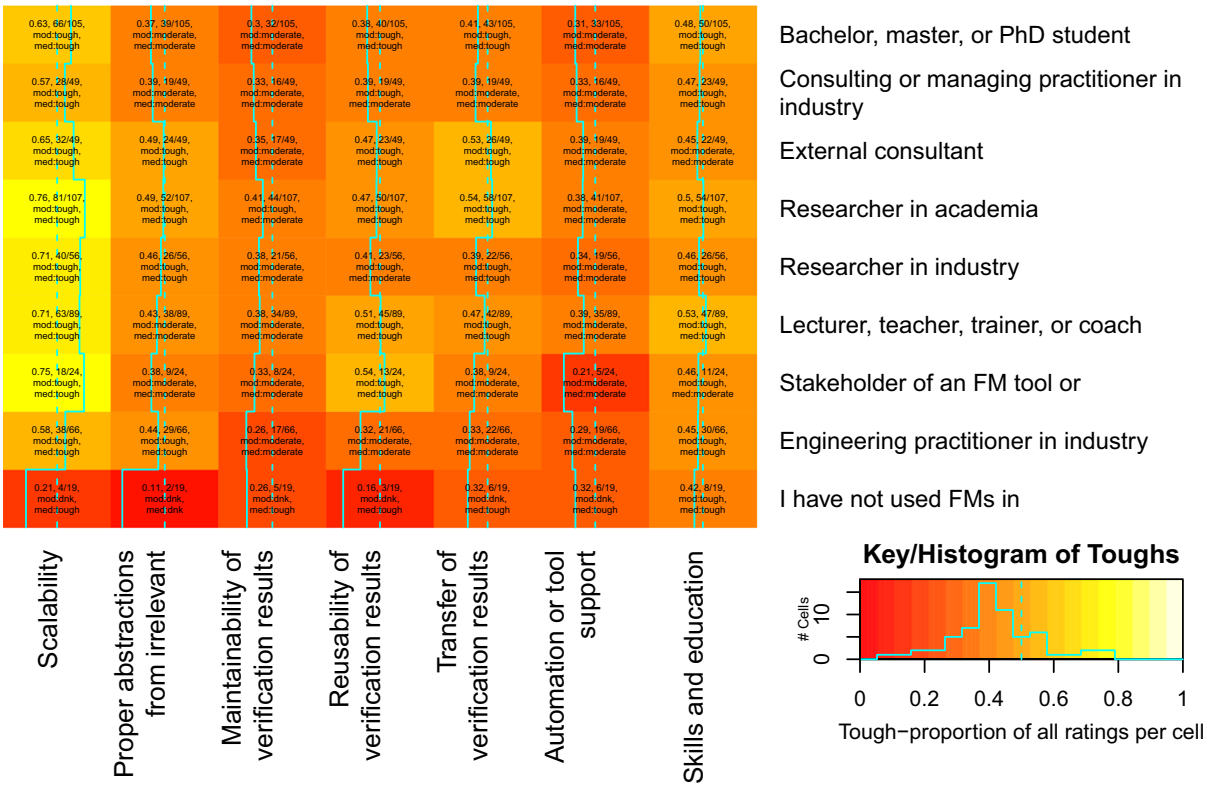

\section{Comparison of Challenge Difficulty across Roles (Future)}

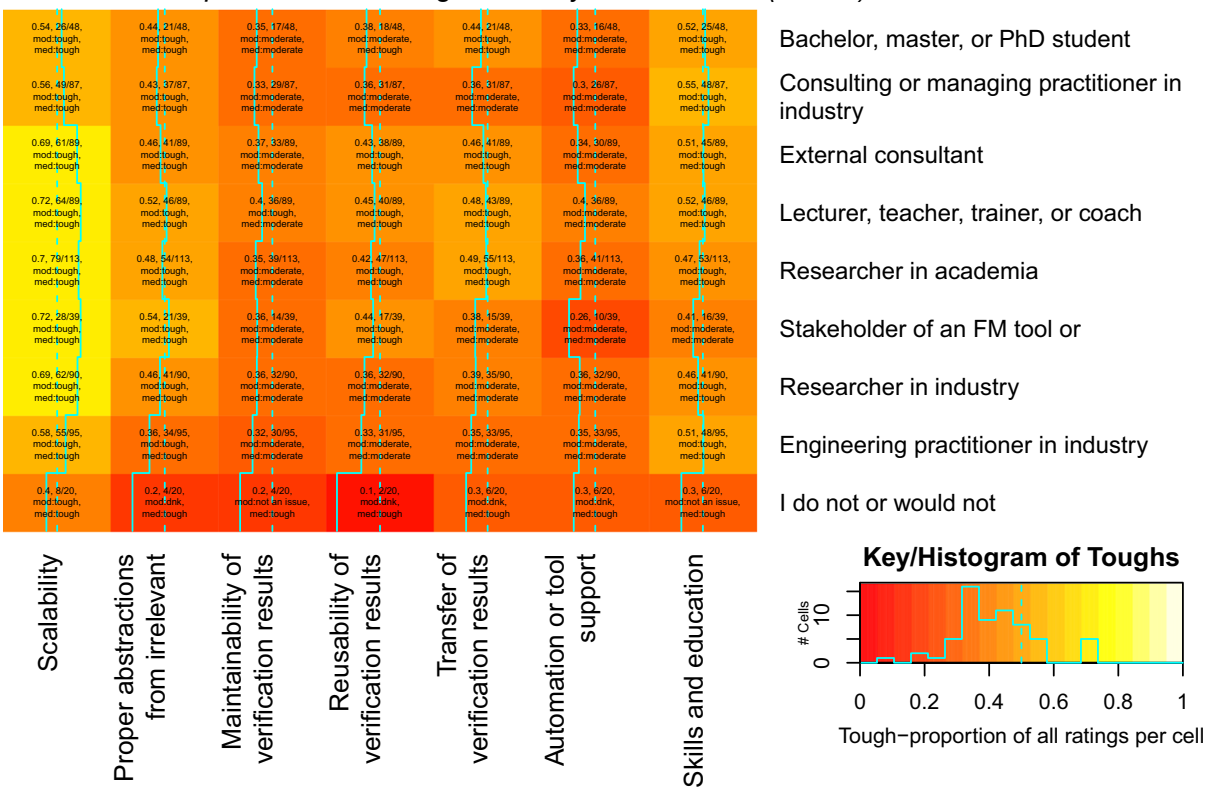

Fig. 27 Comparison of challenge difficulty across roles 


\section{Comparison of Challenge Difficulty across Domains (Past)}

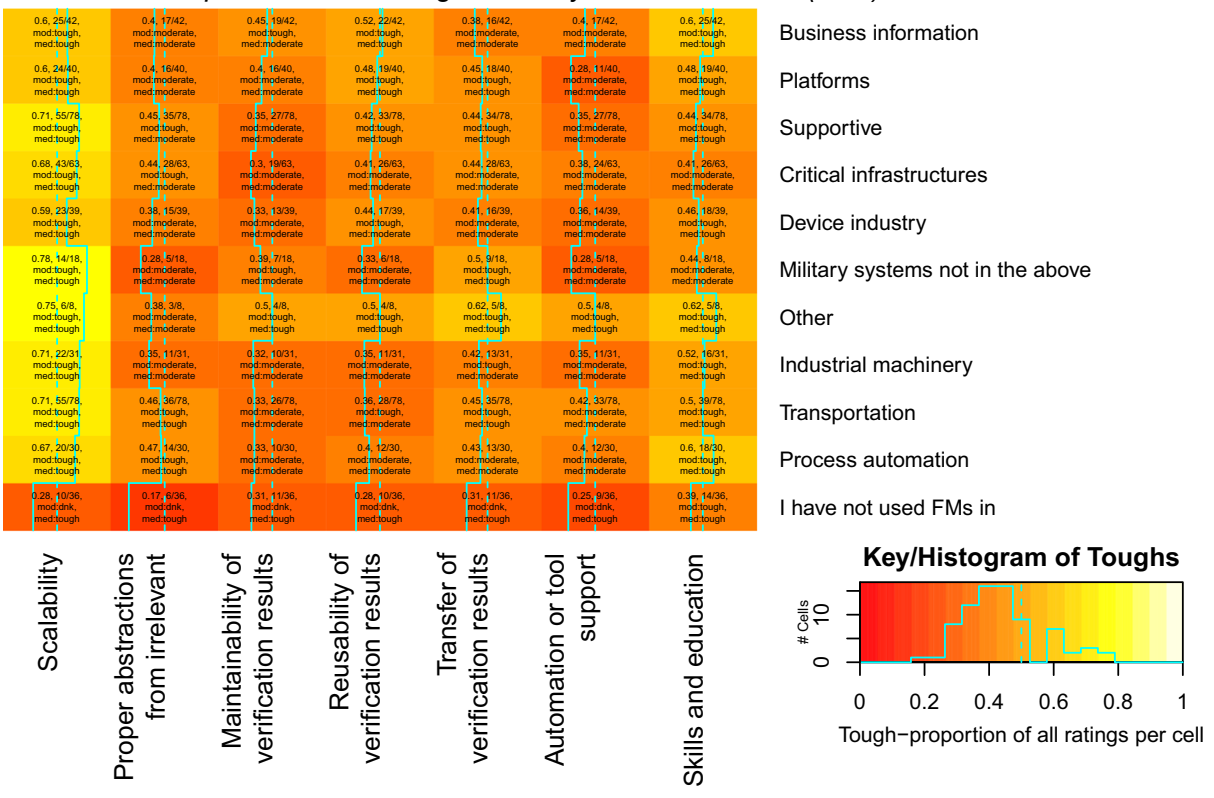

\section{Comparison of Challenge Difficulty across Domains (Future)}

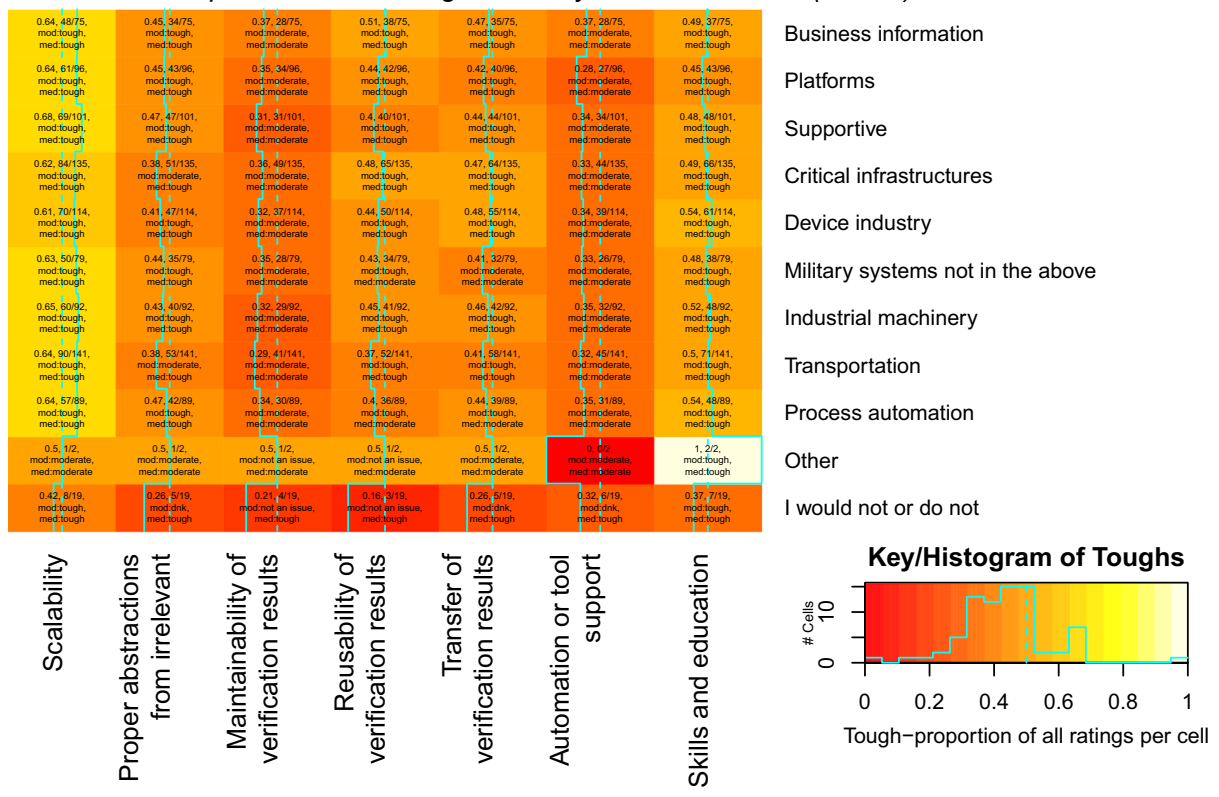

Fig. 28 Comparison of challenge difficulty across domains 

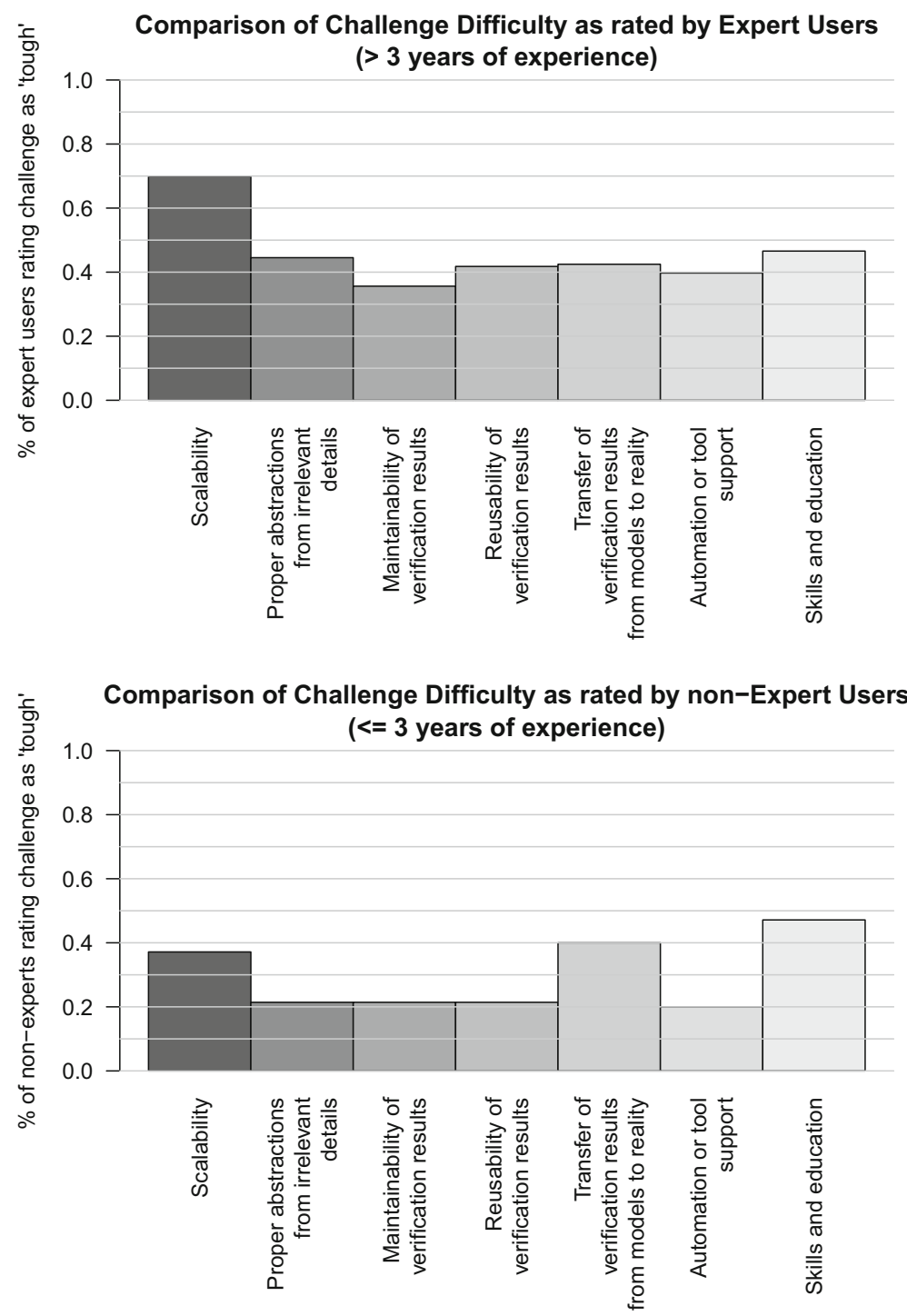

Fig. 29 Comparison of expert and non-expert users by their perception of challenge difficulty

in the matrices represent combinations of the scales, each cell containing data about the mode and median of "degree of difficulty" ratings, their proportion of tough ratings, and the actual numbers of data points. Both the colour gradient (red to white) and the solid vertical lines in the cells represent the tough proportions (left $=0$ to right $=100 \%$ ), with the dotted vertical line signifying the $50 \%$ margin.

\section{A.7 Details on the Systematic Map}

Table 9 contains the data we collected from the literature for the systematic map. 


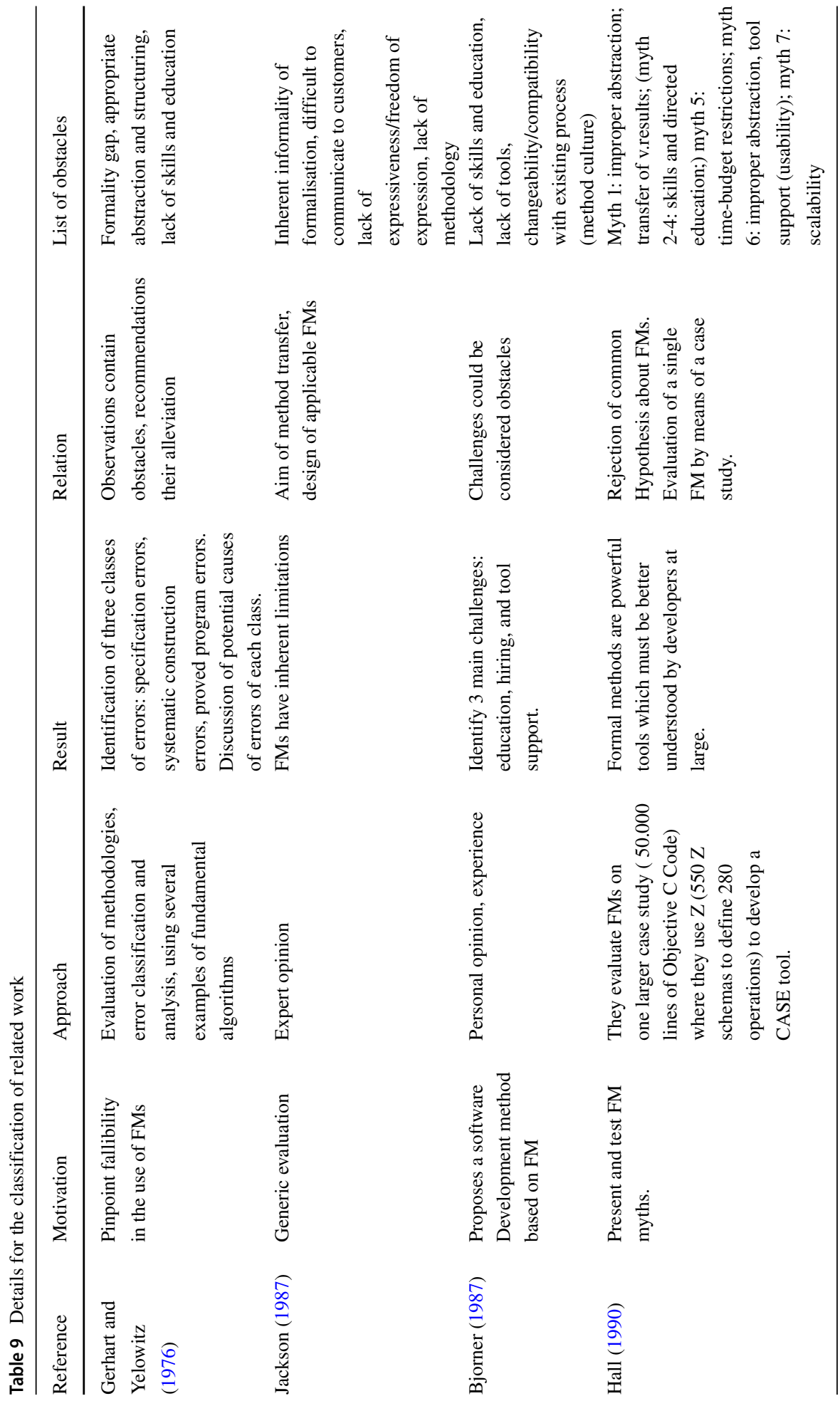




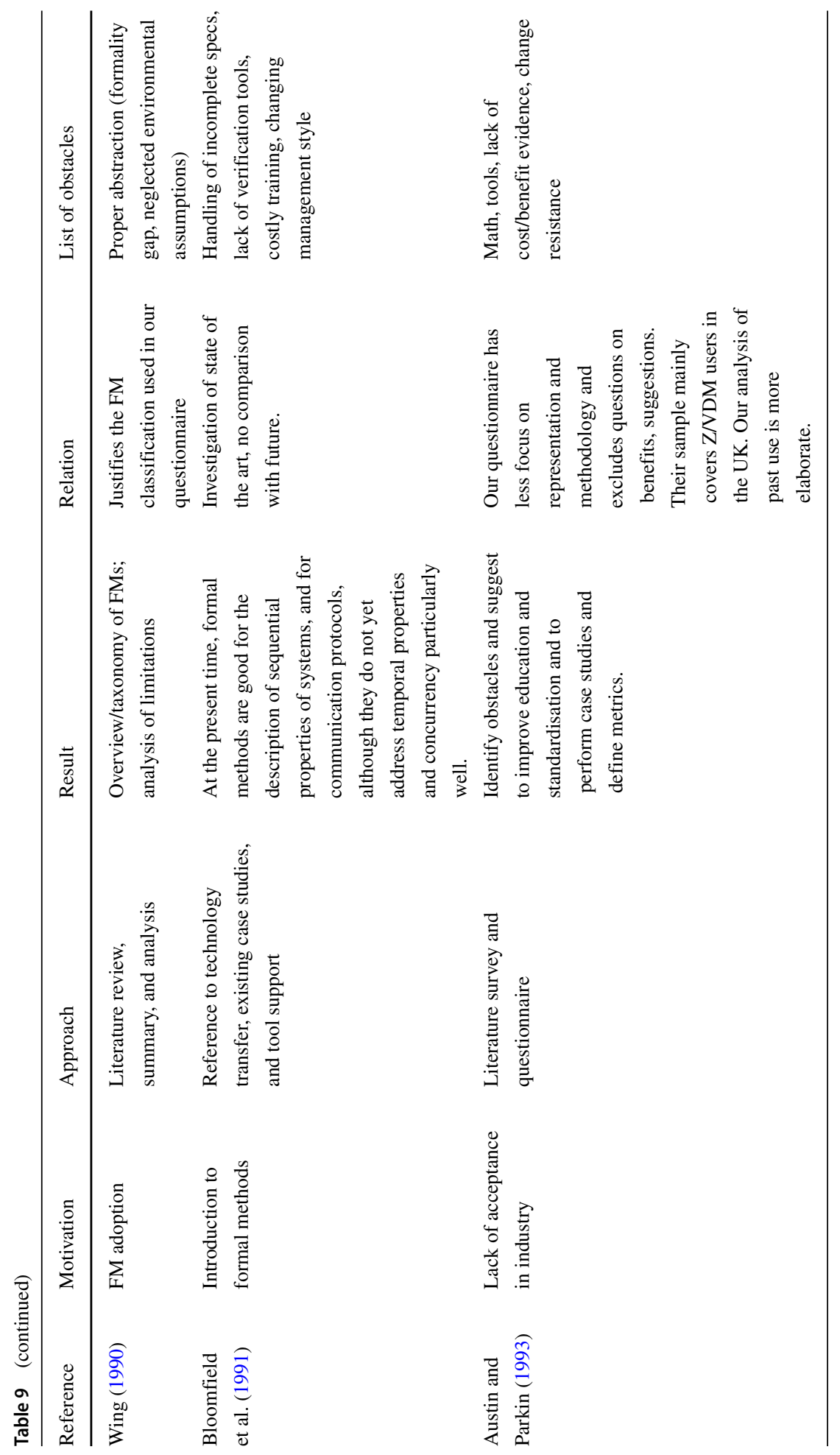




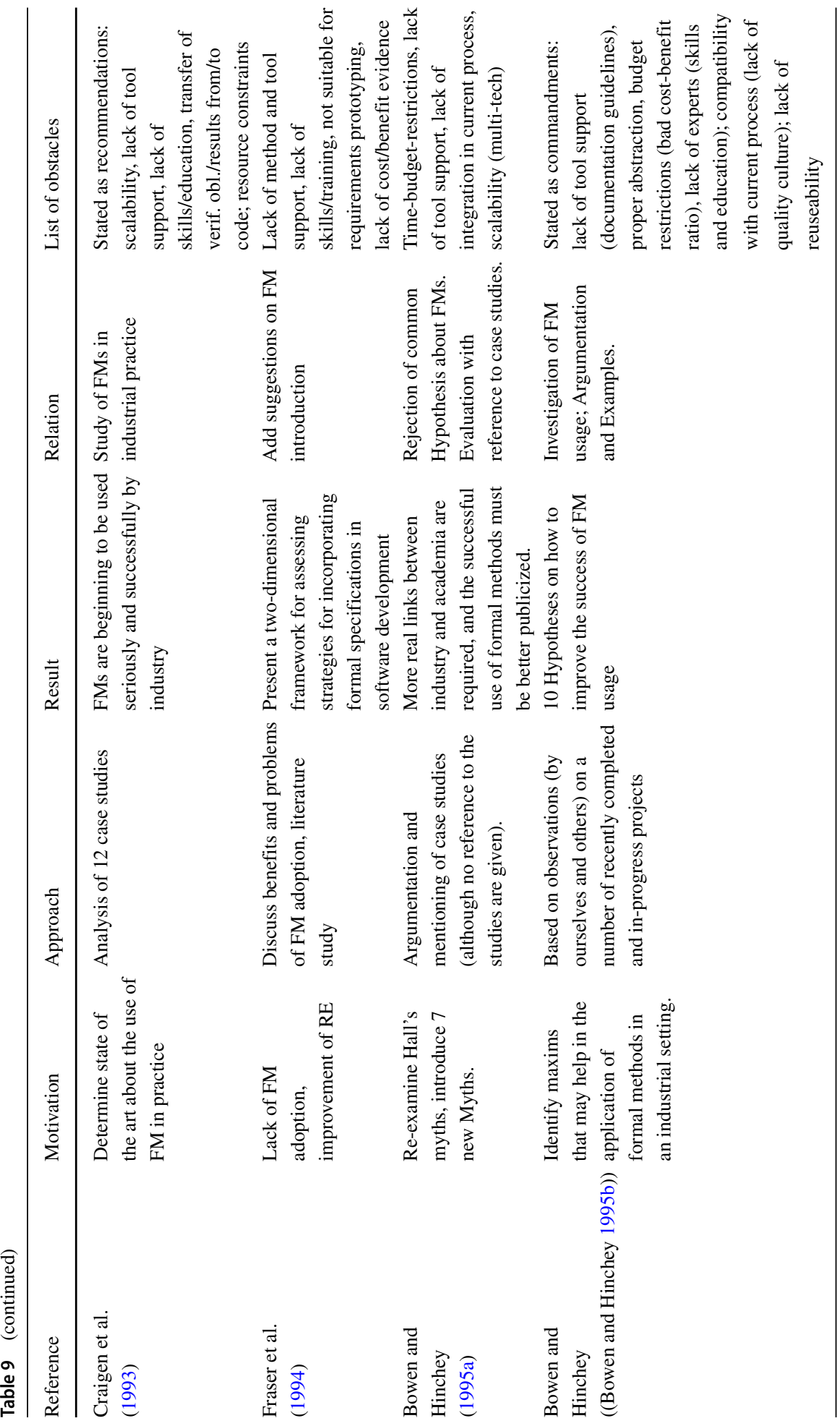




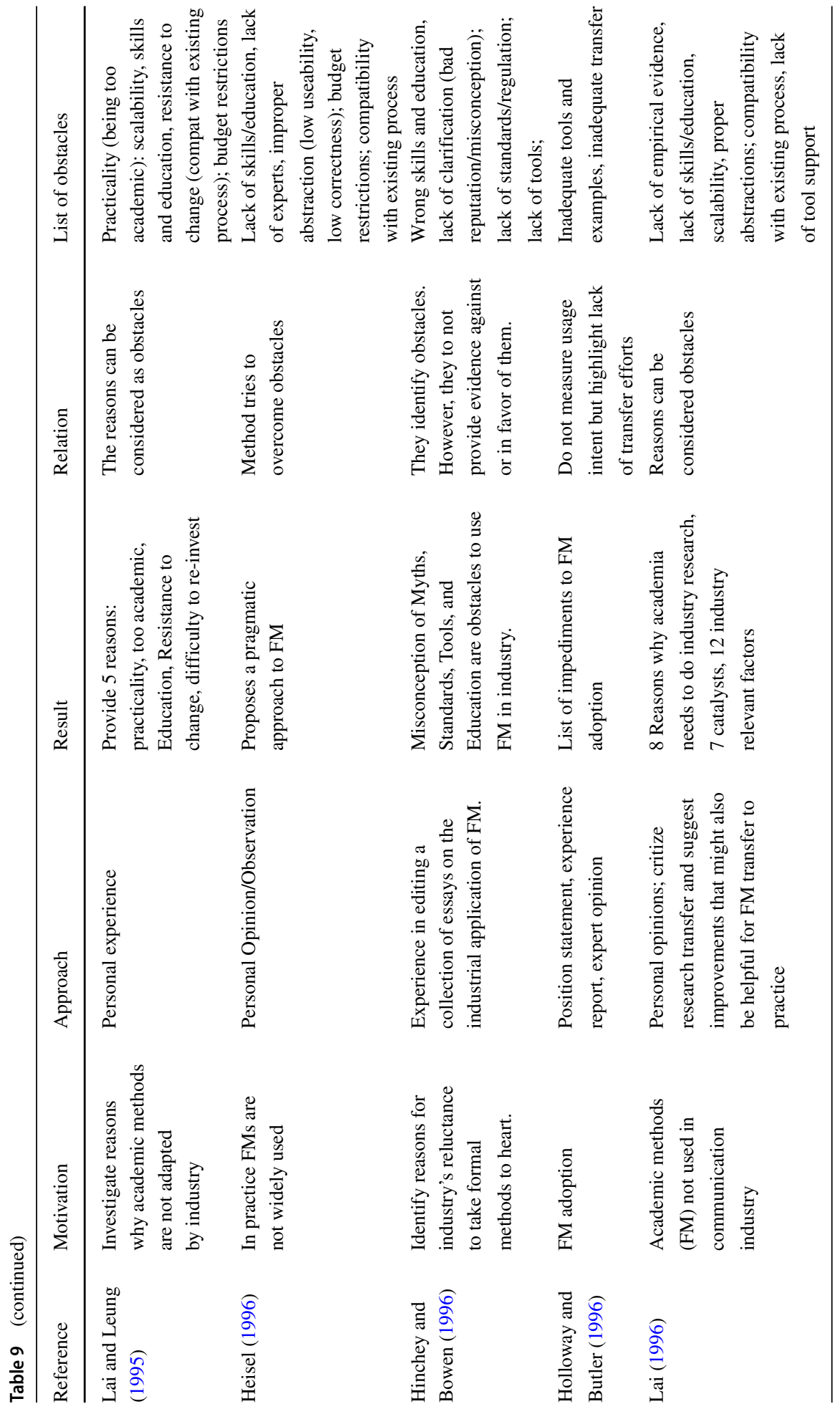




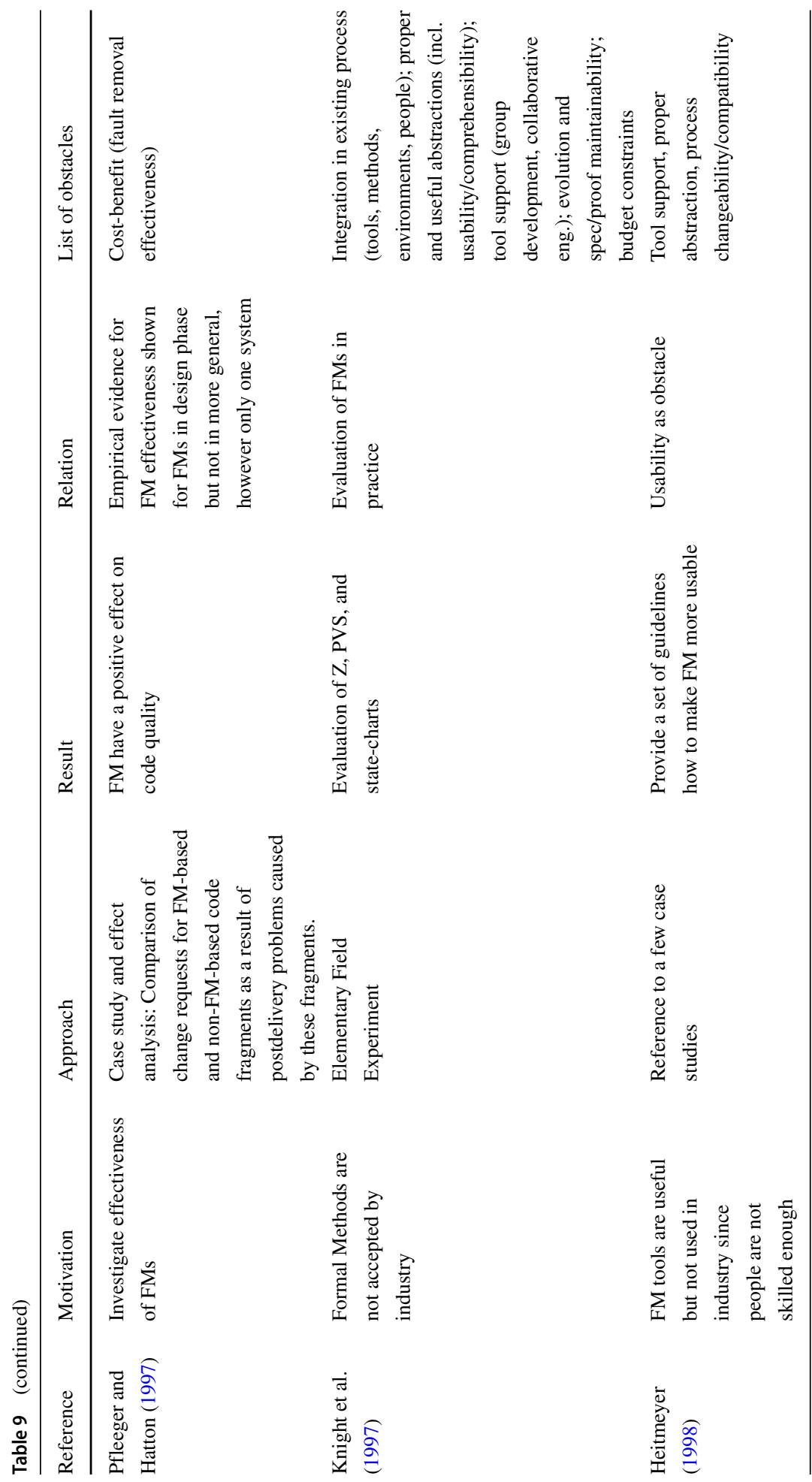




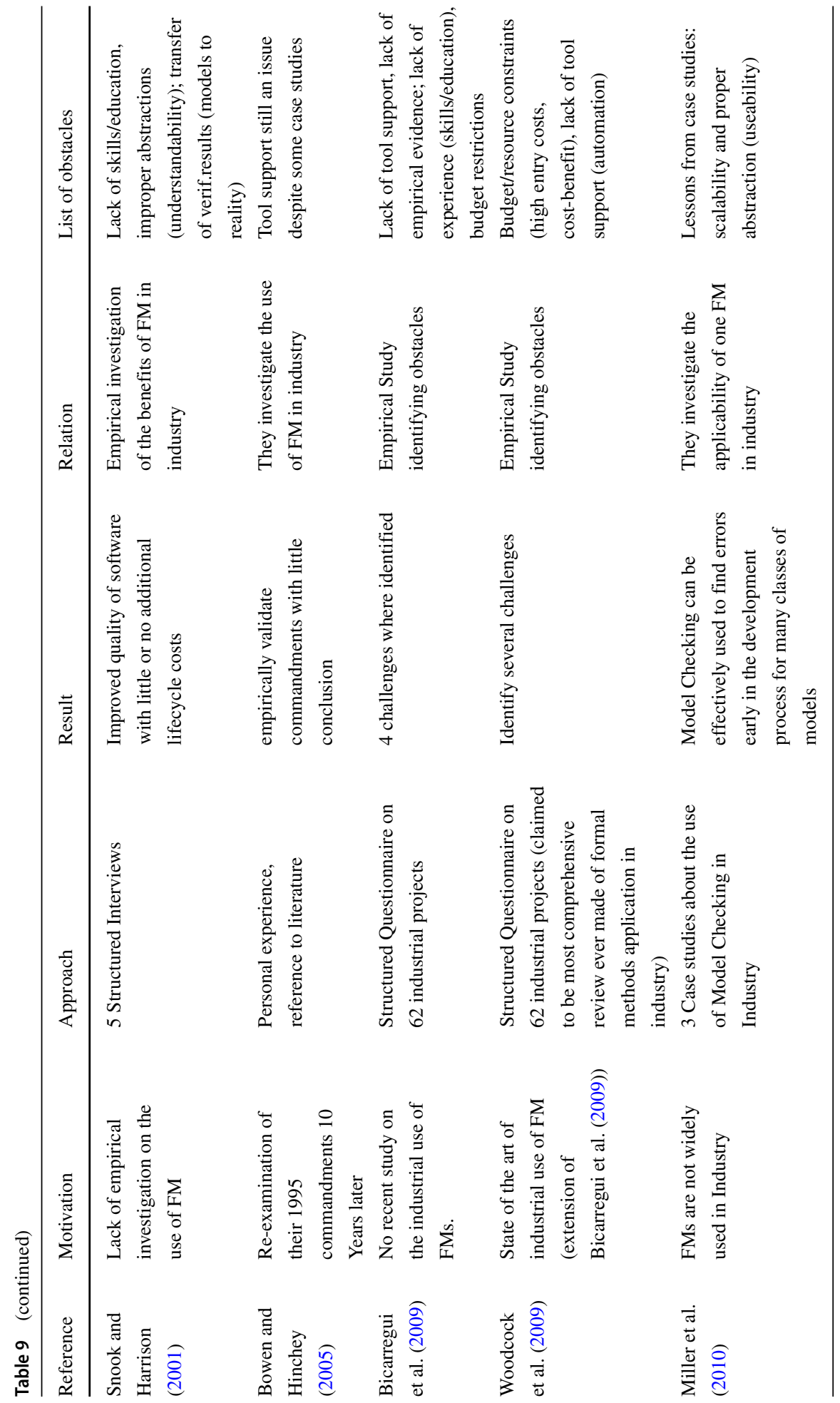




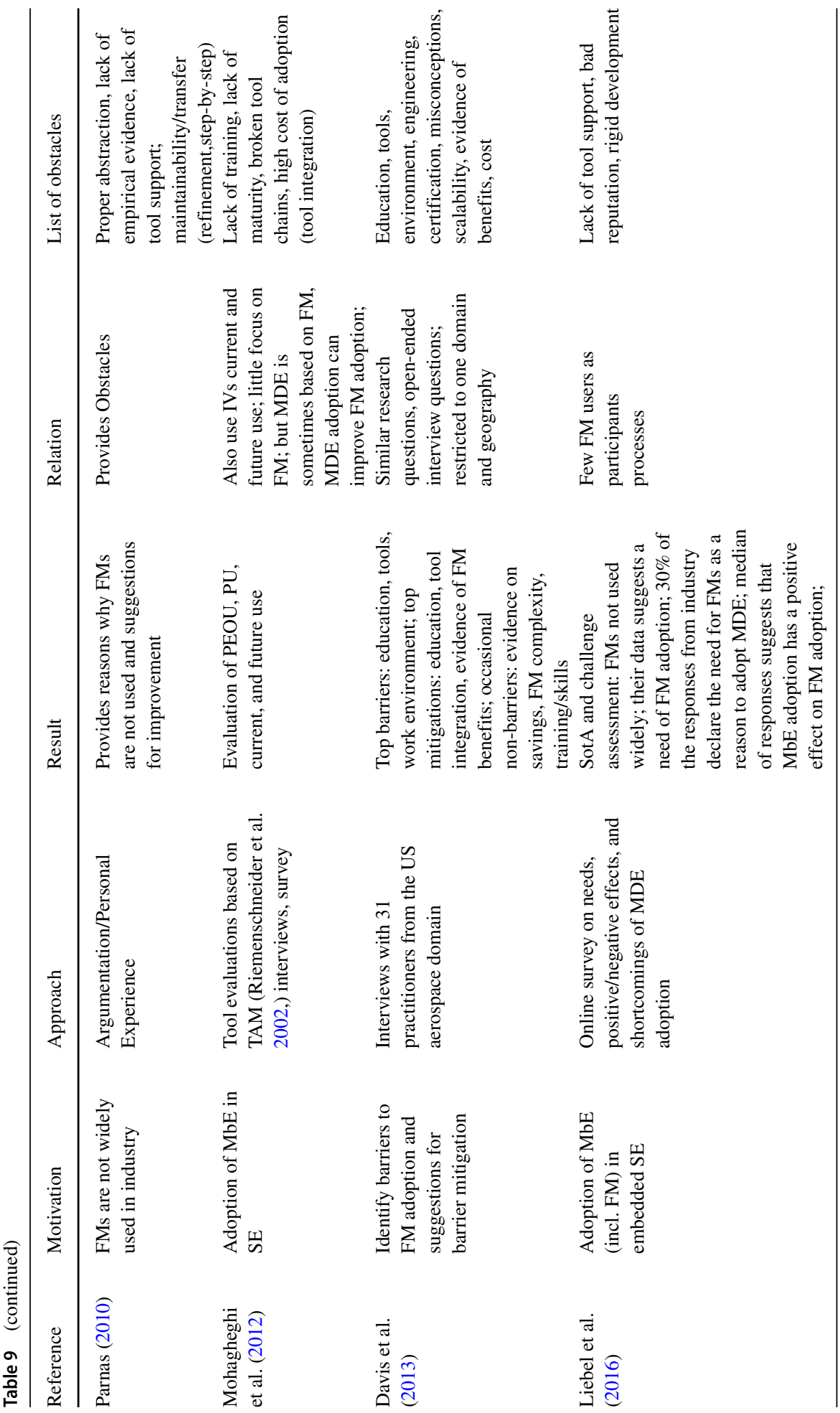




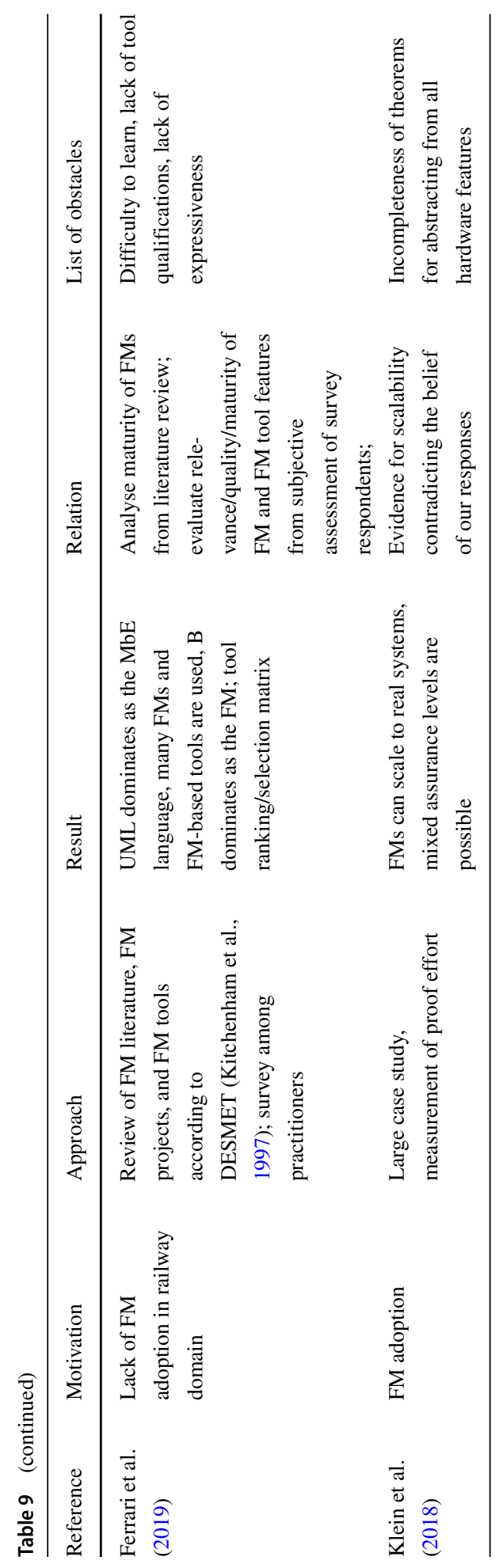




\section{A.8 Mapping of Studies to Challenges for RQ3}

In addition to Table 6 in Section 5.5, Table 10 provides the complete lists of surveyed studies mapped to the corresponding challenges.

Table 10 Mapping of studies to challenge names (with the number of studies in parentheses)

\begin{tabular}{ll}
\hline Challenge name & Supported by \\
\hline Scalability (7) & Hall (1990), Miller et al. (2010), Bowen and Hinchey (1995a), Lai and \\
& $\begin{array}{l}\text { Leung (1995), Lai (1996), Craigen et al. (1993), and Craigen et al. } \\
(1995)\end{array}$ \\
Bjorner (1987), Bicarregui et al. (2009), Hall (1990), Barroca and \\
McDermid (1992), Hinchey and Bowen (1996), Bowen and Hinchey \\
(1995b), Lai and Leung (1995), Lai (1996), Heisel (1996), Craigen et al. \\
(1993), Craigen et al. (1995), and Snook and Harrison (2001)
\end{tabular}

Transfer of Proofs (8)

Jackson (1987), Parnas (2010), Hall (1990), Craigen et al. (1993), Craigen et al. (1995), Snook and Harrison (2001), Bloomfield et al. (1991), and Barroca and McDermid (1992)

Reusability (2)

Abstraction (11)

Tools \& Automation (16)

Maintainability (3)

Resources (11)

Process Compatibility (12)

Practicality \& Reputation (5)
Barroca and McDermid (1992) and Bowen and Hinchey (1995b)

Jackson (1987), Parnas (2010), Miller et al. (2010), Hall (1990), Barroca and McDermid (1992), Bowen and Hinchey (1995b), Lai (1996), Heitmeyer (1998), Heisel (1996), Knight et al. (1997), and Snook and Harrison (2001)

Bjorner (1987), O’Hearn (2018), Hall (1990), Bloomfield et al. (1991), Bowen and Hinchey (1995a), Hinchey and Bowen (1996), Bowen and Hinchey (1995b), Bowen and Hinchey (2005), Bicarregui et al. (2009), Woodcock et al. (2009), Parnas (2010), Lai (1996), Heitmeyer (1998), Craigen et al. (1993), Craigen et al. (1995), and Knight et al. (1997)

Barroca and McDermid (1992), Knight et al. (1997), and Parnas (2010) Hall (1990), Woodcock et al. (2009), Craigen et al. (1993), Craigen et al. (1995), Bloomfield et al. (1991), Bowen and Hinchey (1995a), Bowen and Hinchey (1995b), Lai and Leung (1995), Heisel (1996), Knight et al. (1997), and Bicarregui et al. (2009)

Bjorner (1987), O'Hearn (2018), Bloomfield et al. (1991), Bowen and Hinchey (1995a), Bowen and Hinchey (1995b), Lai and Leung (1995), Hinchey and Bowen (1996), Lai (1996), Heitmeyer (1998), Heisel (1996), Knight et al. (1997), and Craigen et al. (1995)

Lai and Leung (1995), Parnas (2010), Lai (1996), Glass (2002), and Bicarregui et al. (2009) 


\section{A.9 Copy of the Advertisement Flyer}

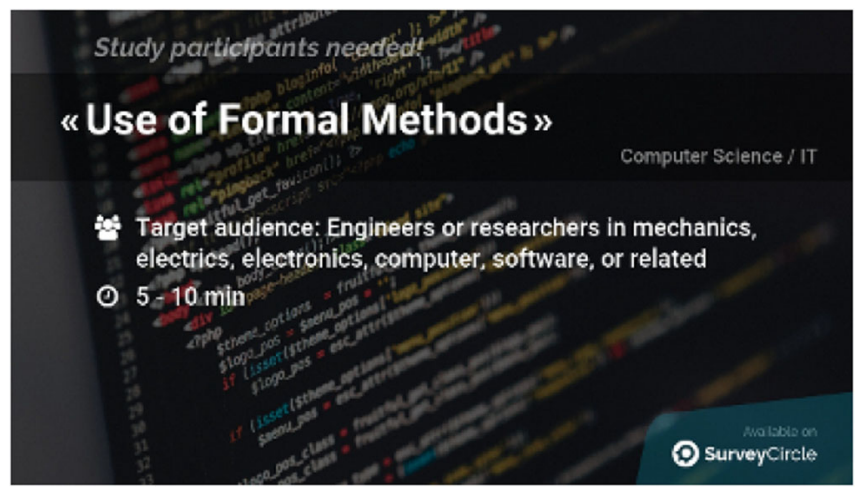

\section{A.10 Screenshot of the Twitter Poll}

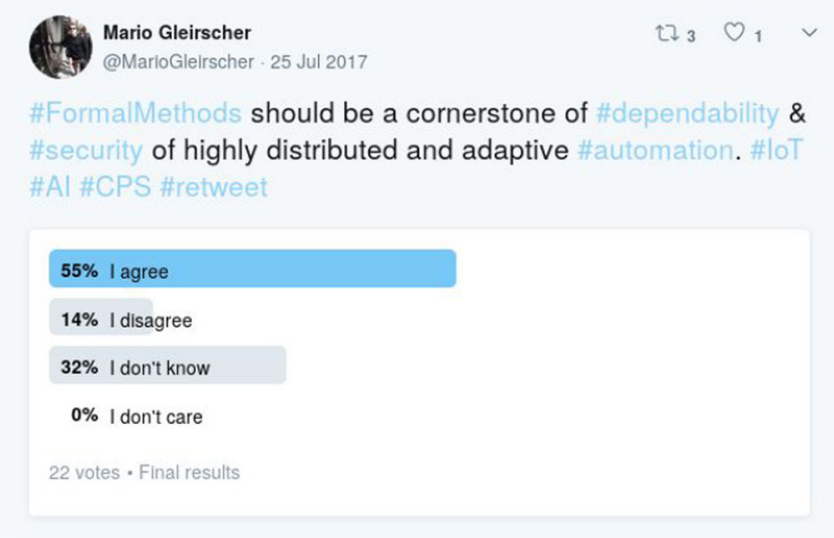

\section{A.11 Copy of the Questionnaire}

The PDF export of our on-line questionnaire on the next page corresponds to the questionnaire we used for the sample taken until 31.3.2019 with $N=220$. Since 26.5.2019, an extended version of the questionnaire had been available online at

$$
\text { https://goo.gl/forms/FnKNQtTmI3A6BekM2. }
$$

We crafted this questionnaire using Google Forms (Google 2018). We use numbered identifiers for each question category, demographic questions are prefixed with a "D", questions about past FM use $\left(U F M_{p}\right)$ with a "P", about future or intended FM use $\left(U F M_{i}\right)$ with an "F", questions about obstacles with an "O". Open questions are suffixed by an "o". 


\section{Use of Formal Methods}

Dear participant, thank you for your interest in this $8-10 \mathrm{~min}$ survey on the use of formal methods (FMs).

This survey does NOT require previous knowledge in FMs or in their actual application in a practical context. However, this survey targets persons with an educational background in engineering and sciences OR with a practical engineering background in a reasonably critical systems or product domain.

By "FMs", we refer to explicit mathematical models and sound formal logical reasoning about critical properties---such as reliability, safety, availability, data privacy or, more generally, dependability and security---of electrical, electronic, and programmable electronic or software systems in critical application domains. FMs include, for example, formal specification, theorem proving, model checking, formal contracts, SMT solving, process algebras.

By "use of FMs", we refer to the application of FMs to engineered systems in the context of education, research, and, particularly, the field of industrial practice and by using formal languages together with manual or automated tool-based techniques.

This survey is anonymous. However, you can provide your email address if you are interested in receiving our final results afterwards.

The underlying study is conducted by Mario Gleirscher at University of York and Diego Marmsoler at Technical University of Munich.

* Erforderlich

\section{Demographic Questions}


1. D1. In which application domain(s) in industry or academia (if any) have you mainly used FMs? *

Wählen Sie alle zutreffenden Antworten aus.

I have not used FMs in any academic or industrial domain.

Critical infrastructures (e.g. telecom, energy, road/air/naval/rail traffic, smart buildings or cities)

Process automation (e.g. chemical process plants, power plants, warehouse logistics, production lines)

Industrial machinery (e.g. stationary robotics, production machines)

Transportation (e.g. automotive, utility vehicles, naval, aeronautics, train systems, freight logistics, cable cars, mobile robotics, drones/UAVs)

$\square$ Device industry (e.g. medical, health-care, semi-conductors, consumer electronics)

$\square$ Military systems not in the above domains (e.g. for command, control, surveillance)

Business information (e.g. database applications, banking, finance, ERP, PLM, web services, cloud apps)

Platforms (e.g. operating systems, middle-ware, firmware, drivers, database systems, libraries)

Supportive (e.g. CASE tools, checking or verification tools, CAD/CAM systems)

Sonstiges:

2. D2. How many years of FM experience (including the study of FMs) have you gained? *

Markieren Sie nur ein Oval.

I do not have any knowledge of or experience in FMs.

less than 3 years

3 to 7 years

8 to 15 years

16 to 25 years

more than 25 years 
3. D3. Which have been your motivations (if any) to use FMs? *

Markieren Sie nur ein Oval pro Zeile.

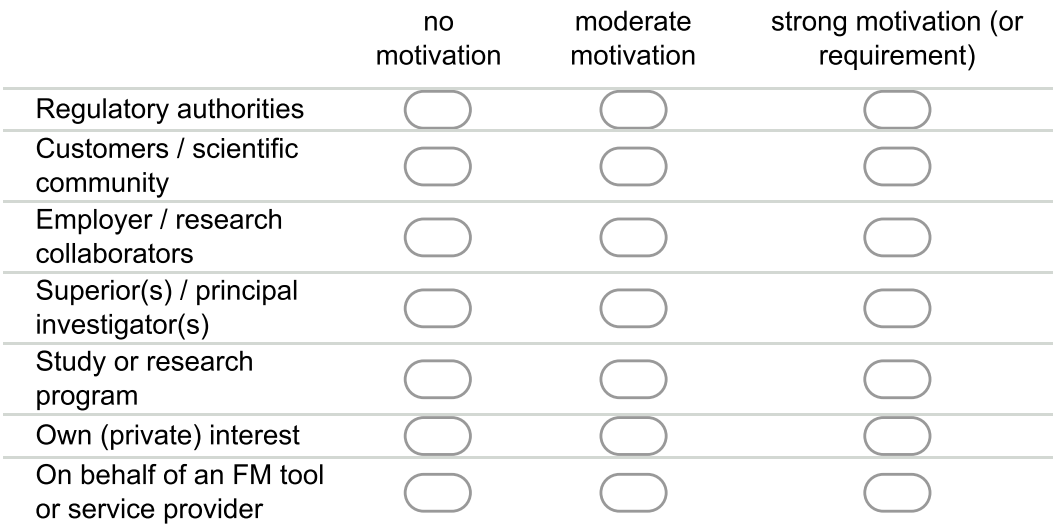

4. D3o. Which have been your further motivations to use FMs (if any)?

\section{Past and Current Use of Formal Methods}

The following questions aim at your EXPERIENCE with the use of FMs in your PAST and CURRENT activities and projects.

NOTE: If you are not able to say anything about past or current use, please, choose the corresponding "not yet used...", "no experience...", or "not at all" options and proceed to the next page!

\section{P1. In which role(s) have you used FMs? *}

Wählen Sie alle zutreffenden Antworten aus.

I have not used FMs in any specific role.

Engineering practitioner in industry (e.g. programmer)

Consulting or managing practitioner in industry (e.g. architect, requirements or systems engineer)

External consultant (e.g. external requirements or systems engineer)

$\square$ Researcher in industry

Researcher in academia

$\square$ Lecturer, teacher, trainer, or coach

$\square$ Bachelor, master, or PhD student

$\square$ Stakeholder of an FM tool or service provider

$\square$ Sonstiges:

\section{Experience in Formal Methods Use}


6. P2. Describe your level of experience with each of the following classes of formal description techniques? *

Markieren Sie nur ein Oval pro Zeile.

\begin{tabular}{|c|c|c|c|c|}
\hline $\begin{array}{c}\text { no } \\
\text { experience } \\
\text { or no } \\
\text { knowledge }\end{array}$ & $\begin{array}{c}\text { studied in } \\
\text { (university) } \\
\text { course }\end{array}$ & $\begin{array}{c}\text { applied in } \\
\text { lab, } \\
\text { experiments, } \\
\text { case studies }\end{array}$ & $\begin{array}{c}\text { applied } \\
\text { once in } \\
\text { engineering } \\
\text { practice }\end{array}$ & $\begin{array}{c}\text { applied } \\
\text { several } \\
\text { times in } \\
\text { engineering } \\
\text { practice }\end{array}$ \\
\hline
\end{tabular}

Predicative,

relational, or

algebraic
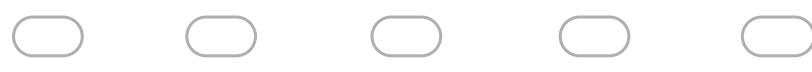

specification

Modal and

temporal logic

specification

Process models

(e.g. Petri nets,

Mealy machines,

LTS, Markov

processes)

Dynamical

systems (i.e.

differential

equations) 
7. P3. Describe your level of experience with each of the following classes of formal reasoning techniques?

Markieren Sie nur ein Oval pro Zeile.

\begin{tabular}{|c|c|c|c|c|}
\hline $\begin{array}{c}\text { no } \\
\text { experience } \\
\text { or no } \\
\text { knowledge }\end{array}$ & $\begin{array}{l}\text { studied in } \\
\text { (university) } \\
\text { lectures }\end{array}$ & $\begin{array}{c}\text { applied in } \\
\text { lab, } \\
\text { experiments, } \\
\text { case studies }\end{array}$ & $\begin{array}{c}\text { applied } \\
\text { once in } \\
\text { engineering } \\
\text { practice }\end{array}$ & $\begin{array}{c}\text { applied } \\
\text { several } \\
\text { times in } \\
\text { engineering }\end{array}$ \\
\hline
\end{tabular}

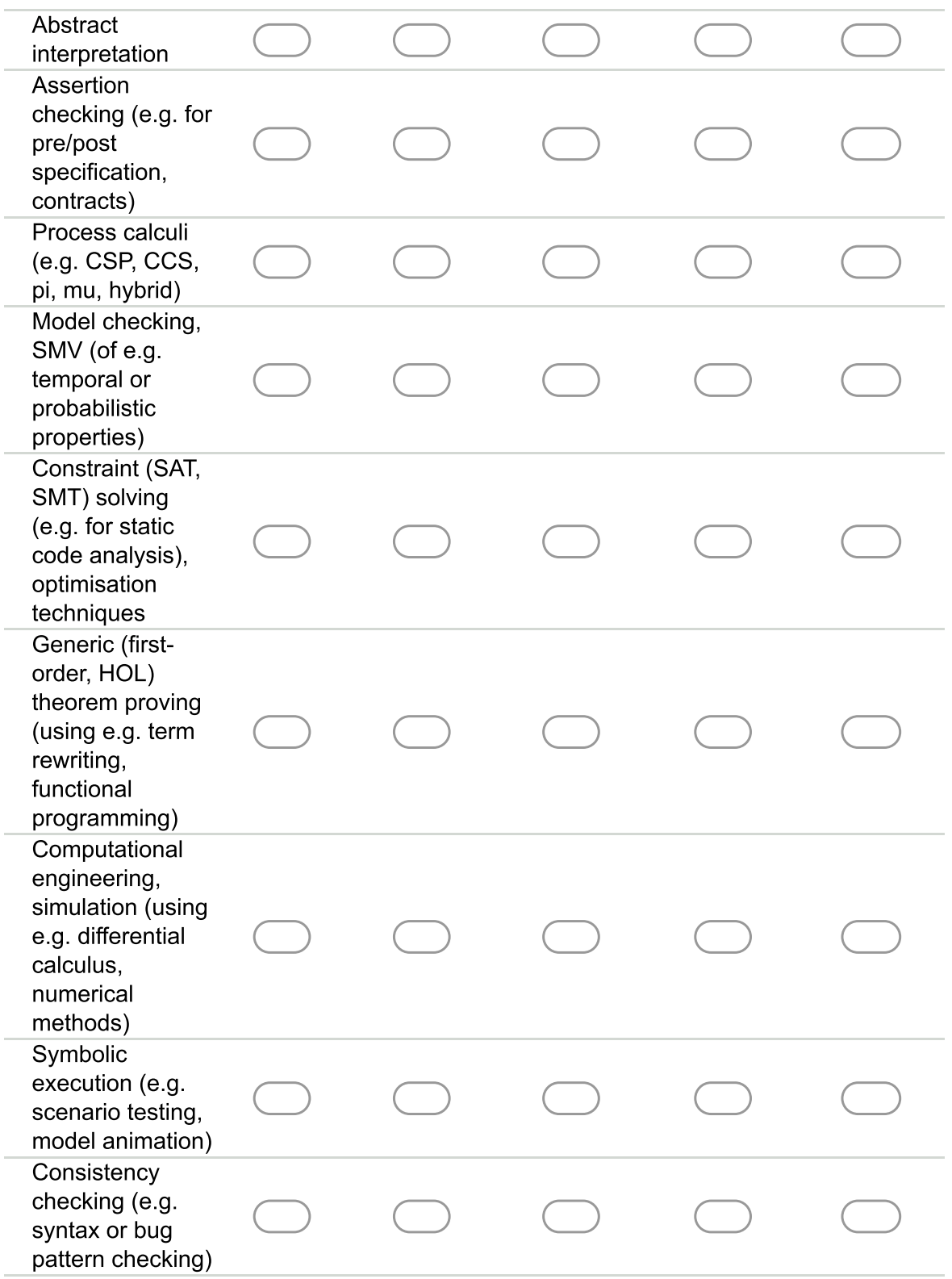


9. P4. I have mainly used FMs for ... *

Markieren Sie nur ein Oval pro Zeile.
... not
$\ldots$ in 2 to 5
... in more than 5
at all. once. separate tasks. separate tasks.

... clarification (i.e. explicit description for analyzing a problem)

... specification (e.g. contracts, documentation and communication of requirements and design) ... inspection (i.e. error detection, e.g. nonconformance checking,

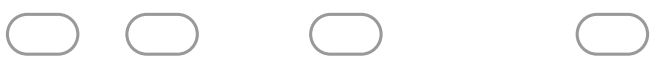
model-based testing) ... synthesis (e.g. transformation, compilation)
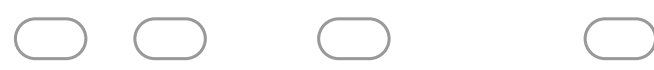
... assurance (e.g. error removal, property verification, refinement or equivalence proofs, argumentation)

10. P4o. I have used FMs for other purposes (if any):

\section{Intended Future Use of Formal Methods}

The following questions aim at your INTENT to use FMs in your FUTURE activities and projects.

NOTE: Your intend to use FMs will also be interpreted as the "mere possibility of FM usage in the corresponding ways" according to and based on your responses.

\section{Future Extent of Formal Methods Use}


11. F1. In which application domain(s) in industry or academia (if any) would (or do) you intend or recommend to use FMs? *

Wählen Sie alle zutreffenden Antworten aus.

I would not or do not intend (or recommend) to use FMs in any academic or industrial domain.

Critical infrastructures (e.g. telecom, energy, road/air/naval/rail traffic, smart buildings or cities)

Process automation (e.g. chemical process plants, power plants, warehouse logistics, production lines)

Industrial machinery (e.g. stationary robotics, production machines)

$\square$ Transportation (e.g. automotive, utility vehicles, naval, aeronautics, train systems, freight logistics, cable cars, mobile robotics, drones/UAVs)

Device industry (e.g. medical, health-care, semi-conductors, consumer electronics)

Military systems not in the above domains (e.g. for command, control, surveillance)

Business information (e.g. database applications, banking, finance, ERP, PLM, web services, cloud apps)

Platforms (e.g. operating systems, middle-ware, firmware, drivers, database systems, libraries)

Supportive (e.g. CASE tools, checking or verification tools, CAD/CAM systems)

Sonstiges:

12. F2. In which role(s) would (or do) you intend to use FMs? *

Wählen Sie alle zutreffenden Antworten aus.

I do not or would not intend to use FMs in any specific role.

Engineering practitioner in industry (e.g. programmer, test or verification engineer)

Consulting or managing practitioner in industry (e.g. architect, requirements or systems engineer)

External consultant (e.g. external requirements or systems engineer)

Researcher in industry

Researcher in academia

Lecturer, teacher, trainer, or coach

$\square$ Bachelor, master, or PhD student

$\square$ Stakeholder of an FM tool or service provider

$\square$ Sonstiges: 
13. F3. I (would) intend to use ... *

Markieren Sie nur ein Oval pro Zeile.

$\begin{array}{ccccc}\text {... no } & \begin{array}{c}\text {.. less } \\ \text { often than }\end{array} & \begin{array}{c}\text {... as } \\ \text { often as }\end{array} & \begin{array}{c}\text {... more } \\ \text { often than }\end{array} & \text { I don't } \\ \text { more or } & \begin{array}{c}\text { in the } \\ \text { in the }\end{array} & \begin{array}{c}\text { in the past. } \\ \text { past. }\end{array} & \text { kast. } & \text { inow. }\end{array}$

... predicative, relational, or algebraic
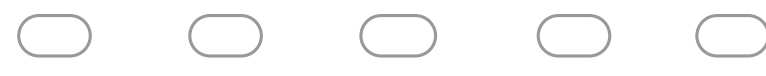
specification ... modal or temporal logic specification

... process models (e.g. Petri nets, Mealy machines, LTS, Markov processes)

... dynamical system models (i.e. differential equations)
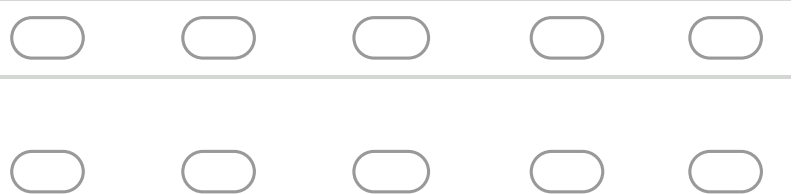
14. F4. I (would) intend to use ... *

Markieren Sie nur ein Oval pro Zeile.

$\begin{array}{ccccc}\text {... no } & \begin{array}{c}\text {.. less } \\ \text { often than }\end{array} & \begin{array}{c}\text {.. as } \\ \text { often as }\end{array} & \begin{array}{c}\text {... more } \\ \text { often than }\end{array} & \text { I don't } \\ \text { more or } & \begin{array}{c}\text { in the } \\ \text { in the } \\ \text { not at all. }\end{array} & \begin{array}{c}\text { past. } \\ \text { past. }\end{array} & \text { in the past. } & \text { know. }\end{array}$

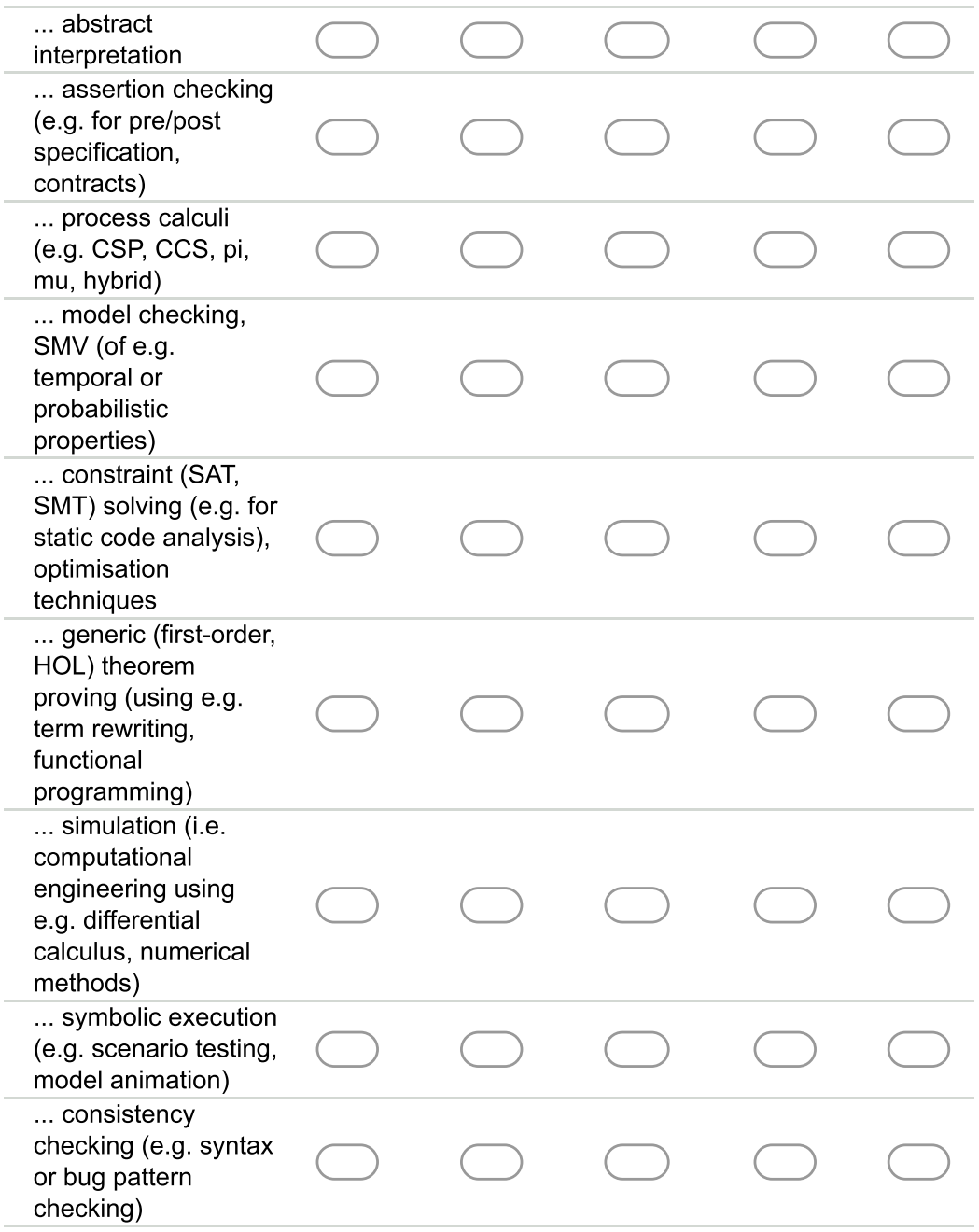

15. F40. I (would) intend to use other FMs, semi-FMs (i.e. without formal semantics and proof system), or highly systematic procedure (if any, please, provide some details):

Future Purposes of Formal Methods Use 
16. F5. I (would) intend to use FMs for ... *

Markieren Sie nur ein Oval pro Zeile.

$\begin{array}{ccccc}\text {... no } & \begin{array}{c}\text {.. less } \\ \text { often than }\end{array} & \begin{array}{c}\text {... as } \\ \text { often as }\end{array} & \begin{array}{c}\text {... more } \\ \text { often than }\end{array} & \text { I don't } \\ \text { more or } & \text { in the } & \text { in the } & \text { in the past. } & \text { know. } \\ \text { not at all. } & \text { past. } & \text { past. } & \text { in phent. }\end{array}$

... clarification (i.e.

explicit description for

analyzing a problem)
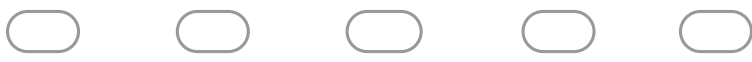

... specification (e.g.

contracts,

documentation and

communication of
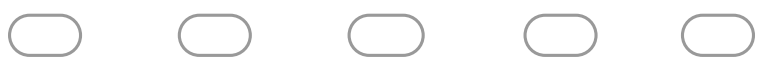

requirements and

design)

... inspection (i.e.

error detection, e.g.

non-conformance

checking, model-

based testing)

... synthesis (e.g.

transformation,

compilation)

... assurance (e.g.

error removal,

property verification,

refinement or
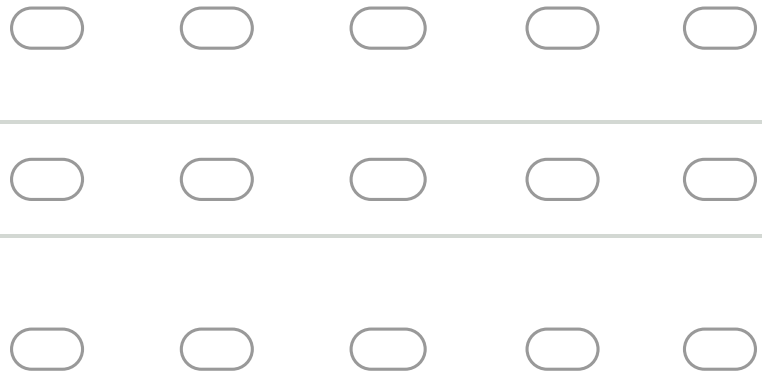

equivalence proofs, argumentation)

17. F5o. I (would) intend to use FMs for other purposes (if any):

\section{Potential Obstacles to the Intended Use of Formal Methods}


18. 01. For any potential use of FMs in my future activities and projects, I consider ...*

Markieren Sie nur ein Oval pro Zeile.

\begin{tabular}{|c|c|c|}
\hline $\begin{array}{l}\ldots \text { not as } \\
\text { an issue. }\end{array}$ & $\begin{array}{c}\ldots \text { as a } \\
\text { moderate } \\
\text { challenge. }\end{array}$ & $\begin{array}{l}\ldots \text { as a tough } \\
\text { challenge. }\end{array}$ \\
\hline
\end{tabular}

... scalability (e.g.

towards large or

heterogeneous

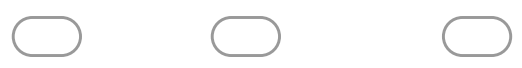

systems)

... proper (automated)

abstractions from

irrelevant details

... maintainability of

verification results (e.g.

stable proofs)

... reusability of

verification results (e.g.

parametric proofs)

... transfer of

verification results from

models to reality

... automation or tool

support (incl. notations,

DSLs, IDEs)

... skills and education

(e.g. methods known

and ready to use)

19. O10. Which further obstacles (if any)

would potentially hinder you to use

FMs as intended?

\section{Thank you for your participation!}

For SurveyCircle users (www.surveycircle.com): The Survey Code is: $X X X X-X X X X-X X X X-$ $\mathrm{XXXX}$

20. Please, feel free to provide us any feedback on the questionnaire or on its topic: 


\title{
21. If you are interested in our results you can provide us your email address below:
}

\author{
Bereitgestellt von \\ :Eoogle Forms
}

\section{References}

Aichernig BK, Tom M (eds) (2003) Formal methods at the crossroads. From panacea to foundational support. Springer, Berlin. ISBN: 3-540-20527-6

ATOMICO (2019) The State of European Tech 2019. Section 6.4. URL: https://web.archive.org/web/ 20191220234928/http://2019.stateofeuropeantech.com/chapter/people/article/strong-talent-base/

Austin S, Graeme P (1993) Formal methods: A survey. Tech. rep. Teddington, Middlesex, UK: National Physical Laboratory

Barroca LM, McDermid JA (1992) Formal methods: Use and relevance for the development of safety-critical systems. Comp J 35(6):579-99. https://doi.org/10.1093/comjn1/35.6.579

Basili VR (1985) Quantitative evaluation of software bibmethodology. Tech. rep. TR-1519. University of Maryland. URL: https://drum.lib.umd.edu/bitstream/handle/1903/7520/Quantitative+Evaluation.pdf? sequence $=1$ (visited on 05/30/2019)

Bicarregui JC et al (2009) Industrial practice in formal methods: A review. In: Cavalcanti A, Dams DR (eds) FM 2009: Formal Methods. Springer, Berlin, pp 810-813. ISBN: 978-3-642-05089-3

Biernacki P, Waldorf D (1981) Snowball sampling: Problems and techniques of chain referral sampling. In: Sociological methods\&research 10.2, pp 141-163. https://doi.org/10.1177/004912418101000205

Bjorner D (1987) On the use of formal methods in software development. In: Proceedings of the 9th international conference on software engineering. ICSE'87. Monterey, IEEE Computer Society Press, pp 17-29. ISBN: 0-89791-216-0. https://doi.org/10.5555/41765.41768. URL: http://dl.acm.org/citation. cfm?id=41765.41768

Bloomfield RE, Froome PKD, Monahan BQ (1991) Formal methods in the production and assessment of safety critical software. In: Reliability Engineering \& System Safety 32, vol 1-2, pp 51-66

Boulanger J-L (2012) Industrial use of formal methods: Formal verification. Wiley-ISTE. 298 pp. ISBN: 9781848213630

Bowen JP, Hinchey MG (1995a) Seven bibmore bibmyths of formal methods. In: IEEE Software 12.4, pp. 34-41. ISSN: 0740-7459. https://doi.org/10.1109/52.391826

Bowen JP, Hinchey MG (1995b) Ten commandments of formal methods. In: Computer 28.4, pp. 56-63. ISSN: 0018-9162. https://doi.org/10.1109/2.375178

Bowen JP, Hinchey MG (2005) Ten commandments revisited: A Ten-year perspective on the industrial application of formal methods. In: Proceedings of the 10th international workshop on formal methods for industrial critical systems. FMICS'05. ACM, Lisbon, pp 8-16. ISBN: 1-59593-148-1. https://doi.org/10.1145/1081180.1081183

Campbell MJ, Gardner MJ (1988) Calculating confidence intervals for some non-parametric analyses. In: British Medical Journal, vol 296, p 1454

Charette RN (2018) Fiat chrysler is being sued over a software flaw. IEEE. https://web. archive.org/web/20180629231601/https://spectrum.ieee.org/riskfactor/computing/software/ courtallows-lawsuit-to-proceed-against-fiat-chrysler-over-software-flaw

Chudnov A et al (2018) Continuous formal verification of amazon s2n. In: Computer aided verification. Springer International Publishing, pp 430-446. https://doi.org/10.1007/978-3-319-96142-2 26

Cofer DD et al (2012) Compositional verification of architectural models. In: NASA formal methods - 4th international symposium, NFM 2012. Proceedings, Norfolk, pp 126-140. https://doi.org/10.1007/978-3-642-28891-3n 13

Craigen D (1995) Formal methods technology transfer: Impediments and innovation (abstract). In: Lee I, Smolka SA (eds) CONCUR'95: Concurrency theory: 6th international conference Philadelphia, PA, 
USA, August 21-24, 1995 Proceedings. Springer, Berlin, pp 328-332. ISBN: 978-3-540-44738-2. https://doi.org/10.1007/3-540-60218-6_24

Craigen D, Gerhart S, Ralston T (1993) An international survey of industrial applications of formal methods. In: Bowen JP, Nicholls JE (eds) Z User Workshop, London 1992: Proceedings of the 7th annual Z user meeting, London 14-15 December 1992. Springer, London, pp 1-5. ISBN: 978-1-4471-3556-2. https://doi.org/10.1007/978-1-4471-3556-2_1

Craigen D, Gerhart S, Ralston T (1995) Formal methods reality check: industrial usage. In: IEEE Transactions on Software Engineering 21.2, pp 90-98. ISSN: 0098-5589. https://doi.org/10.1109/32.345825

Davis FD (1989) Perceived Usefulness, Perceived Ease of Use, and User Acceptance of Information Technology. In: MIS Quarterly 13, vol 3, pp 319-40

Davis JA et al (2013) Study on the barriers to the industrial adoption of formal methods. In: Formal methods for industrial critical systems. Springer, Berlin, pp 63-77. https://doi.org/10.1007/ 978-3-642-41010-9_5

Decision Analyst (2018) Technology advisory board. Decision analyst, Inc. https://web.archive.org/web/ 20191214142906/https://www.decisionanalyst.com/online/acop/

Evans Data (2018) Global Developer Population and Demographic Study. Tech. rep. Volume 1. Evans Data Corporation. https://web.archive.org/web/20191015060004/https://evansdata.com/reports/viewRelease. php?reportID=9

Fagan ME (1976) Design and code inspections to reduce errors in program development. In: IBM Systems Journal 15.3, pp 182-211. https://doi.org/10.1147/sj.153.0182

Ferrari A et al (2019) Survey on formal methods and tools in railways technical report on the activities performed within ASTRail, Deliverable D4.1. https://doi.org/10.5281/zenodo.2535023

Fraser MD, Kumar K, Vaishnavi VK (1994) Strategies for incorporating formal specifications in software development. In: Communications of the ACM 37.10, pp 74-86. https://doi.org/10.1145/194313.19439

Galloway AJ, Cockram TJ, McDermid JA (1998) Experiences with the application of discrete formal methods to the development of engine control software. In: IFAC Proceedings Volumes 31.32, pp 49-56. https://doi.org/10.1016/S1474-6670(17)36335-8

Gerhart S, Yelowitz L (1976) Observations of fallibility in applications of modern programming methodologies. In: IEEE Trans. Software Eng. 2.3, pp 195-207. https://doi.org/10.1109/TSE. 1976.233815

Glass RL (2002) Facts and fallacies of software engineering. Pearson Education (US). ISBN978-0321117427

Gleirscher M, Marmsoler D (2018) Electronic supplementary material for formal methods: Oversold? underused? a survey. Zenodo. https://doi.org/10.5281/zenodo.1487596

Gleirscher M, Nyokabi A (2018) System safety practice: An interrogation of practitioners about their activities, challenges, and views with a Focus on the European Region. Tech. rep. York, UK: Department of Computer Science, University of York, UK. arXiv:1812.08452 [cs.SE]

Gleirscher M, Foster S, Woodcock J (2019) New opportunities for integrated formal methods. ACM Comput Surv 52 (6):117:1-117:36. ISSN: 0360-0300. https://doi.org/10.1145/3357231 arXiv:1812.10103 [cs.SE]

Gnesi S, Margaria T (2013) Formal methods for industrial critical systems: A survey of applications. WileyIEEE Press. ISBN: 9781118459898

Google (2018) Google forms service. Google, Inc. http://forms.google.com

Graydon PJ (2015) Formal assurance arguments: A solution in search of a problem? In: 2015 45th annual IEEE/IFIP international conference on dependable systems and networks (DSN), pp 517-528. https://doi.org/10.1109/DSN.2015.28

Hall A (1990) Seven myths of formal methods. In: IEEE Software 7.5, pp 11-19. https://doi.org/10.1109/52. 57887

Heisel M (1996) A pragmatic approach to formal specification. In: Object-oriented behavioral specifications. Springer. ISBN: 978-0-7923-9778-6. https://doi.org/10.1007/978-0-585-27524-6_4

Heitmeyer CL (1998) On the need for 'practical' formal methods. In: Proceedings of the 5th international symposium on formal techniques in real-time fault tolerant systems (FTRTFT). Vol. LICS, vol 1486. Lyngby, DenmarkLyngby, Denmark, pp 18-26

Hinchey MG, Bowen JP (1996) To formalize or not to formalize? In: IEEE computer 29, vol 4, pp 18-19

Holloway CM (1997) Why engineers should consider formal methods. In: 16th DASC. AIAA/IEEE digital avionics systems conference. Reflections to the future. Proceedings. vol 1, pp 16-22. https://doi.org/10.1109/DASC.1997.635021

Holloway CM, Butler RW (1996) Impediments to industrial use of formal methods. In: Computer 29.4, pp 25-26. https://doi.org/10.1109/MC.1996.488298

Jackson M (1987) Power and limitations of formal methods for software fabrication. In: Journal of Information Technology 2.2, pp 72-76. https://doi.org/10.1177/026839628700200204

Jeffery R et al (2015) An empirical research agenda for understanding formal methods productivity. In: Information and software technology 60, pp 102-112. https://doi.org/10.1016/j.infsof.2014.11.005 
Kaner C, Pels D (1998) Bad software, Wiley. ISBN: 978-0471318262

Kaner C, Pels D (2018) Bad software: Website. https://web.archive.org/web/20191210042547/http:// badsoftware.com/

Kitchenham BA, Pfleeger SL (2008) Guide to advanced empirical software engineering. In: Springer. Chap. Personal Opinion Surveys, pp 63-92

Kitchenham B, Linkman S, Law D (1997) DESMET: A methodology for evaluating software engineering methods and tools. In: Computing \& Control Engineering Journal 8.3, pp 120-126. https://doi.org/10.1049/cce:19970304

Klein G et al (2018) Formally verified software in the real world. In: Communications of the ACM 61.10, pp 68-77. https://doi.org/10.1145/3230627

Knight JC et al (1997) Why are formal methods not used more widely? In: Fourth NASA formal methods workshop, pp 1-12

Lai R (1996) How could research on testing of communicating systems become more industrially relevant? In: Springer, pp 3-13. https://doi.org/10.1007/978-0-387-35062-2_1

Lai R, Leung W (1995) Industrial and academic protocol testing: The gap and the means of convergence. In: Computer Networks and ISDN Systems 27.4, pp 537-547. https://doi.org/10.1016/0169-7552(93) E0110-Z

Leiner DJ (2014) SoSci Survey. Tech. rep. https://web.archive.org/web/20191202015133/https://www. soscisurvey.de/

Leino K, Rustan M (2017) Accessible Software Verification with Dafny. In: IEEE Software 34.6, pp 94-97. https://doi.org/10.1109/bibms.2017.4121212

Liebel $G$ et al (2016) Model-based engineering in the embedded systems domain: an industrial survey on the state-of-practice. In: Software and systems modeling 17.1, pp 91-113. https://doi.org/10.1007/s10270-016-0523-3

Mathieson K (1991) Predicting user intentions: Comparing the technology acceptance model with the theory of planned behavior. In: Information Systems Research 2.3, pp. 173-191. https://doi.org/10.1287/isre.2.3.173

Miller SP, Whalen MW, Cofer DD (2010) Software bibmodel checking takes off. In: Communications of the ACM 53.2, pp 58-64. https://doi.org/10.1145/1646353.1646372

Miyoshi T, Azuma M (1993) An empirical study of evaluating software development environment quality. In: IEEE Transactions on Software Engineering 19.5, pp 425-435. https://doi.org/10.1109/32.232010

Mohagheghi $\mathrm{P}$ et al (2012) An empirical study of the state of the practice and acceptance of modeldriven engineering in four industrial cases. In: Empirical software engineering 18.1, pp 89-116. https://doi.org/10.1007/s10664-012-9196-x

Murphy GC, Walker J, Banlassad ELA (1999) Evaluating emerging software development technologies: lessons learned from assessing aspect-oriented programming. In: IEEE Transactions on Software Engineering 25.4, pp 438-455. https://doi.org/10.1109/32.799936

Neuendorf KA (2016) The content analysis guidebook. 2nd. Sage. ISBN: 9781412979474

Neumann PG (2018) Risks to the public. In: ACM SIGSOFT software engineering notes 43.2, pp 8-11. https://doi.org/10.1145/3203094.3203102

O'Hearn PW (2018) Continuous reasoning. In: Proceedings of the 33rd annual ACM/IEEE symposium on logic in computer science - LICS'18. ACM Press. https://doi.org/10.1145/3209108.3209109

Oliveira JN (2004) A survey of formal methods courses in European higher education. In: Teaching formal methods. Springer, Berlin, pp 235-248. https://doi.org/10.1007/978-3-540-30472-2_16

Oliveira JN et al (2018) Formal methods body of knowledge (FMBoK). https://web.archive.org/web/ 20200109111534/https://formalmethods.wikia.org/wiki/FMBoK

Parnas Dl (2010) Really rethinking 'Formal Methods'. In: IEEE Computer 43.1, pp. 28-34. https://doi.org/10.1109/mc.2010.22

Petersen K et al (2008) Systematic mapping studies in software engineering. In: 12th international conference on evaluation and assessment in software engineering, EASE 2008. University of Bari, Italy, pp 26-27. https://doi.org/10.14236/ewic/ease2008.8

Pfleeger SL, Hatton L (1997) Investigating the influence of formal methods. In: Computer 30.2, pp 33-43. https://doi.org/10.1109/2.566148

Poston RM, Sexton MP (1992) Evaluating and selecting testing tools. In: IEEE Software 9.3, pp 33-42. https://doi.org/10.1109/52.136165

Riemenschneider CK, Hardgrave BC, Davis FD (2002) Explaining software developer acceptance of methodologies: A comparison of five theoretical models. In: IEEE transactions on software engineering 28.12, pp 1135-1145. https://doi.org/10.1109/tse.2002.1158287

Robbins NB, Heiberger RM (2011) Plotting Likert and other rating scales. In: Joint statistical meeting, pp 1058-66 
Rushby J (1994) Critical system properties: Survey and taxonomy. In: Reliability engineering and system safety 43.2, pp 189-219. https://doi.org/10.1016/0951-8320(94)90065-5

SEI (2010) CMMI for Development. Tech. rep. CMU/SEI-2010-TR-033. CMU

Shull F, Singer J, Sjøberg DIK (eds) (2008) Guide to advanced empirical software engineering. Springer, London

Snook C, Harrison R (2001) Practitioners' views on the use of formal methods: An industrial survey by structured interview. In: Information and Software Technology 43.4, pp 275-283. ISSN: 0950-5849. https://doi.org/10.1016/S0950-5849(00)00166-X

Sobel AEK, Clarkson MR (2002) Formal methods application: an empirical tale of software development. In: IEEE transactions on software engineering 28.3, pp 308-320. https://doi.org/10.1109/32.991322

The R Project (2018). R. The R Project. URL: https://web.archive.org/web/20200109063512/https://www. r-project.org/

Wikipedia contributors (2018) Software engineering demographics - Wikipedia, The Free Encyclopedia. URL: https://en.wikipedia.org/w/index.php?title=Software_engineering_demographics\&oldid=823840899 (visited on 01/09/2020)

Wing JM (1990) A specifier's introduction to formal methods. In: Computer 23.9, pp 8-22. https://doi.org/10.1109/2.58215

Wohlin C et al (2012) Experimentation in software engineering. Springer. ISBN: 9783642290435

Woodcock J et al (2009) Formal methods: Practice and experience. ACM Comput Surv 41(4):9:1-19:36. ISSN: 0360-0300. https://doi.org/10.1145/1592434.1592436

Publisher's note Springer Nature remains neutral with regard to jurisdictional claims in published maps and institutional affiliations.

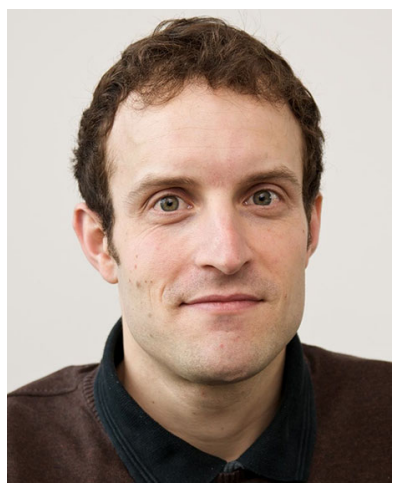

Mario Gleirscher is a postdoctoral researcher in the Computer Science Department at the University of York, U.K. He received the M.Sc. degree in computer science with a minor in mathematics and the Ph.D. degree in computer science, both from the Technical University of Munich, Germany. He is also a qualified production engineer and has collected several years of practical experience as a consultant, method engineer, and software developer. He has been awarded a DFG research fellowship in 2017. His interests cover applied formal methods, particularly, algebraic methods, formal reasoning about risk in machines, and controller design for risk-aware autonomous machines. 


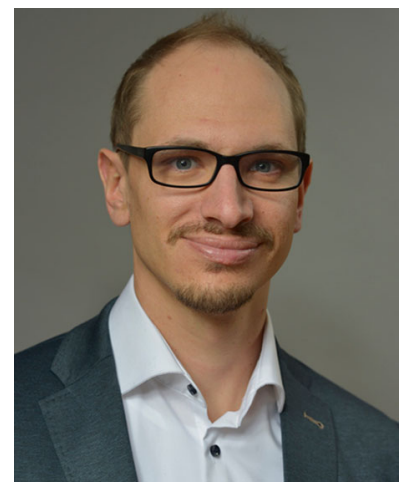

Diego Marmsoler is a postdoctoral researcher at the Software and Systems group of Prof. Manfred Broy at the Technical University of Munich. He obtained a B.Sc. from the Free University of Bozen-Bolzano and an M.Sc. from the Technical University of Munich, Ludwig Maximilian University of Munich, and Augsburg University. He received a Ph.D. in Computer Science from the Technical University of Munich in 2019. His research focuses on the formal specification and verification of distributed, component-based systems. In particular, he works on the integration of various formal methods for the verification of such systems. 